FERNANDO GARCIA

SOLEIRA NORMAL MODELADA POR CURVA COSSENOIDAL

São Paulo

2018 


\section{SOLEIRA NORMAL MODELADA POR CURVA COSSENOIDAL}

Dissertação apresentada à Escola

Politécnica da Universidade de São Paulo para obtenção do título de Mestre em Ciências

Área de Concentração:

Engenharia Hidráulica e Sanitária

Orientador: Prof. Dr. Podalyro Amaral de Souza

São Paulo 
Este exemplar foi revisado e alterado em relação à versão original, sob responsabilidade única do autor e com a anuência de seu orientador.

São Paulo, 29 de Junho de 2018

Assinatura do autor:

Assinatura do orientador:

Catalogação-na-publicação

Garcia, Fernando

SOLEIRA NORMAL MODELADA POR CURVA COSSENOIDAL / F.

Garcia - versão corr. -- São Paulo, 2018.

$63 \mathrm{p}$.

Dissertação (Mestrado) - Escola Politécnica da Universidade de São Paulo. Departamento de Engenharia de Hidráulica e Ambiental.

1.Estruturas Hidráulicas 2.Vertedor 3.Soleira I.Universidade de

São Paulo. Escola Politécnica. Departamento de Engenharia de Hidráulica e Ambiental II.t. 


\section{DEDICATÓRIA}

Dedico este trabalho a meu avô Paulo Garcia pela inspiração na arte da Engenharia e a minha avó Edith Faht que sempre me apoio com amor e carinho 


\section{AGRADECIMENTOS}

Agradeço ao professor Podalyro Amaral de Souza, pelos ensinamentos transmitidos e pela paciência e apoio no desenvolvimento deste trabalho.

Agradeço aos meus pais e familiares que sempre me apoiaram neste projeto de vida.

Agradeço aos meus amigos e colegas que me deram apoio para a realização desta dissertação. 


\section{RESUMO}

Os vertedores são estruturas hidráulicas de suma importância no controle de escoamento e também para medição de vazões. Estas estruturas são amplamente utilizadas em aproveitamento múltiplos principalmente como controle de vazão.

Neste trabalho é apresentado um histórico dos estudos elaborados para vertedores, demonstrando as principais características entre cada estudo.

Também são apresentados os resultados obtidos através dos cálculos de linha d'água é pressão utilizando as equações para superfícies de fundo curvo para um perfil segundo o equacionamento de Creager e o perfil Cossenoidal proposto por este trabalho.

$\mathrm{O}$ escoamento realizado em um perfil Cossenoidal apresenta um comportamento muito semelhante ao escoamento realizado em um perfil do tipo Creager.

Com a utilização do perfil Cossenoidal foi possível realizar a coincidência de raio de curvatura no trecho da crista onde o raio de curvatura do perfil Cossenoidal ajustado a um perfil do tipo Creager, apresentou o mesmo valor para o raio de curvatura para uma elipse proposta por Maynord modificado por este trabalho.

Os resultados de linha d'água e pressão foram bons e satisfatórios muito semelhantes aos valores já apresentados pelas soleiras convencionais (Creager e Maynord). 


\begin{abstract}
The spillways are hydraulic structures very important in the control flow and for measuring flow rates. These structures are widely used mainly for multiple use flow control.

This work presents a history of the studies prepared for spillways, showing the main features of each study.

It is intended to study a cosinusoidal profile through a mathematical model seeking to obtain satisfactory answers to the water lines and pressure for the studied profile.

Showing the results obtained through the water level and pressure calculations, using the equations for curve surface for a Creager's profile and Cossenoidal's profile suggest in this work.

The flow realized in a Cossenoidal's profile show a behavior similar at the flow realized in a Creager's profile.

The utilization of the Cossenoidal's profile was possible to realize the coincidence of the curvature radius in the crest between Cossenoidal's profile and Maynord Modified ellipse, and this profile was adjusted with a Creager's profile and Maynord's ellipse.

The results of water level and pressure showed goods and satisfactory, very similar with the values showed in other studies for a conventional weirs (Creager and Maynord).
\end{abstract}




\section{LISTA DE FIGURAS}

Figura 1 - Jato livre de um vertedor de parede delgada.

Figura 2 - Características do vertedor parede delgada - Adaptado de CHANSON(2004)

Figura 3 - Sistema de Coordenadas Adotado, Adaptado de CHANSON (2004)

Figura 4 - Perfil detalhe na região da crista - Fonte: CHANSON (2004) ...................... 13

Figura 5 - Perfil comparação entre Scimemi e Creager - Fonte: CHANSON (2004) .... 14

Figura 6 - Perfil da Soleira Vertente apresentada pelo Hydraulic Design Criteria. Fonte: Hydraulic Design Criteria Sheets 111-1 to 111-2/1, 1987 ............... 16

Figura 7 - Variação da linha d'água de acordo com o princípio do lançamento de projétil - Fonte: CHOW, 2009

Figura 8 - Variação do perfil vertente para as propostas de Scimemi e Creager - Fonte: GARCIA (2014) . 21

Figura 9 - Distribuição de pressões, antes e depois da inserção do arco de circunferência $0,04 \mathrm{H}_{\mathrm{d}}$ entre o paramento de montante e o perfil USBR. Fonte: Maynord,1985 apud ARAUZ (2005)

Figura 10 - Perfis tipo Maynord+Creager e Lemniscata - Fonte: KANASHIRO. (1989)

24

Figura 11 - Perfis tipo USBR e perfil elíptico adotado para a análise numérica - Fonte: DANESHFARAZet al.. (2012)

Figura 12 - Linhas de pressão para o perfil USBR obtidas pelo experimento de Maynord e da análise numérica - Fonte: DANESHFARAZet al.. (2012) ................... 25

Figura 13 - Linhas de pressão para o perfil elíptico obtidas pelo experimento de Maynord e da análise numérica - Fonte: DANESHFARAZet al.. (2012).... 25

Figura 14 - Linhas de pressão para os perfis USBR e elíptico considerando a relação de $\mathrm{He} / \mathrm{Hd}=1,33$ - Fonte: DANESHFARAZet al.. (2012) ................................ 26

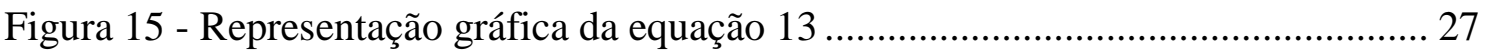

Figura 16 - Coordenadas curvilíneas definidas pelo fundo curvo - Fonte: SOUZA.

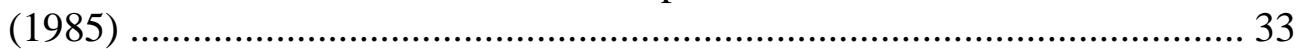

Figura 17 - Distribuição de Velocidades para Fundo convexo $(\mathrm{k}<0)$ e fundo côncavo

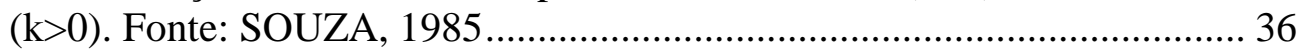

Figura 18 - Distribuição de Pressão $\mathrm{p}(\mathrm{s}, \mathrm{n}, \mathrm{t})$ para fundo convexo $(\mathrm{k}<0)$ e fundo côncavo

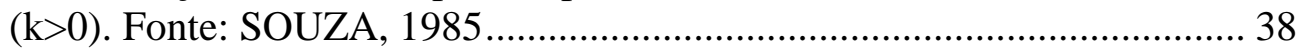

Figura 19 - Perfil cossenoidal com os pontos de coincidência .................................... 42

Figura 20 - Perfis Cossenoidal ajustado e Creager, adimensionalizados....................... 43

Figura 21 - Perfis Maynord e "Maynord Modificado", adimensionalizados ................ 45

Figura 22 - Perfis agrupados (Maynord, Maynord Modificado, Creager e Cossenoidal)

Figura 23 - Vista geral da planilha eletrônica de cálculo............................................... 49

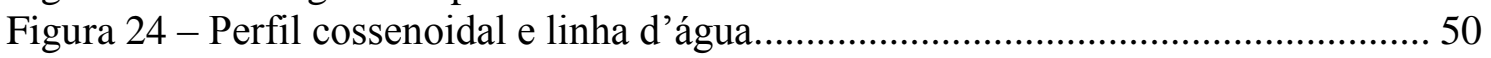

Figura 25 - Linha d'água para perfil Cregaer................................................................. 51

Figura 26 - Linhas d'água para perfil Maynord e "Maynord Modificado" ...................... 52

Figura 27 - Linhas d'água para perfil cossenoidal e perfil Creager ............................... 53

Figura 28 - Linhas de pressão para perfil cossenoidal e perfil Creager.......................... 55 


\section{LISTA DE QUADROS}

Quadro 1 - Valores adimensionalizados para perfil geométrico da soleira Cossenoidal 44 Quadro 2 - Posições X,Y para linha d'água em perfil do tipo Creager .......................... 51

Quadro 3 - Posições X,Y para linha d'água em perfil do tipo Maynord Modificado ..... 53 Quadro 4 - Valores de pressão adimensionalizados para os perfis cossenoidal e Creager 


\section{SUMÁRIO}

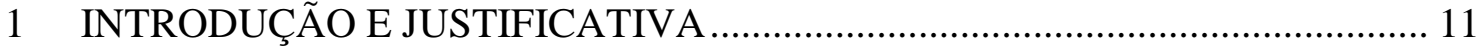

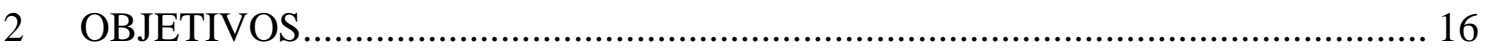

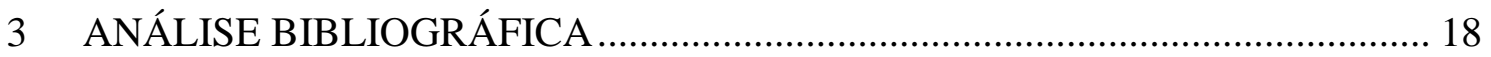

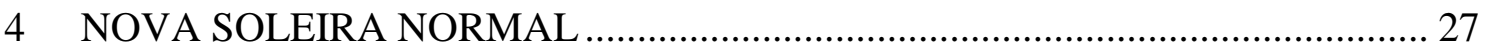

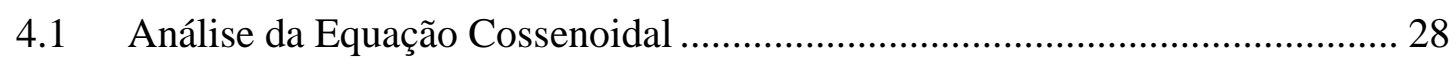

5 MODELAÇÃO DAS LINHAS D'ÁGUA E PRESSÃO ………………………..... 30

5.1 Coordenadas Curvilíneas ………………………….................................. 30

5.2 Coordenadas Cartesianas ....................................................................... 32

5.3 Equacionamento em Coordenadas Curvilíneas ……………………………..... 33

5.4 Distribuição de Velocidades ....................................................................... 35

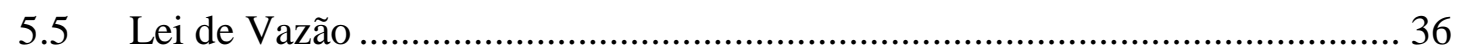

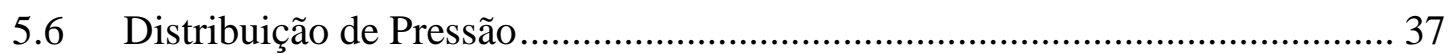

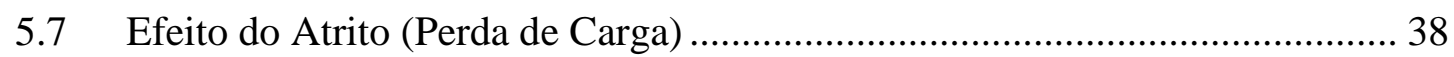

6 EQUACIONAMENTO PROPOSTO ……………......................................... 41

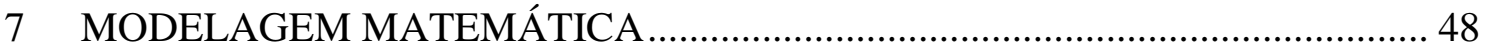

7.1 Determinação da Linha d'água......................................................................... 48

7.2 Cálculo do Coeficiente de Descarga ………………….................................... 54

7.3 Determinação da Linha de Pressão ………………………………................. 54

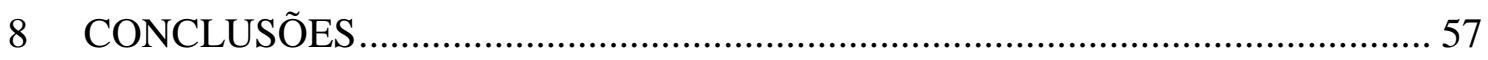

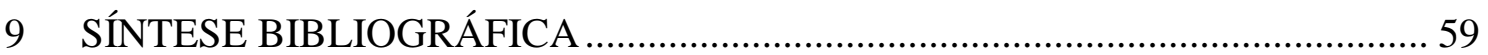

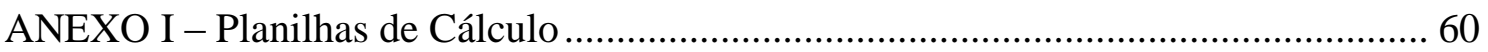




\section{INTRODUÇÃO E JUSTIFICATIVA}

O vertedor é uma estrutura hidráulica desenvolvida com o objetivo de medir vazão, controlar níveis e descarregar os excessos de vazão oriundos de eventos hidrológicos extremos.

De acordo com Porto (2003) os vertedores são constituídos por:

- Crista ou Soleira: parte superior da parede em que há contato com a lâmina vertente;

- Carga sobre a Soleira (h): é a diferença entre as cotas do nível d'água de montante e o nível da crista da soleira;

- Altura do Vertedor (P): é a diferença entre as cotas da soleira e o fundo do canal de aproximação;

- Largura ou Luz da Soleira (L): é a largura da soleira onde ocorre o escoamento.

Além das terminologias citadas, Porto (2003) classifica os vertedores de acordo com:

a) Forma geométrica da abertura: retangulares, circulares, trapezoidais, triangulares e parabólicas;

b) Altura relativa da soleira: descarga livre se $\mathrm{P}>\mathrm{P}^{\prime}$ (são os mais utilizados) e descarga afogada quando $\mathrm{P}<\mathrm{P}^{\prime}$, quando o nível d'água de jusante é superior ao nível da soleira;

c) Natureza da parede: parede delgada se a espessura for inferior a dois terços da carga hidráulica (e<2/3h); e de parede espessa caso contrário ao da parede delgada $(e>2 / 3 h)$;

d) Largura relativa da soleira: sem contrações laterais quando a largura da soleira for igual a largura do canal $(\mathrm{L}=\mathrm{B})$ e com contrações laterais quando a largura da soleira for inferior a largura do canal $(\mathrm{L}<\mathrm{B})$;

e) Natureza da lâmina: lâmina livre quando a região abaixo da lâmina for devidamente arejada, de modo que a pressão seja a pressão atmosférica, lâmina deprimida quando a pressão abaixo da lâmina for inferior à pressão atmosférica e lâmina aderente que é quando não há mais a formação de bolsa de ar abaixo da lâmina e esta cola no paramento de jusante; 
f) Inclinação do paramento da estrutura: sendo ele vertical ou inclinado;

g) Geometria da crista: cristas retilíneas, circulares, poligonais ou em labirinto.

Embora os vertedores apresentem grandes dimensões, eles comumente são caracterizados como vertedores de parede delgada, isto é possível devido aos estudos de soleira vertente. Desta forma Scimemi e Creager apud Chanson (2004) desenvolveram estudos baseado no jato livre formado por um vertedor de parede delgada. A Figura 1 apresenta o jato livre de um vertedor de parede delgada.

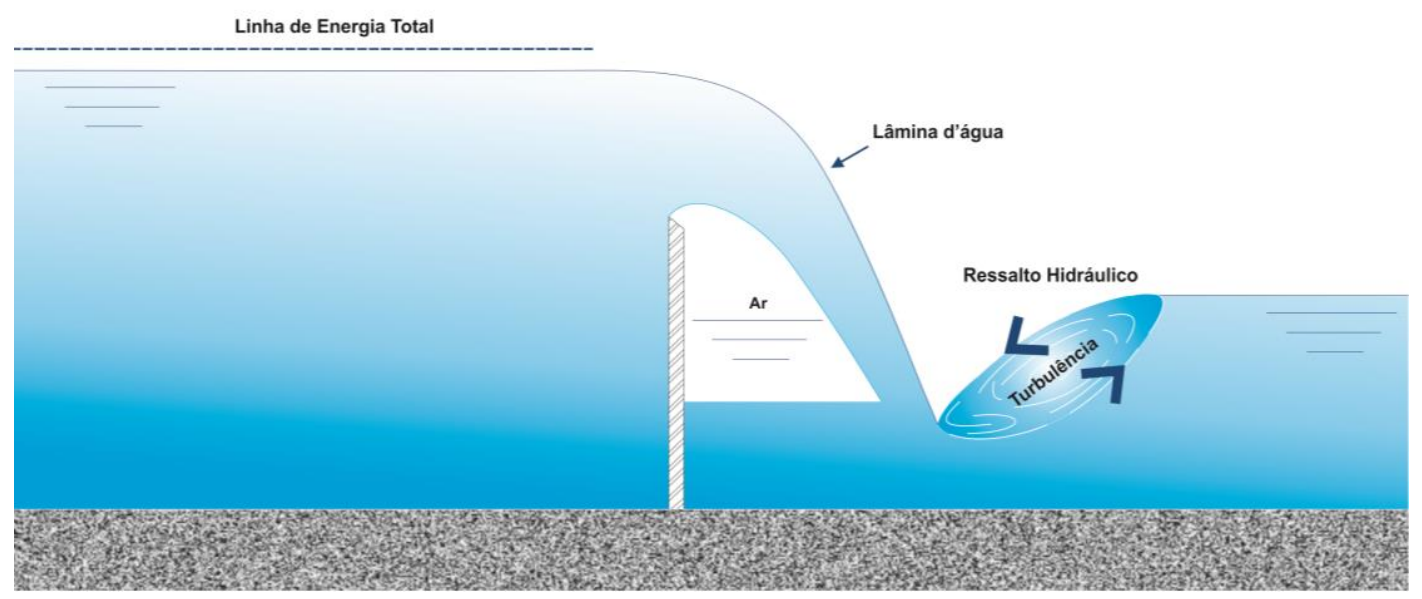

Figura 1 - Jato livre de um vertedor de parede delgada

Observando o formato que o jato livre formava, Scimemi 1930 propôs uma curva parabólica ajustada conforme apresentada na equação 1 .A Figura 2 apresenta as premissas adotadas para a formulação. A Figura 3 apresenta o sistema de referência paras as coordenadas do perfil.

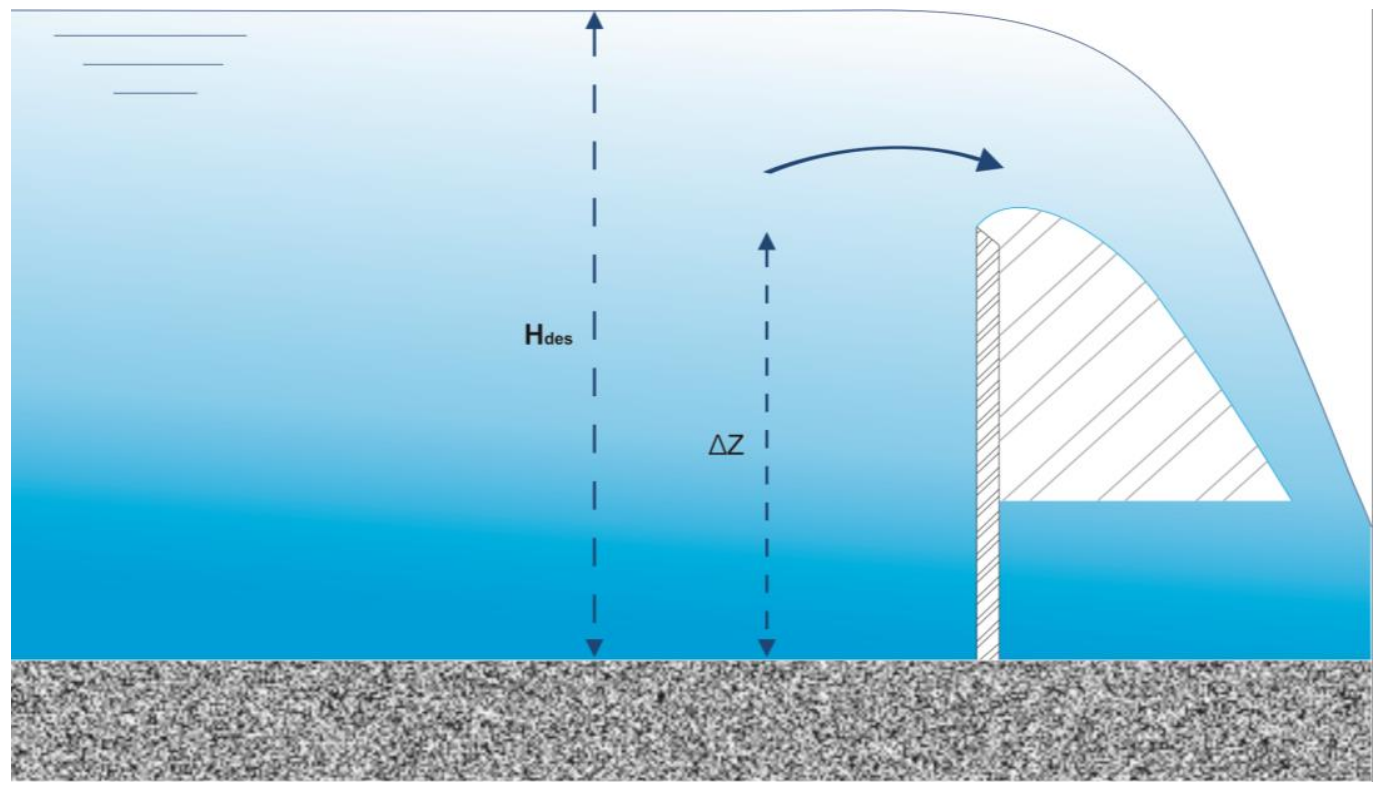

Figura 2 - Características do vertedor parede delgada - Adaptado de CHANSON(2004) 


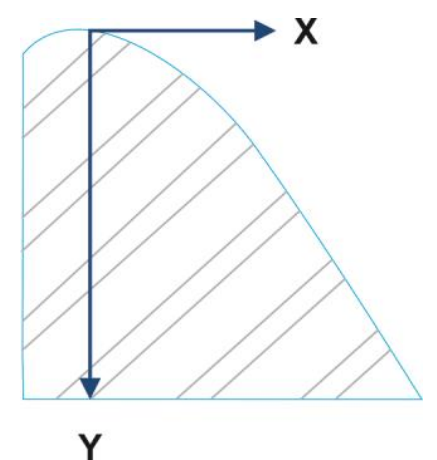

Figura 3 - Sistema de Coordenadas Adotado, Adaptado de CHANSON (2004)

$$
Y=0,50 \times \frac{X^{1,85}}{\left(H_{\text {des }}-\Delta z\right)^{0,85}}
$$

Creager realizou em seus estudos uma relação de pontos para a determinação do perfil, considerando o perfil inferior da lâmina vertente, a qual Scimemi, realizou um ajuste matemático e propôs a equação 2 apresentando a proposta de Creager.

$$
Y=0,47 \times \frac{X^{1,80}}{\left(H_{\text {des }}-\Delta z\right)^{0,80}}
$$

Além de Creager e Scimemi vários outros cientistas hidráulicos estudaram a forma do jato livre para vertedor de parede delgada, desenvolvendo assim diversas outras equações. A Figura 4 apresenta os perfis na região da crista do vertedor, enquanto que a Figura 5 apresenta a continuação das curvas estudadas.

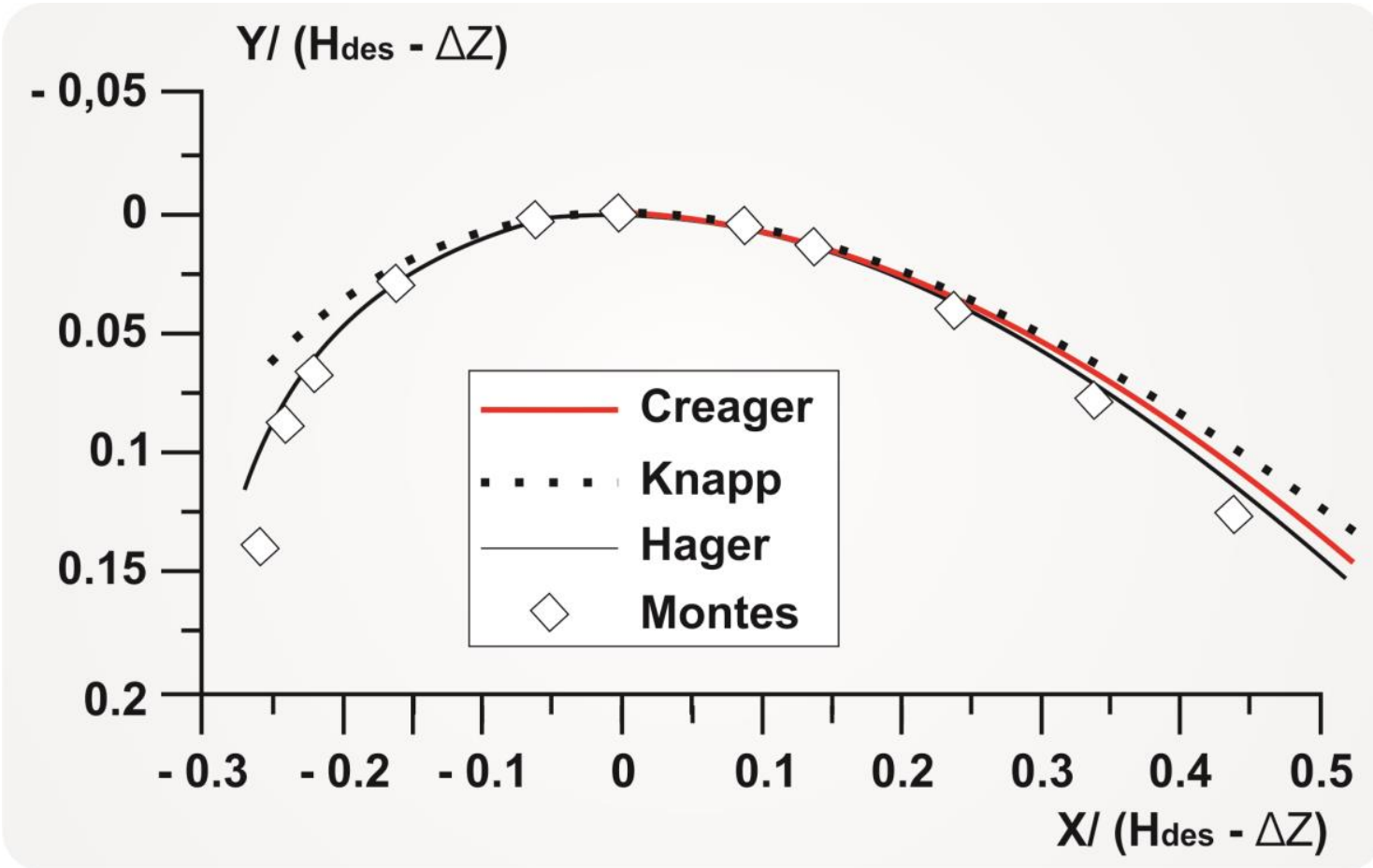

Figura 4 - Perfil detalhe na região da crista - Fonte: CHANSON (2004) 


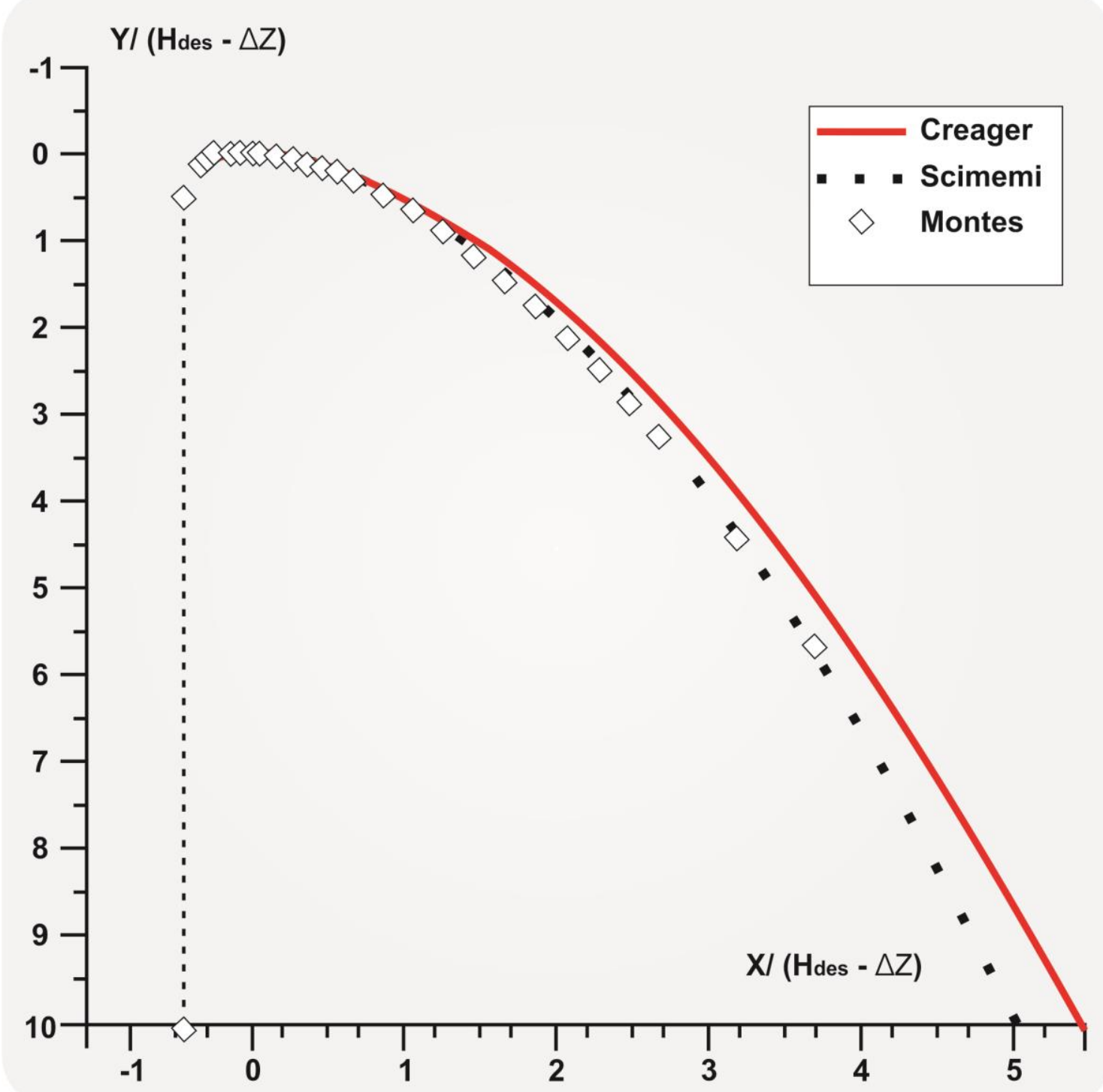

Figura 5 - Perfil comparação entre Scimemi e Creager - Fonte: CHANSON (2004)

Observando os estudos realizados pode-se verificar que há descontinuidade no raio de curvatura, principalmente na região da crista, para os perfis propostos.

Devido ao exposto pretende-se ajustar uma equação cossenoidal conforme apresentado na equação 3, ao perfil Creager.

$$
Y=a \cos \left(\frac{\pi}{2} \times \frac{X}{b}\right)
$$

Através do ajuste desta equação a uma soleira normal do tipo Creager obtêm-se um ponto com raio "r" na crista da soleira e uma variação gradual do raio até atingir raio infinito onde se faz a transição para uma reta. Com a utilização desta curva elimina-se a transição de um raio finito para um raio infinito, desfazendo-se um ponto de geração de instabilidade. 
No trecho do quadrante superior de montante normalmente se utiliza a composição de dois ou três arcos de círculo. Através de um ajuste de uma equação elíptica é possível realizar a transição eliminando os pontos de descontinuidades no raio de curvatura, fazendo coincidir, na crista, com os raios do quadrante superior de montante e jusante.

Desta forma eliminam-se diversos pontos de descontinuidade no raio de curvatura, reduzindo assim o efeito da geração de instabilidade no escoamento da soleira vertente; 


\section{OBJETIVOS}

Este trabalho tem por objetivo desenvolver e apresentar um estudo sobre a soleira vertente desenhada a partir de uma curva cossenoidal para o vertedor, substituindo-se o perfil Creager, comumente utilizado.

O principal objetivo deste trabalho é apresentar subsídios para que os projetistas de obras hidráulicas desenvolvam projetos de soleiras vertentes eliminando as descontinuidades existentes nos perfis atuais.

Atualmente é amplamente adotado como o perfil de soleira padrão aquela estudada e desenvolvida pelo United States Army Corps of Engineers, composta por três arcos de circunferência no quadrante superior de montante e uma parábola modificada no quadrante superior de jusante. A Figura 6 apresenta a composição do perfil da soleira vertente.

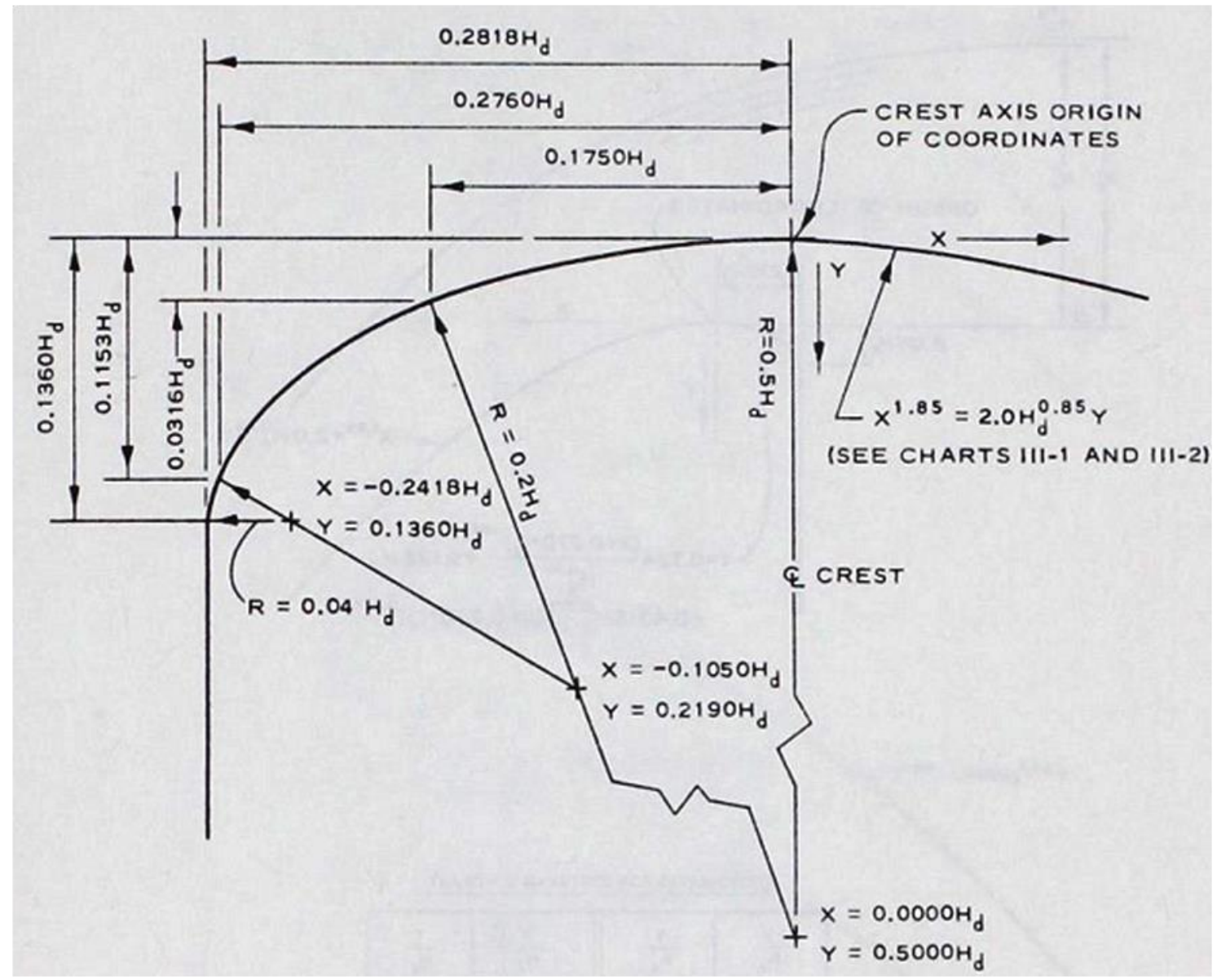

Figura 6 - Perfil da Soleira Vertente apresentada pelo Hydraulic Design Criteria. - Fonte: Hydraulic Design Criteria Sheets 111-1 to 111-2/1, 1987 
Este tipo de concordância apresenta quatro pontos de descontinuidade no raio de curvatura, pontos este que causam instabilidade no escoamento sobre a soleira vertente. Partindo como ponto de início a soleira vertente apresentada pelo Hydraulic Design Criteria propõe-se um estudo para a eliminação dos pontos de transição entre os segmentos de arcos de circunferências e entre o ponto de tangência da parábola modificada e o terceiro arco de circunferência.

Desta forma, utilizando-se de uma curva cossenoidal ajustada a um perfil Creager no trecho da crista para jusante e realizando-se uma transição no trecho de montante a partir de uma curva elíptica, objetivando-se a eliminação das descontinuidades existentes na crista do vertedor e entre a transição dos três arcos de circunferência. 


\section{ANÁLISE BIBLIOGRÁFICA}

Conforme Porto (2003) estudos sobre a soleira vertente deu-se início pelo engenheiro hidráulico francês Henri-Émile Bazin (1829-1917), que iniciou seus estudo em vertedores de parede delgada, com soleira horizontal e biselada. Para que fosse denominado descarregador de Bazin, além de apresentar as características citadas anteriormente, o escoamento deve ocupar a totalidade da largura do canal, não podendo haver contrações e deveria haver espaço sob a lâmina vertente onde deveria constar ar à pressão atmosférica.

Bélanger, 1828 apud Chanson (2004) afirma que uma soleira apresentará capacidade máxima se esta estiver funcionando em estado de fluxo crítico, ou seja, considerando um fluido ideal transbordando um vertedor de seção retangular e assumindo pressão hidrostática, a máxima vazão de descarga por unidade de comprimento do vertedor, será obtido através da equação de Bernoulli obtendo-se como resultado final a equação 4 .

$$
q=\frac{2}{3} \sqrt{g}(H-\Delta z)^{3 / 2}
$$

Onde:

$H$ = Carga total d'água $(\mathrm{m})$;

$\Delta z=$ Altura da Soleira $(\mathrm{m})$;

Verificou-se através de experimentos que, na prática, os valores observados de descarga não coincidiam com os valores calculados, devido à distribuição de pressão na crista não ser hidrostática, fazendo assim que fosse inserido no equacionamento um coeficiente denominado de coeficiente de descarga " $\mathrm{C}_{\mathrm{d}}$ ". A equação 5 apresenta a formulação corrigida (CHANSON, 2004).

$$
q=C_{d} \frac{2}{3} \sqrt{g}(H-\Delta z)^{3 / 2}
$$

O estudo do coeficiente de descarga " $\mathrm{C}_{\mathrm{d}}$ ", é motivo de estudos há mais de 100 anos, onde Ackers et.al lista mais de 100 referências sobre os estudos de vertedores e formulações para diversos tipos de vertedores.

O coeficiente de descarga, " $\mathrm{C}_{\mathrm{d}}$ ", que serve para corrigir os valores de vazão é um importante parâmetro utilizado para verificar a eficiência que uma determinada forma geométrica em relação à outra forma, levando-se em consideração basicamente a largura do vertedor, a carga hidráulica e o perfil vertente. 
De acordo com Chow (2009) o perfil do jato d'água em um vertedor se assemelha ao princípio de lançamento de projétil conforme apresentado na Figura 7
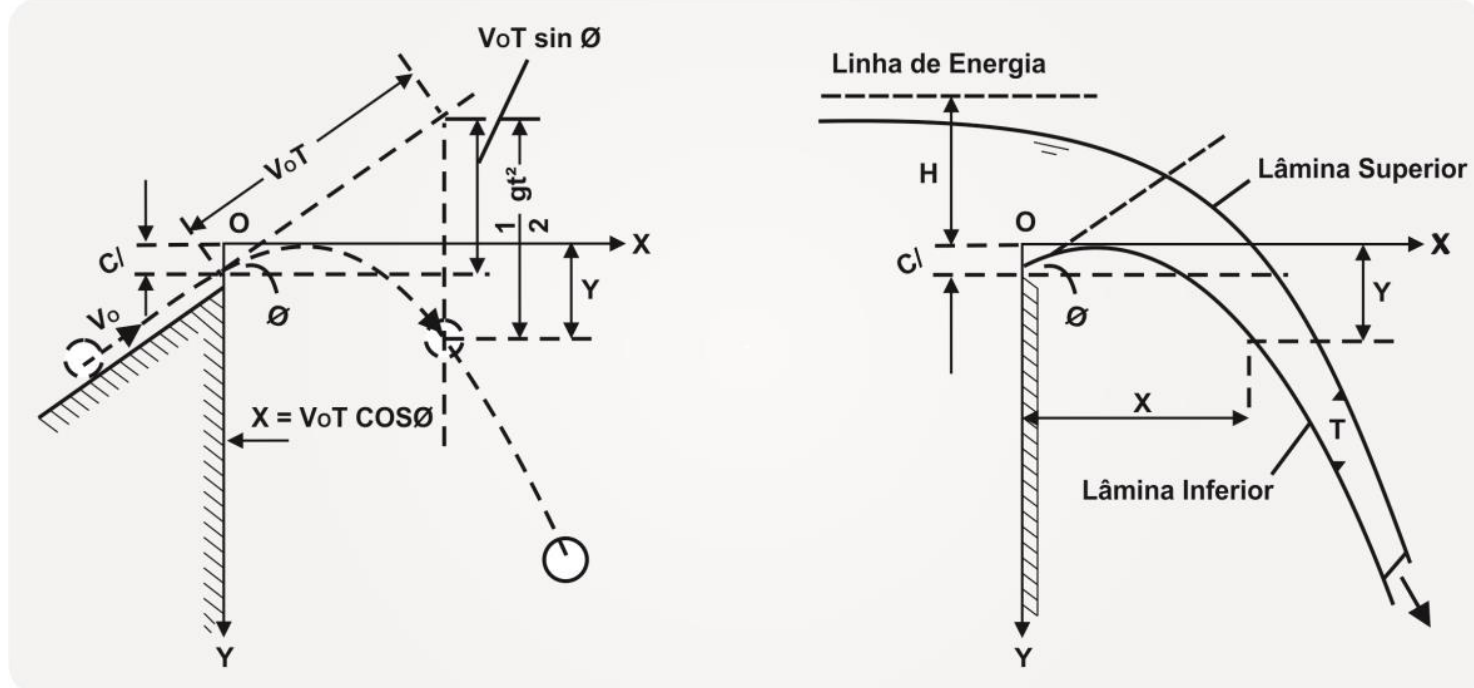

Figura 7 - Variação da linha d'água de acordo com o princípio do lançamento de projétil - Fonte:

CHOW, 2009

Este conceito admite que a velocidade horizontal é constante, agindo apenas a força da gravidade na lâmina d'água; num tempo "t" uma partícula de água na lâmina inferior percorrerá uma distância "x" conforme equação 6.

$$
x=v_{0} t \cos \theta
$$

Em um mesmo tempo "t" a partícula irá percorrer na distância "y" vertical conforme a equação 7 .

$$
y=-v_{0} t \sin \theta+\frac{1}{2} g t^{2}+C^{\prime}
$$

Onde "x" e "y" são as posições segundo um plano cartesiano, " $v_{0}$ " é a velocidade inicial no ponto onde o valor de "x" é igual a 0 , o valor " $\theta$ " corresponde ao ângulo da inclinação da velocidade com a horizontal e por fim $\mathrm{C}^{\prime}$ corresponde a altura entre $\mathrm{o}$ ponto mais alto da lâmina d'água na crista. Eliminando a variável "t" da equação e dividindo pela carga hidráulica a equação para a lâmina inferior adimensionalizada será.

$$
\frac{y}{H}=A\left(\frac{x}{H}\right)^{2}+B\left(\frac{x}{H}\right)+C
$$

Onde:

$$
\begin{aligned}
& A=g H / 2 v_{0}^{2} \cos ^{2} \theta \\
& B=-\tan \theta \\
& C=C^{\prime} / H
\end{aligned}
$$


Uma vez que a velocidade é constante pode-se afirmar que a espessura da lâmina d'água também será constante, assim adiciona-se mais um termo à equação 8 sendo este termo $\mathrm{D}=\mathrm{T} / \mathrm{H}$, assim tem-se a equação para lâmina d'água superior, conforme apresentada na equação 9.

$$
\frac{y}{H}=A\left(\frac{x}{H}\right)^{2}+B\left(\frac{x}{H}\right)+C+D
$$

Como estas duas equações apresentam o expoente dois pode-se afirmar que são equações parabólicas.

Conforme Chanson (2004), a partir do estudo de lançamento de projéteis o engenheiro Scimemi, propôs fazer o preenchimento da parte inferior da lâmina vertente, propondo assim uma soleira espessa com características de soleira delgada, criando assim o vertedor de soleira padrão.

A soleira padrão possui o equacionamento de uma parábola modificada conforme apresentado na equação 10 .

$$
Y=0,50 \times \frac{X^{1,85}}{\left(H_{d e s}-\Delta z\right)^{0,85}} \quad(\text { Scimemi })
$$

Desta forma a pressão na crista do vertedor deveria ser a pressão atmosférica; mas devido ao atrito existente, surge a subpressão, fenômeno que pode causar cavitação.

Assim, Creager propôs um ajuste ao perfil de Scimemi, objetivando a redução da subpressão. Este ajuste consistiu em fazer com que a curva se elevasse, compensando assim o efeito de atrito. A equação 11 apresenta o perfil proposto por Creager, modificando assim o perfil de Scimemi.

$$
Y=0,47 \times \frac{X^{1,80}}{\left(H_{d e s}-\Delta z\right)^{0,80}} \quad(\text { Creager })
$$

A Figura 8 mostra o resultado das duas equações, verificando que o perfil de Creager apresenta uma elevação em relação ao de Scimemi. 


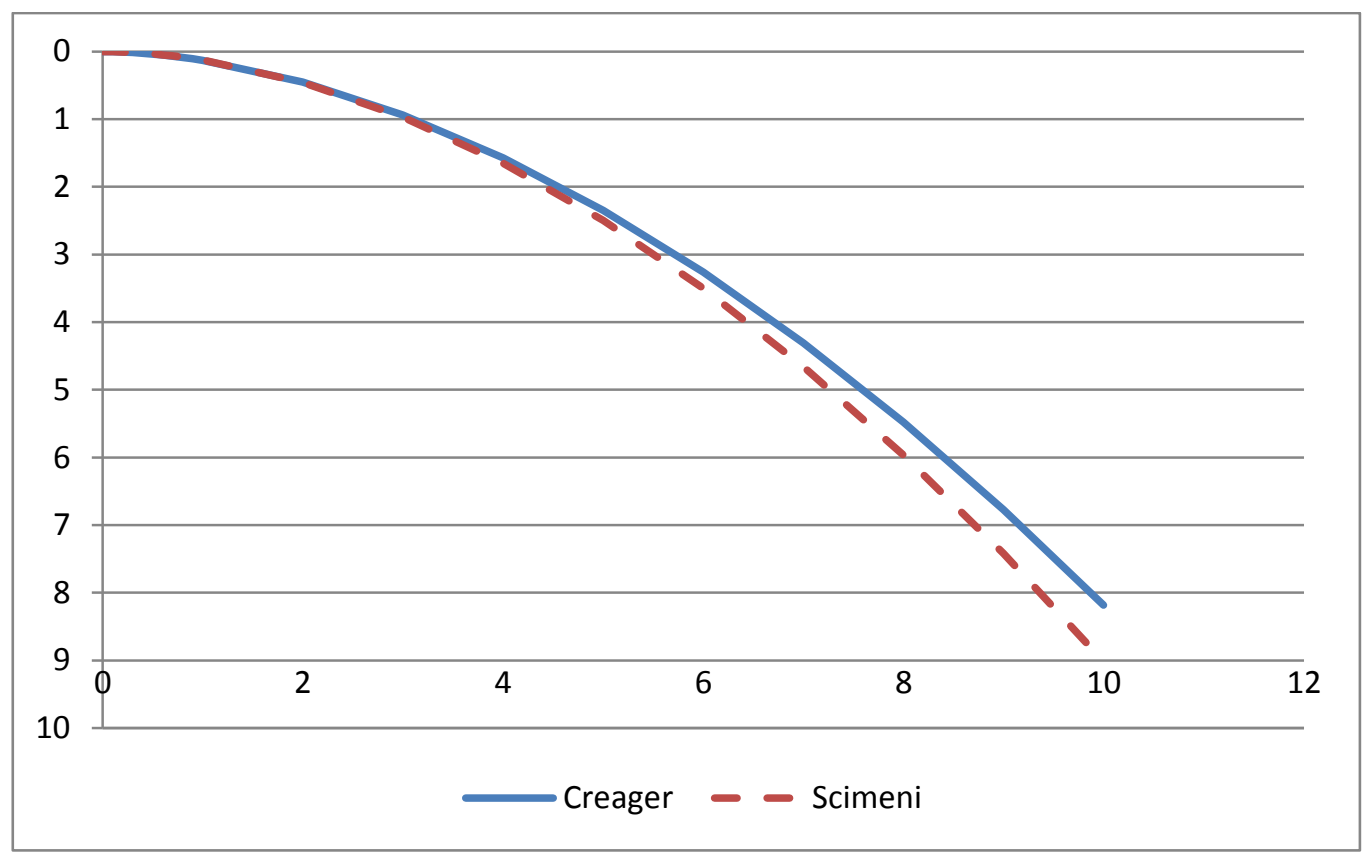

Figura 8 - Variação do perfil vertente para as propostas de Scimemi e Creager - Fonte: GARCIA (2014)

Abecasis apud Arauz (2005) realizou estudos referente à concordância entre o paramento de montante e a crista. Inicialmente esta transição era realizada por um arco de circunferência, mas estudos do USBR (1966) incorporou mais um arco de circunferência realizando assim a transição através de dois arcos de circunferência. Nos estudos Abecasis verificou que a concordância do USBR provocava picos de subpressão na região a montante da crista do vertedor. Através de modelos físicos, Abecassis propôs a inserção de um terceiro arco de circunferência objetivando eliminar a aresta viva que havia entre o paramento de montante e o arco de circunferência. Desta forma foi adotado pelo Hydraulic Design Criteria (HDC) a inclusão deste terceiro arco de circunferência na proporção de $0,04 \mathrm{H}_{d}$, sendo $\mathrm{H}_{\mathrm{d}}$ a carga hidráulica de projeto sobre o vertedor, fazendo com isso uma redução e/ou eliminação do descolamento e da ocorrência de pressões negativas. A Figura 9 demonstra o gráfico de distribuição de pressões entre o antes e o depois da inserção do arco de circunferência de $0,04 \mathrm{H}_{\mathrm{d}}$. 

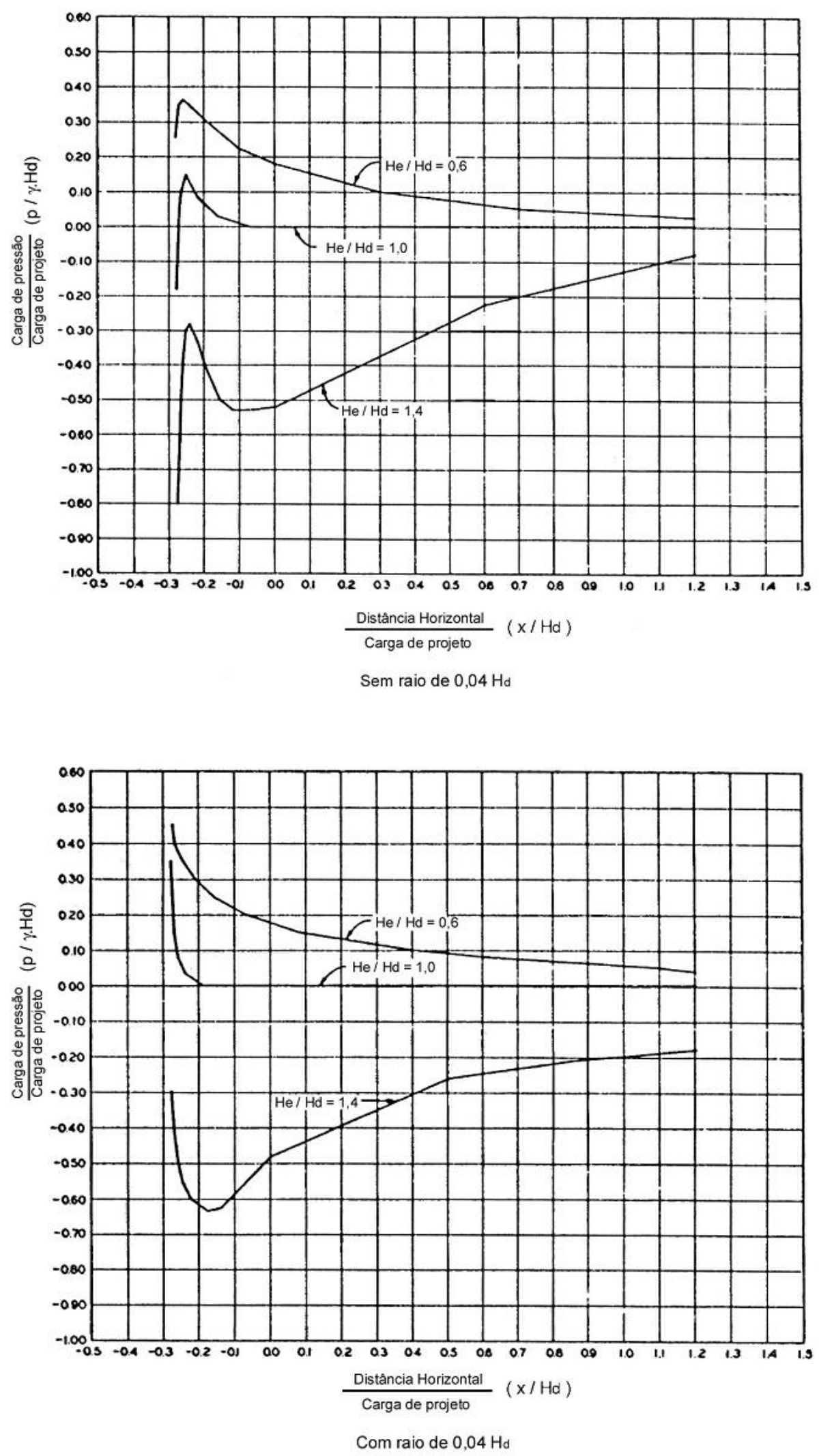

Figura 9 - Distribuição de pressões, antes e depois da inserção do arco de circunferência $0,04 H_{d}$ entre o paramento de montante e o perfil USBR. Fonte: Maynord,1985 apud ARAUZ (2005) 
Murphy (1973) apresentou em seu trabalho sobre projeto de cristas de vertedor considerações sobre a curvatura da crista, afirmando que a região mais crítica é a que se encontra imediatamente a jusante do ponto de crista, onde nesta região a velocidade é relativamente alta e com a camada limite subdesenvolvida. Além da região de crista Murphy (1973) ainda menciona a descontinuidade da transição entre a crista e o trecho de jusante, bem como o paramento de montante com o quadrante superior de montante.

Souza em seu estudo intitulado Histerese em Escoamento sobre Salto-de-Esqui, realizou um estudo similar ao dar continuidade ao perfil vertente modelado. Foi utilizada uma curva lemniscata ajustando seu raio inicial ao do arco de círculo e realizando ao final a tangência com um paramento com proporções de $0,80 \mathrm{~m}$ na horizontal para cada $1,00 \mathrm{~m}$ na vertical.

Kanashiro (1989) realizou, em sua dissertação de mestrado, um amplo estudo sobre vertedor com perfil do tipo lemniscata. Uma lemniscata é uma curva cuja equação apresenta como propriedade uma continuidade em sua curvatura, podendo ser adaptada às condições propostas. A equação 12 é que caracteriza uma curva lemniscata.

$$
\rho=a \sqrt{\cos \left(\frac{\pi \alpha}{2 \alpha_{0}}\right)}
$$

Onde:

$\rho=$ raio do vetor;

$a=$ semi eixo maior;

$\alpha=$ ângulo que o raio do vetor faz com $a$;

$\alpha_{0}=$ ângulo que a tangente à lemniscata na origem faz com o raio vetor.

De acordo com Kanashiro (1989), para que haja validade entre o perfil lemniscata é necessário que o perfil da apresente no mínimo 3 pontos de coincidência com um perfil Creager conhecido, além de concordância por tangência nos dois perfis.

Kanashiro (1989), em seu estudo, realizou a avaliação dos perfis Creager e Lemniscata, a Figura 10 apresenta os perfis estudados Creager e Lemniscata, em seu estudo no trecho de montante foi realizado o estudo através de "Creager Normal" onde é realizada através de três arcos de circunferência e através da proposta de Maynord onde realiza a concordância através de uma elipse e por final através de uma lemniscata. 


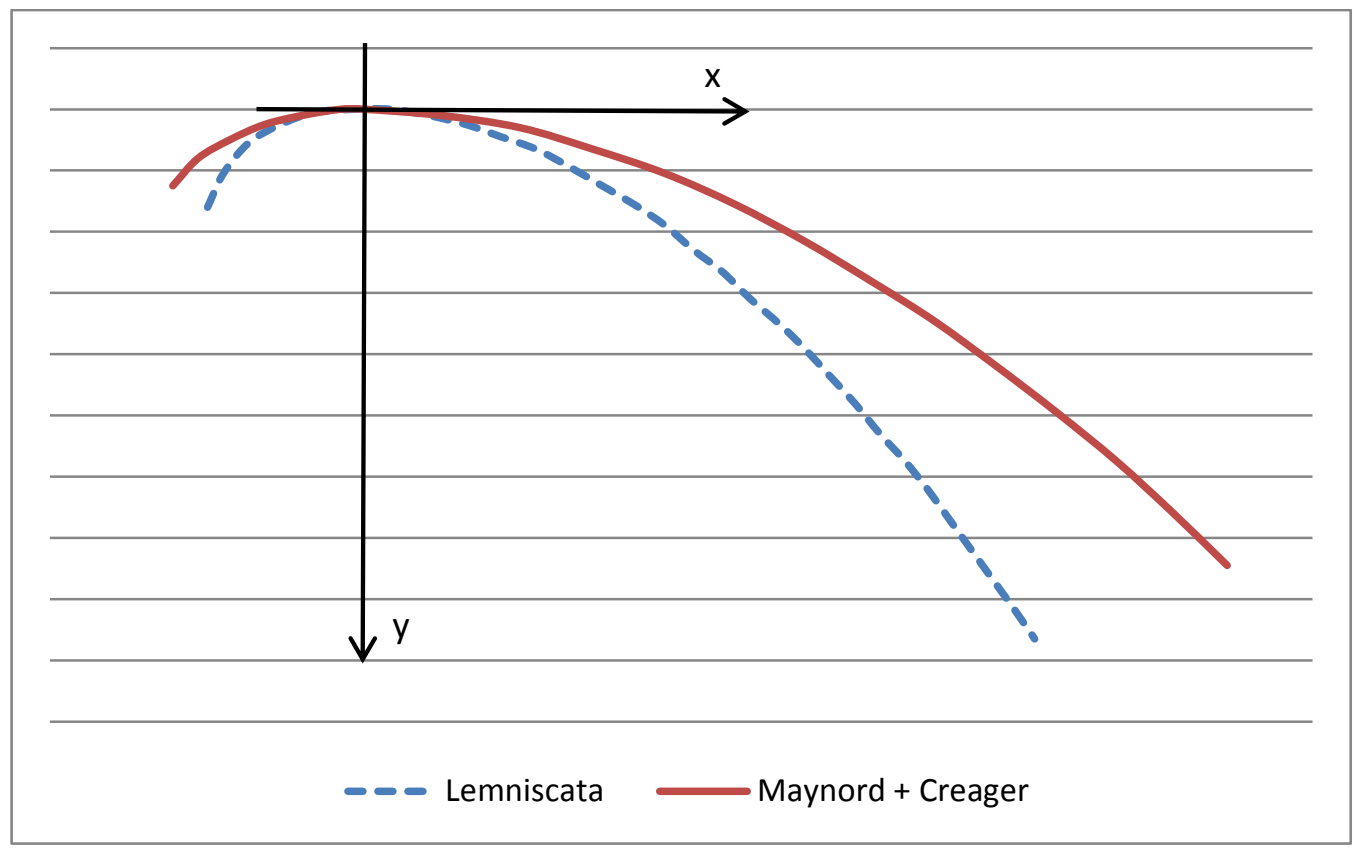

Figura 10 - Perfis tipo Maynord+Creager e Lemniscata - Fonte: KANASHIRO. (1989)

$\mathrm{Na}$ atualidade têm-se desenvolvidos diversos estudos sobre soleiras vertentes, dentre eles podemos citar o estudo desenvolvido por Daneshfarazet al.. (2012), onde é apresentada uma análise numérica para vertedor com crista elíptica e USBR no quadrante de montante do vertedor. A Figura 11apresenta os perfis adotados para a análise numérica.

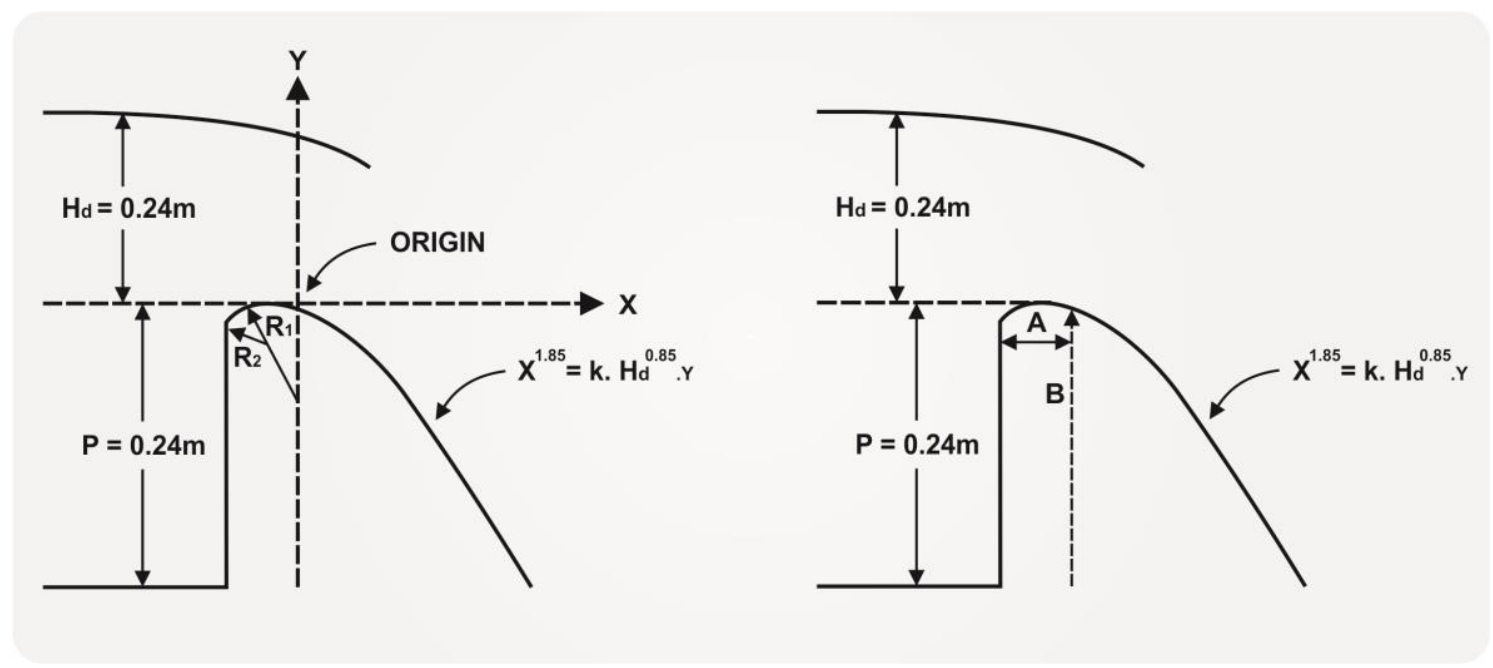

Figura 11 - Perfis tipo USBR e perfil elíptico adotado para a análise numérica - Fonte: DANESHFARAZet al.. (2012)

Daneshfarazet al.. (2012) elaborou uma análise numérica utilizando os dados disponibilizados pelo experimento de Maynord onde realizou, através de um modelo físico, as curvas de pressão para o vertedor considerando o perfil do USBR e o elíptico. 


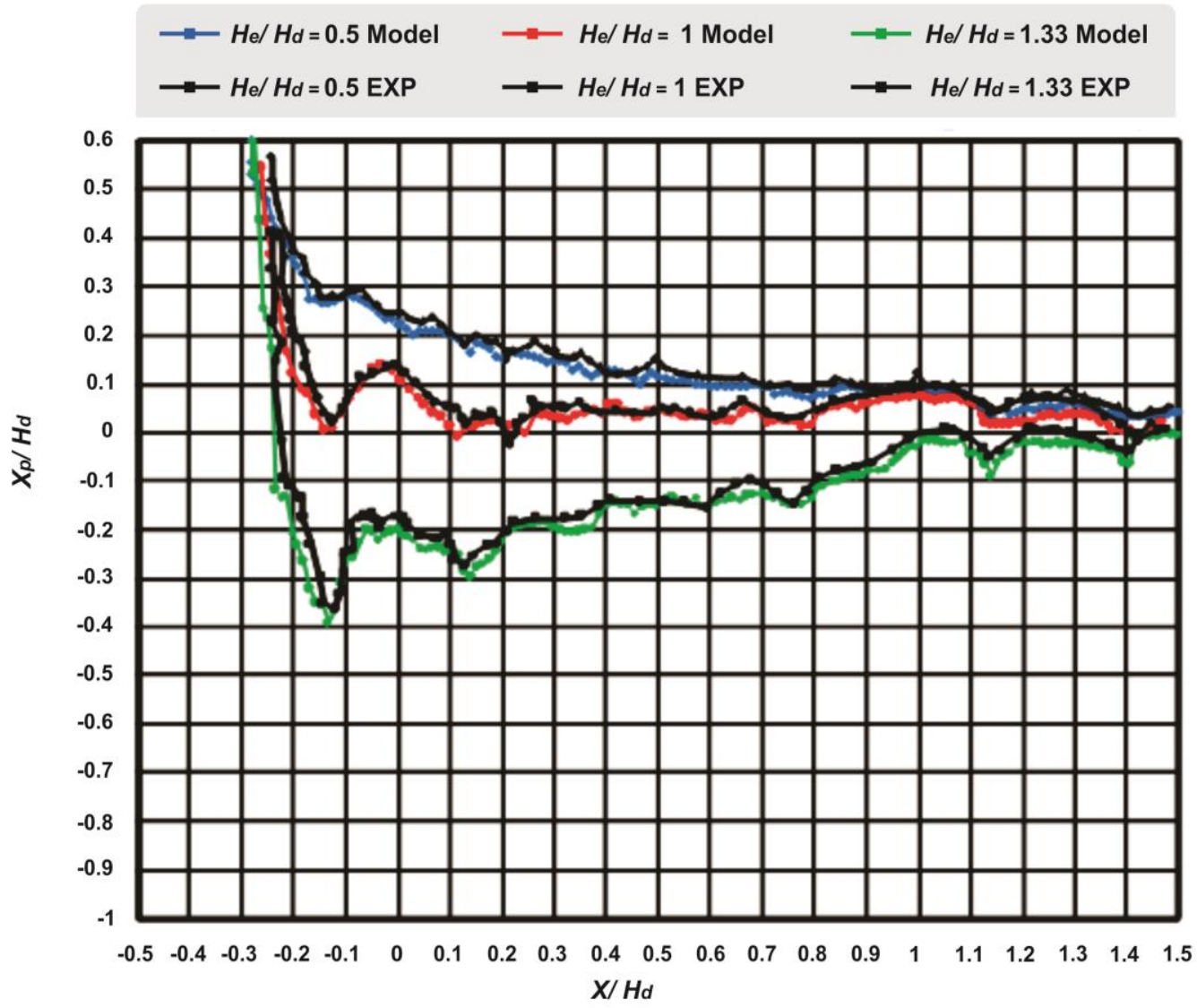

Figura 12 - Linhas de pressão para o perfil USBR obtidas pelo experimento de Maynord e da análise numérica - Fonte: DANESHFARAZet al.. (2012)

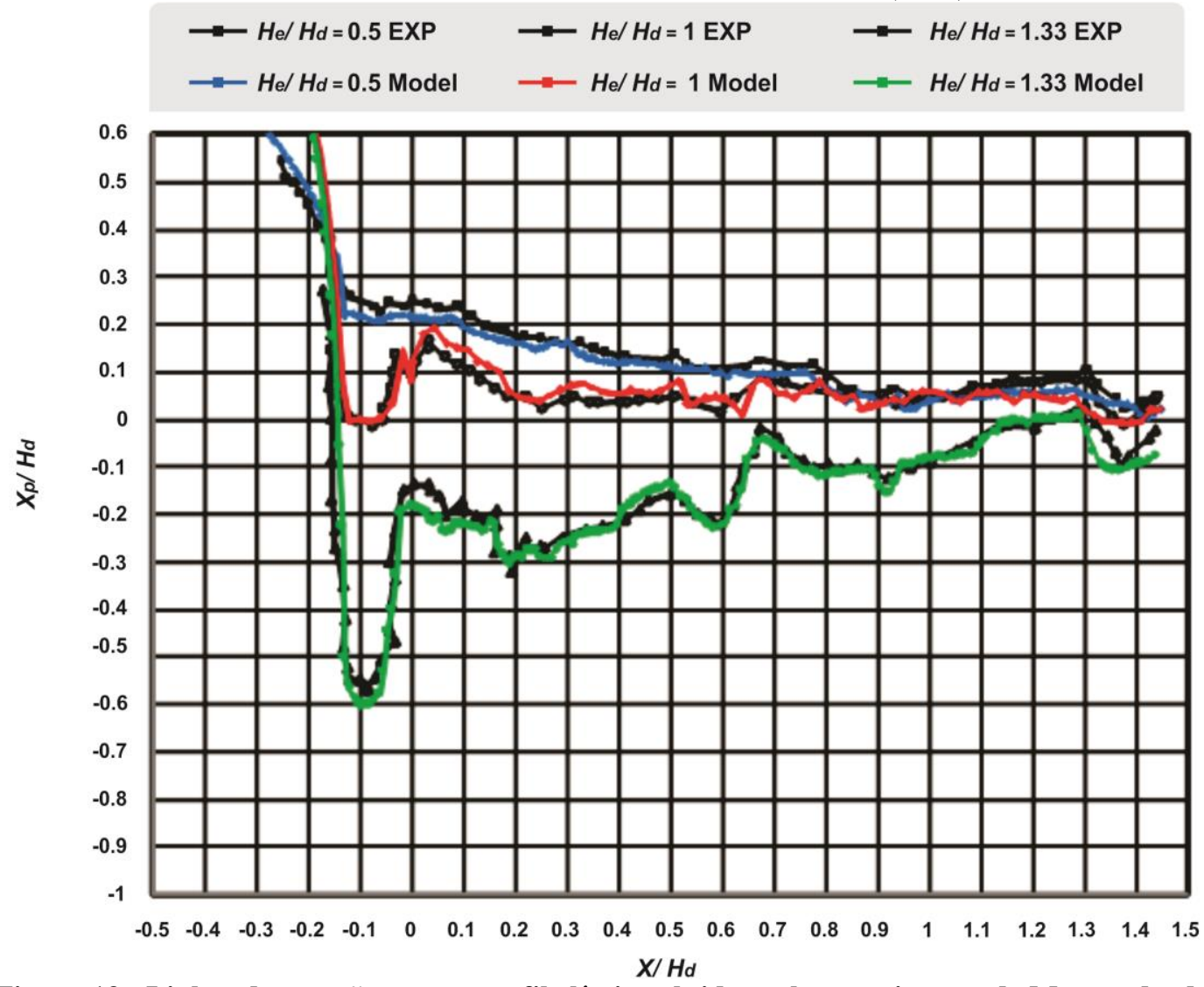

Figura 13 - Linhas de pressão para o perfil elíptico obtidas pelo experimento de Maynord e da análise numérica - Fonte: DANESHFARAZet al.. (2012) 
Desta forma Daneshfarazet al. (2012) comparam a linha de pressão para a condição de soleira com o perfil USBR e elíptico, ambos através de modelo numérico e por fim a linha de pressão para o experimento realizado por Maynord. A Figura 14 apresenta a linha de pressão para as situações estudadas por Daneshfarazet al. (2012).

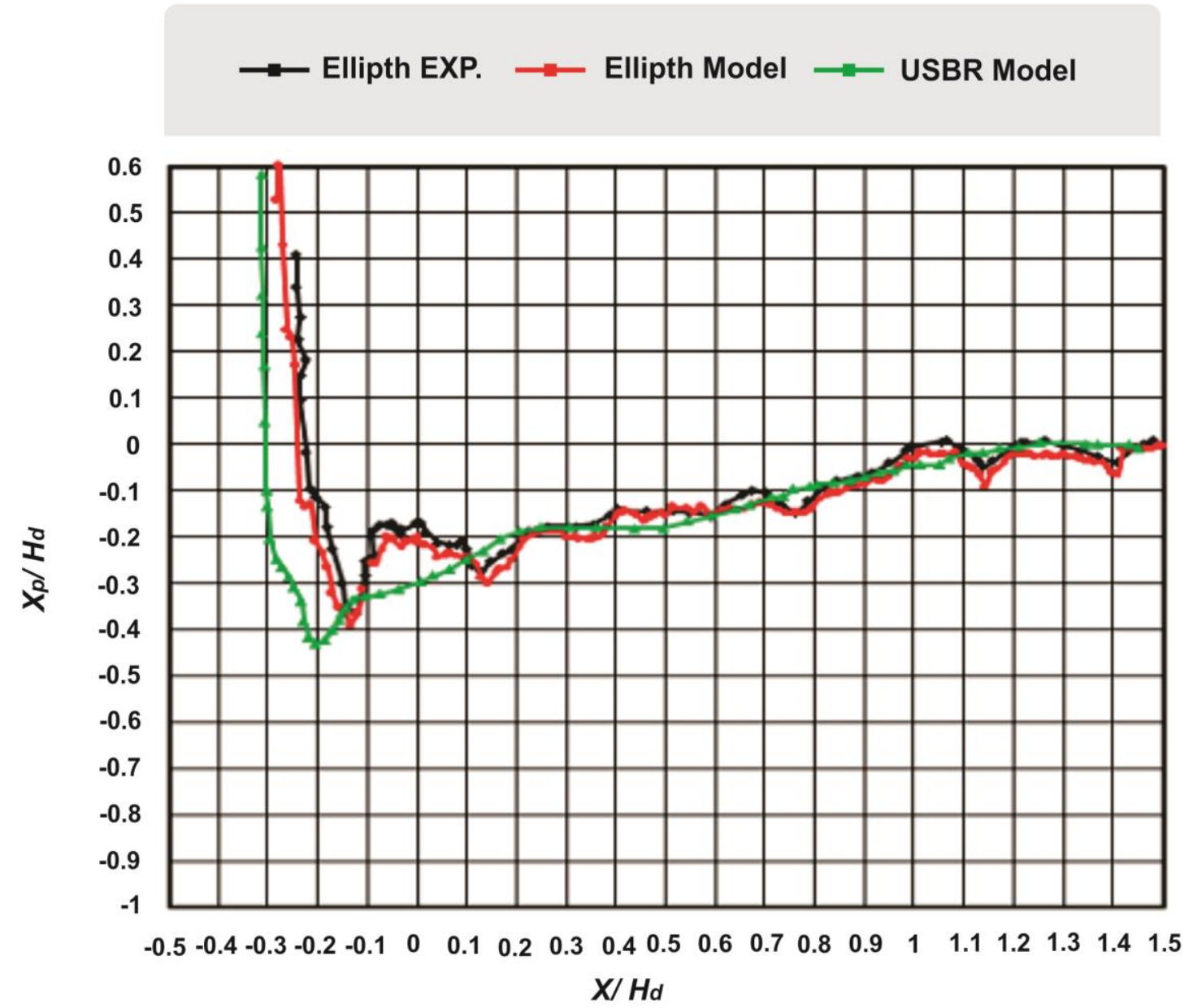

Figura 14 - Linhas de pressão para os perfis USBR e elíptico considerando a relação de He/Hd=1,33 - Fonte: DANESHFARAZet al.. (2012)

Savageet al. (2001) realizaram estudos objetivando comparar resultados entre modelos físicos, análise numérica e literaturas existentes. Neste estudo foi adotado um perfil padrão proposto por Maynord (1985) apud Savageet al. (2001) e comparado os resultados obtidos. Savegeet al. (2001) concluíram que os modelos numéricos estão suficientemente adequados para obter valores precisos quanto ao cálculo de descarga e pressão no vertedor, e que os modelos físicos são a base dos estudos hidrodinâmicos, mas apresentam custos elevados e necessitam de mais tempo. 


\section{NOVA SOLEIRA NORMAL}

Com base nos diversos estudos já realizados por diversos autores pelo mundo é possível verificar que há uma busca contínua por um perfil de soleira em vertedores que reduza os efeitos indesejados no escoamento.

Nos perfis de soleiras há boas conexões no trecho de montante e jusante da crista, com continuidades por tangência, mas ainda apresentam descontinuidades por raio de curvatura. Desta forma estas descontinuidades apresentam problemas de instabilidade com uma probabilidade de início de vórtices que poderão causar danos à estrutura com o passar do tempo.

A proposição deste trabalho é apresentar uma soleira para o trecho de jusante do vertedor, substituindo a tradicional equação proposta por Creager por uma equação cossenoidal conforme apresentada na equação 13.

$$
y=\operatorname{arcos}\left(\frac{\pi}{2} \cdot \frac{x}{b}\right)
$$

A Figura 15 apresenta graficamente o comportamento da equação 13 que foi proposta para o intervalo $-b \leq x \leq+b$.

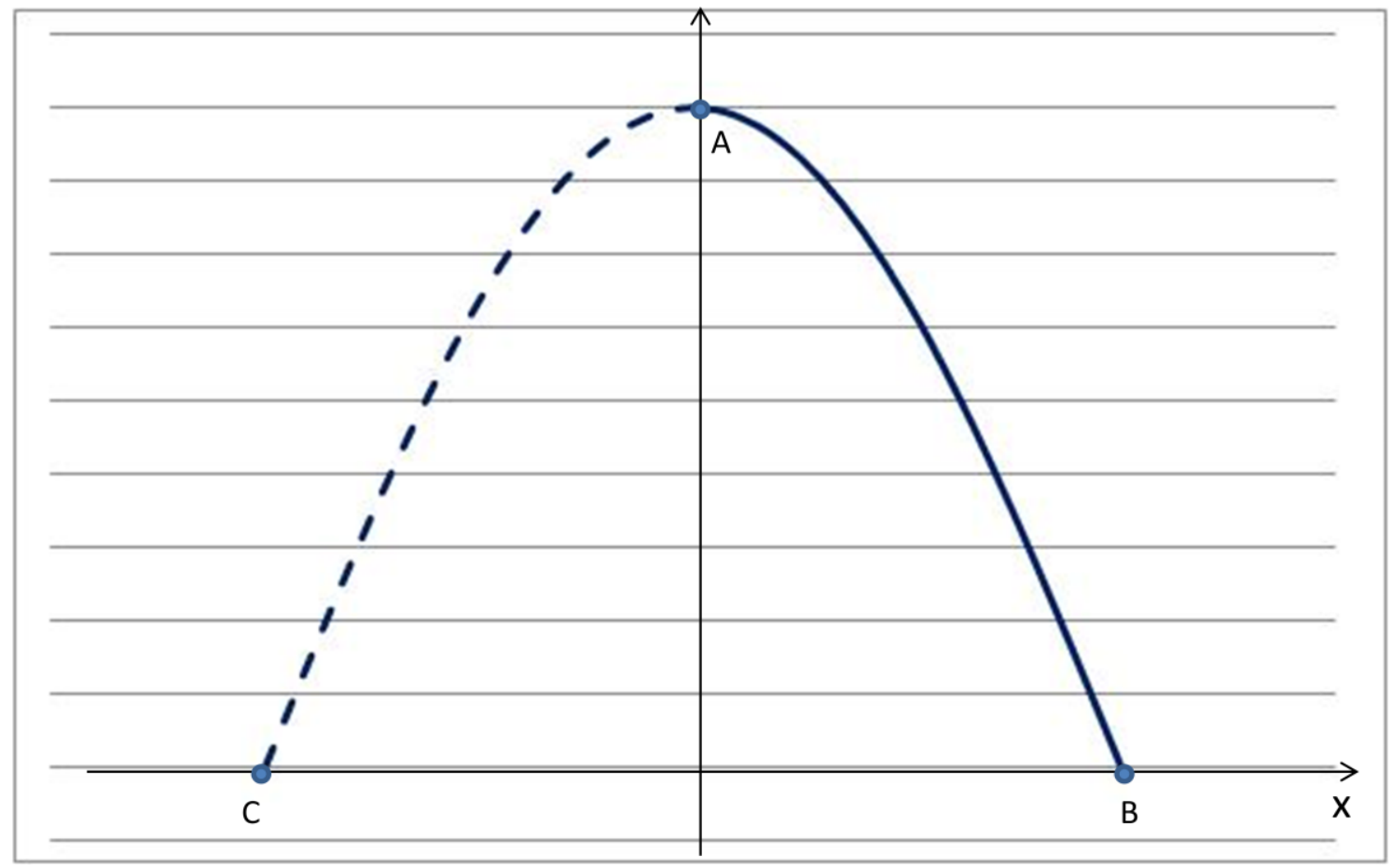

Figura 15 - Representação gráfica da equação 13 


\subsection{Análise da Equação Cossenoidal}

Através de uma análise de tangências onde a derivada primeira em relação a "x" na equação 13, é possível verificar que a inclinação da tangente à curva é:

$$
\frac{d y}{d x}=-\frac{a \pi}{2 b} \sin \left(\frac{\pi}{2} \cdot \frac{x}{b}\right)
$$

Desta forma tem-se:

Ponto A: $\frac{d y}{d x}=0$;

Ponto B: $\frac{d y}{d x}=\frac{a \pi}{2 b}$;

Ponto $\mathrm{C}: \frac{d y}{d x}=-\frac{a \pi}{2 b}$;

Através das definições matemáticas o raio de curvatura de uma função $y=f(x)$ é diferenciável por pelo menos duas vezes sendo o raio de curvatura obtido através de:

$$
\begin{gathered}
r=\frac{\left[1+\left(\frac{d y}{d x}\right)^{2}\right]^{3 / 2}}{\left|\frac{d^{2} y}{d x^{2}}\right|} \\
\frac{d^{2} y}{d x^{2}}=-\frac{a \pi^{2}}{4 b^{2}} \cdot \cos \left(\frac{\pi}{2} \cdot \frac{x}{b}\right) \\
r=\frac{\left[1+\frac{a^{2} \pi^{2}}{4 b^{2}} \sin ^{2}\left(\frac{\pi}{2} \cdot \frac{x}{b}\right)\right]^{3 / 2}}{\left|\frac{a \pi^{2}}{4 b^{2}} \cdot \cos \left(\frac{\pi}{2} \cdot \frac{x}{b}\right)\right|}
\end{gathered}
$$

Desta forma temos:

Ponto A: $r=\frac{4 b^{2}}{a \pi^{2}}$;

Ponto B: $r=\infty$;

Ponto C: $r=\infty$;

Com a utilização desta equação é possível realizar ajustes de maneira que haja concordância por tangência e raio de curvatura na crista do vertedor e no trecho final onde atualmente já é realizada uma união por reta. 
Através da eliminação destas descontinuidades busca-se obter uma melhora hidráulica no escoamento, reduzindo efeitos de pressão negativa e a ocorrência de cavitação. 


\section{MODELAÇÃO DAS LINHAS D'ÁGUA E PRESSÃo}

Para a validação deste novo equacionamento será utilizado um modelo computacional onde será calculado com base nos estudos de SOUZA (1985) na sua tese sobre Histerese em Escoamento sobre Salto de Esqui onde é apresentada a formulação para determinação de linha d'água e distribuição de pressão sobre a superfície de fundo curvo.

\subsection{Coordenadas Curvilíneas}

Um ponto $\mathrm{P}$ que está sobre um fundo curvo de um canal de coordenadas $x=\xi$, $y=\eta$, e s o comprimento de arco ao longo do fundo curvo é definido por:

$$
\begin{aligned}
& x=\xi(s) \\
& y=\eta(s)
\end{aligned}
$$

Seja n a distância medida a partir do fundo do canal e perpendicular a este, as novas variáveis $(\mathrm{s}, \mathrm{n})$ formam um sistema curvilíneo ortogonal (ver Figura 16). A velocidade $\vec{V}$ do escoamento num ponto pode ser descrita em coordenadas cartesianas ou coordenadas curvilíneas

$$
\vec{V}=u \hat{\imath}+w \hat{\jmath}=U \hat{e}_{s}+W \hat{e}_{\eta}
$$

Desta forma o perfil da superfície livre do escoamento fica definido por:

$$
\eta=N(s, t)
$$

e o fundo do canal por:

$$
\eta \cong 0
$$

Os versores das direções "s" e "n" são relacionados por:

$$
\begin{gathered}
\hat{e}_{s}(s)=\xi^{\prime} \hat{\imath}+\eta^{\prime} \hat{\jmath} \\
\hat{e}_{n}(s)=-\eta^{\prime} \hat{\imath}+\xi^{\prime} \hat{\jmath}
\end{gathered}
$$

Onde $\xi^{\prime}=\cos \theta$ e $\eta^{\prime}=\sin \theta$

A transformação entre os dos sistemas de coordenadas é:

$$
\begin{aligned}
& x(s, n)=\xi-\eta^{\prime} n \\
& y(s, n)=\eta+\xi^{\prime} n
\end{aligned}
$$

A curvatura do fundo do canal é definida por: 


$$
k(s)=\frac{|\dot{\vec{r}} \wedge \ddot{\vec{r}}|}{|\dot{\vec{r}}|^{3}}
$$

Onde $\vec{r}$ é o raio vetor que posiciona um ponto genérico do fundo do canal e é dado por:

$$
\vec{r}(s)=\xi(s) \hat{\imath}+\eta(s) \hat{\jmath}
$$

de onde se obtém as derivadas primeira e segunda:

$$
\begin{aligned}
\dot{\vec{r}} & =\xi^{\prime}(s) \hat{\imath}+\eta^{\prime}(s) \hat{\jmath} \\
\ddot{\vec{r}} & =\xi^{\prime \prime}(s) \hat{\imath}+\eta^{\prime \prime}(s) \hat{\jmath}
\end{aligned}
$$

O produto vetorial apresentado na equação 27 é resolvido por:

$$
\dot{\vec{r}} \wedge \ddot{\vec{r}}=\left|\begin{array}{ccc}
\hat{\imath} & \hat{\jmath} & \hat{k} \\
\xi^{\prime} & \eta^{\prime} & 0 \\
\xi^{\prime \prime} & \eta^{\prime \prime} & 0
\end{array}\right|=\left(\xi^{\prime} \eta^{\prime \prime}-\eta^{\prime} \xi^{\prime \prime}\right) \hat{k}
$$

Cujo o módulo é

$$
|\dot{\vec{r}} \wedge \ddot{\vec{r}}|=\left|\xi^{\prime} \eta^{\prime \prime}-n^{\prime} \xi^{\prime \prime}\right|
$$

Como o cubo do módulo da derivada primeira é dado por:

$$
|\dot{\vec{r}}|^{3}=\left(\sqrt{\xi^{\prime 2}+\eta^{\prime 2}}\right)^{3}=1
$$

a curvatura ficará expressa por:

$$
k(s)=\left|\xi^{\prime} \eta^{\prime \prime}-\eta^{\prime} \xi^{\prime \prime}\right|
$$

Pelo fato do fundo do canal ser côncavo ou convexo e a equação 34 só fornecer valor positivo para $\mathrm{k}(\mathrm{s})$ é indispensável que a curvatura seja definida por:

$$
k(s)=\xi^{\prime} \eta^{\prime \prime}-\eta^{\prime} \xi^{\prime \prime}
$$

Deste modo tem-se $\mathrm{k}>0$ para fundo côncavo e $\mathrm{k}<0$ para fundo convexo.

O Jacobiano da transformação entre sistemas $(\mathrm{x}, \mathrm{y})$ e (s,n) é definido por:

$$
J=\operatorname{det}\left|\begin{array}{ll}
\frac{d x}{d s} & \frac{d x}{d n} \\
\frac{d y}{d s} & \frac{d y}{d n}
\end{array}\right|=\frac{d x}{d s} \cdot \frac{d y}{d n}-\frac{d x}{d n} \cdot \frac{d y}{d s}
$$

e pode, com ajuda das equações 25 e 26 , ser expresso por:

$$
J=\left(\xi^{\prime}-\eta^{\prime \prime} n\right)\left(\xi^{\prime}\right)-\left(-\eta^{\prime}\right)\left(\eta^{\prime}+\xi^{\prime \prime} n\right)
$$

Organizando os termos da equação tem-se:

$$
J=\left(\xi^{\prime 2}+\eta^{2}\right)-\left(\xi^{\prime} \eta^{\prime \prime}-\eta^{\prime} \xi^{\prime \prime}\right) n
$$

Como na equação 37 o primeiro termo $\left(\xi^{\prime 2}+\eta^{2}\right)$ tem o valor unitário e a expressão que multiplica $n$ é exatamente a definição do raio de curvatura, equação 35 , o Jacobiano da transformação fica finalmente expresso por: 


$$
J(s, n)=1-k(s) \cdot n
$$

O módulo do raio local de curvatura, que é sempre positivo, fica definido por:

$$
R=\frac{1}{|k(s)|}
$$

A aplicação permanece injetora a menos que $\mathrm{k}>0$ e $n \geq(1 / k)=R$. Para que a aplicação permaneça injetora é óbvio que a profundidade $\mathrm{N}$ deve satisfazer a condição:

$$
k N<1, k>0
$$

\subsection{Coordenadas Cartesianas}

O escoamento pela soleira está restrito às condições:

- O fluído é incompressível ( $\rho$ = constante);

- Tensão de cisalhamento é nula no contato parede e fluído $(\tau=0)$;

- O escoamento é irrotacional $(\nabla \wedge \vec{V}=0)$;

- Apenas o campo gravitacional atua no fluído;

- O escoamento é bidimensional.

Obedecendo as condições apresentadas, tem-se as equações diferenciais 41, 42 e 43, que correspondem à formulação necessária para o trabalho.

$$
\begin{gathered}
\nabla \cdot \vec{V}=0 \\
\frac{\partial \bar{V}}{\partial t}+(\vec{V} \cdot \nabla) \vec{V}=-\frac{1}{\rho} \nabla p-g \hat{\jmath} \\
\nabla \wedge \vec{V}=0
\end{gathered}
$$

Estas equações correspondem à forma diferencial do Princípio de Conservação de Massa (Eq. 41), forma diferencial da Lei de Newton da Quantidade de Movimento (Eq. 42) e o princípio de escoamento irrotacional (Eq. 43).

Em resumo essas condições representam: 
1) a pressão na superfície livre do escoamento é constante e igual a pressão atmosférica local, assumindo o valor de zero na escala relativa de pressão;

2) a velocidade de escoamento no fundo, normal à superfície sólida do canal é identicamente nula;

3) qualquer partícula fluída na superfície livre do escoamento permanecerá sempre na superfície livre.

A Figura 16 apresenta parcialmente a relação entre o sistema ortogonal e o sistema curvilíneo de coordenadas.

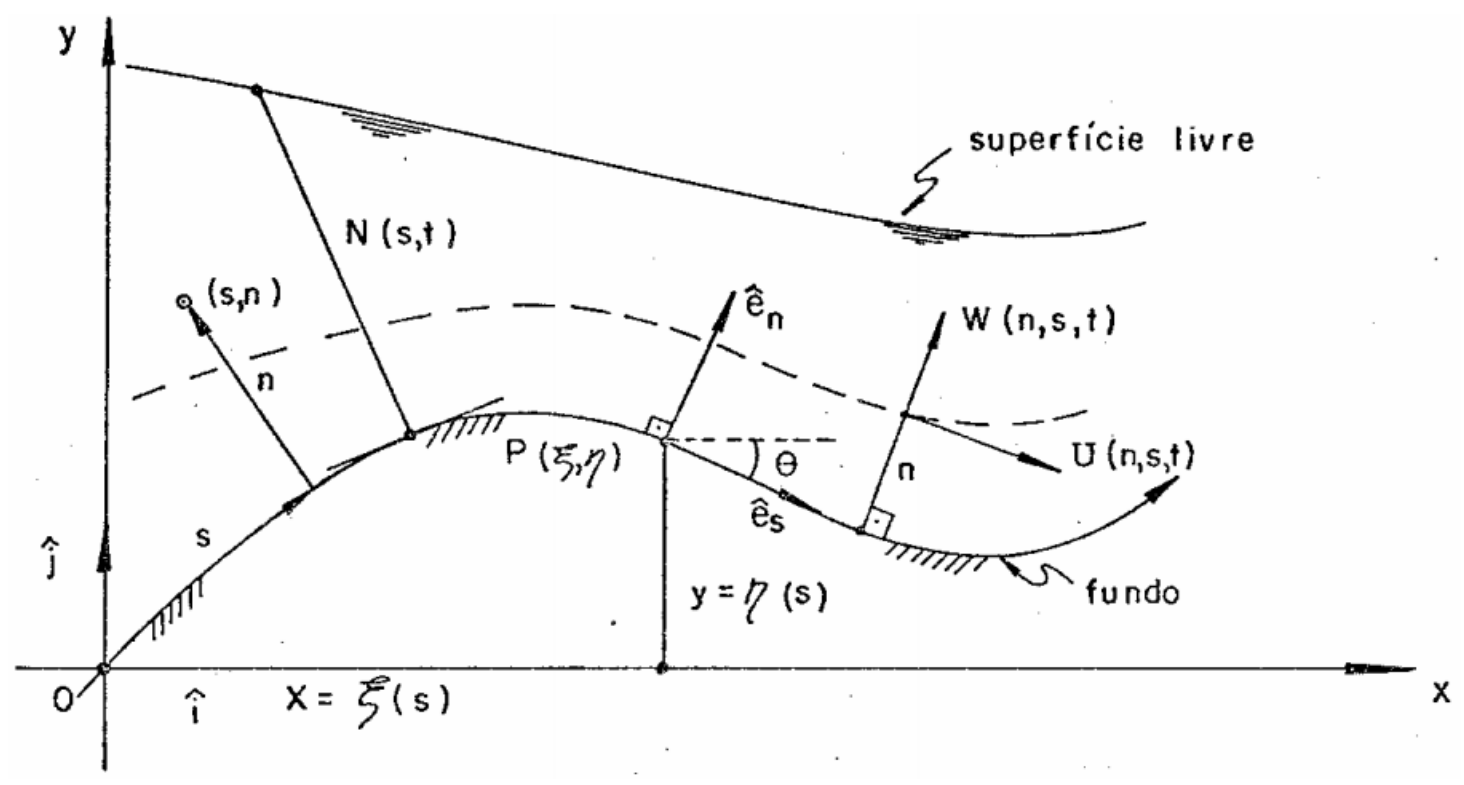

Figura 16 - Coordenadas curvilíneas definidas pelo fundo curvo - Fonte: SOUZA. (1985)

\subsection{Equacionamento em Coordenadas Curvilíneas}

A transformação das equações 41,42 e 43 e das três condições apresentadas anteriormente são resolvidas de modo relativamente simples, tomando-se o cuidado de determinar previamente os algoritmos para a obtenção de gradiente, de divergente e rotacional em coordenadas curvilíneas.

Em coordenadas curvilíneas o gradiente de uma função escalar $\psi(s, n, t)$ é expresso por:

$$
\nabla \psi=\frac{1}{h_{s}} \cdot \frac{d \psi}{d s} \hat{e}_{s}+\frac{1}{h_{n}} \cdot \frac{d \psi}{d n} \hat{e}_{n}
$$


Onde:

$$
\begin{aligned}
h_{s} & =|d \vec{r} / d s| \\
h_{n} & =|d \vec{r} / d n| \\
\vec{r} & =x \hat{\imath}+y \hat{\jmath}
\end{aligned}
$$

De modo que $\vec{r}$ é o raio vetor da posição de um ponto do escoamento em coordenadas cartesianas, $\mathrm{x}$ e y podem ser expresso por:

$$
\begin{aligned}
& x=\xi-\eta^{\prime} n \\
& y=\eta+\xi^{\prime} n
\end{aligned}
$$

As equações 45 e 46 permitem obter $h_{s}$ como apresentado a seguir

$$
\begin{gathered}
h_{s}=\left[\left(\xi^{\prime}-\eta^{\prime \prime} n\right)^{2}+\left(\eta^{\prime}+\xi^{\prime \prime} n\right)^{2}\right]^{1 / 2} \\
h_{s}=\left[\left(\xi^{\prime 2}+\eta^{\prime 2}\right)-2\left(\xi^{\prime} \eta^{\prime \prime}-\eta^{\prime} \xi^{\prime \prime}\right) n+\left(\eta^{\prime \prime 2}+\xi^{\prime \prime 2}\right) n^{2}\right]^{1 / 2} \\
h_{s}=\left[1-2 k(s) n+\left(n^{\prime \prime 2}+\xi^{\prime \prime 2}\right) n^{2}\right]^{1 / 2}
\end{gathered}
$$

A última simplificação é possível pelo fato de: $\xi^{\prime}=\cos \theta, \eta^{\prime}=\sin \theta$ e $\left(\xi^{\prime} \eta^{\prime \prime}-\right.$ $\left.\eta^{\prime} \xi^{\prime \prime}\right)=k(s)$

As derivadas segunda da equação 46 são em relação a s e calculadas como:

$$
\begin{gathered}
\xi^{\prime \prime}=\frac{d \xi^{\prime}}{d s}=\frac{1}{R} \cdot \frac{d \xi^{\prime}}{d \theta}=-\frac{\sin \theta}{R}=-\eta^{\prime} k(s) \\
\eta^{\prime \prime}=\frac{d \eta^{\prime}}{d s}=\frac{1}{R} \cdot \frac{d \eta^{\prime}}{d \theta}=\frac{\cos \theta}{R}=\xi^{\prime} k(s)
\end{gathered}
$$

As equações 48 e 49substituídas na equação 47 levam à equação final do fator de escala $h_{s}$ :

$$
h_{s}=1-k(s) \cdot n=J(n, s)
$$

A obtenção do fator de escala $h_{n}$ é obtida de forma mais simples:

$$
\begin{gathered}
h_{n}=\left[\left(-\eta^{\prime}\right)^{2}+\left(\xi^{\prime}\right)^{2}\right]^{1 / 2} \\
h_{n}=1
\end{gathered}
$$

O operador divergente em coordenadas curvilíneas é dado por:

$$
\nabla \cdot \vec{V}=\frac{1}{h_{s} h_{n}}\left[\frac{\partial}{\partial s}\left(h_{n} U\right)+\frac{\partial}{\partial n}\left(h_{s} W\right)\right]
$$

O operador rotacional em coordenadas curvilíneas é obtido através do algoritmo:

$$
\nabla \wedge \vec{V}=\frac{1}{h_{s} h_{n} h_{m}}\left|\begin{array}{ccc}
h_{s} \hat{e}_{s} & h_{n} \hat{e}_{n} & h_{m} \hat{e}_{m} \\
\frac{\partial}{\partial s} & \frac{\partial}{\partial n} & \frac{\partial}{\partial m} \\
h_{s} U & h_{n} W & h_{m} O
\end{array}\right|
$$


Das equações 41, 42 e 43 e as três condições de contorno apresentadas no item 5.2, podem ser obtidas sete equações escalares em coordenadas curvilíneas, apresentadas pelas equações 54, 55, 56, 57, 58, 59 e 60 .

$$
\begin{array}{cl}
\frac{\partial U}{\partial s}+\frac{\partial}{\partial n}(J W) & =0 \\
\frac{1}{g} \frac{\partial U}{\partial t}+\frac{1}{J} \frac{\partial E}{\partial s}=0 & 54 \\
\frac{1}{g} \frac{\partial W}{\partial t}+\frac{\partial E}{\partial n}=0 & 57 \\
\frac{\partial W}{\partial s}-\frac{\partial}{\partial n}(J U)=0 & 58 \\
\mathrm{p}(\mathrm{s}, \mathrm{n}, \mathrm{t})=P_{\text {atm }} \equiv 0 & 50 \\
\frac{\partial N}{\partial t}+\frac{U}{J} \frac{\partial N}{\partial s}=W, \text { para } n=N(s, t) &
\end{array}
$$

Desta forma têm-se:

$$
E=E(s, n, t)=\eta+n \cdot \cos \theta+\frac{p}{\rho g}+\frac{U^{2}+W^{2}}{2 g}
$$

A equação 54 representa a conservação de massa; a equação 55 representa a quantidade de movimento projetada em $\hat{e}_{s}$; a equação 56 é a quantidade de movimento projetada em $\hat{e}_{n}$; a equação 57 é a equação que corresponde à condição de irrotacionaldade do escoamento; a equação 58 e 60 são condições de contorno na superfície livre, relacionadas à pressão e com a velocidade normal do escoamento; e por fim a equação 59 é a condição de contorno relativa à componente normal da velocidade no fundo.

\subsection{Distribuição de Velocidades}

Conforme apresentada na tese de doutorado de Souza (1984), quando se pode considerar, $\frac{\partial W}{\partial s} \cong 0 \frac{\partial W}{\partial t} \cong 0$ e $|W| \ll|U|$, a equação. 57 fica reduzida a:

$$
\frac{\partial}{\partial n}(J U)=0
$$


A integração desta equação fornece:

$$
J U=C(s, t)
$$

Na equação 63, C é uma constante de integração que pode depender de "s" e " $t$ ", e deverá ser determinado partir da condição de contorno: $n=0, U=U_{0}$. Esta condição, quando substituída na equação 62 , mostra que $\mathrm{C}(\mathrm{s}, \mathrm{t})=\mathrm{U}_{0}(\mathrm{~s}, \mathrm{t})$, o que resulta na seguinte distribuição:

$$
U(s, n, t)=\frac{U_{0}(s, t)}{1-k(s) n}
$$

A obtenção de W(s,n,t) e definida pela equação 65 .

$$
W(s, n, t)=\left[\frac{\ln (1-k n)}{k(1-k n)}\right] \frac{\partial U_{0}}{\partial s}-\frac{1}{k^{2}} \frac{\partial k}{\partial s}\left[\frac{\ln (1-k n)}{(1-k n)}+\frac{k n}{(1-k n)^{2}}\right] U_{0}
$$

A Figura 17 apresenta o esquema dos perfis de velocidade para fundo côncavo e convexo, baseada na equação 64

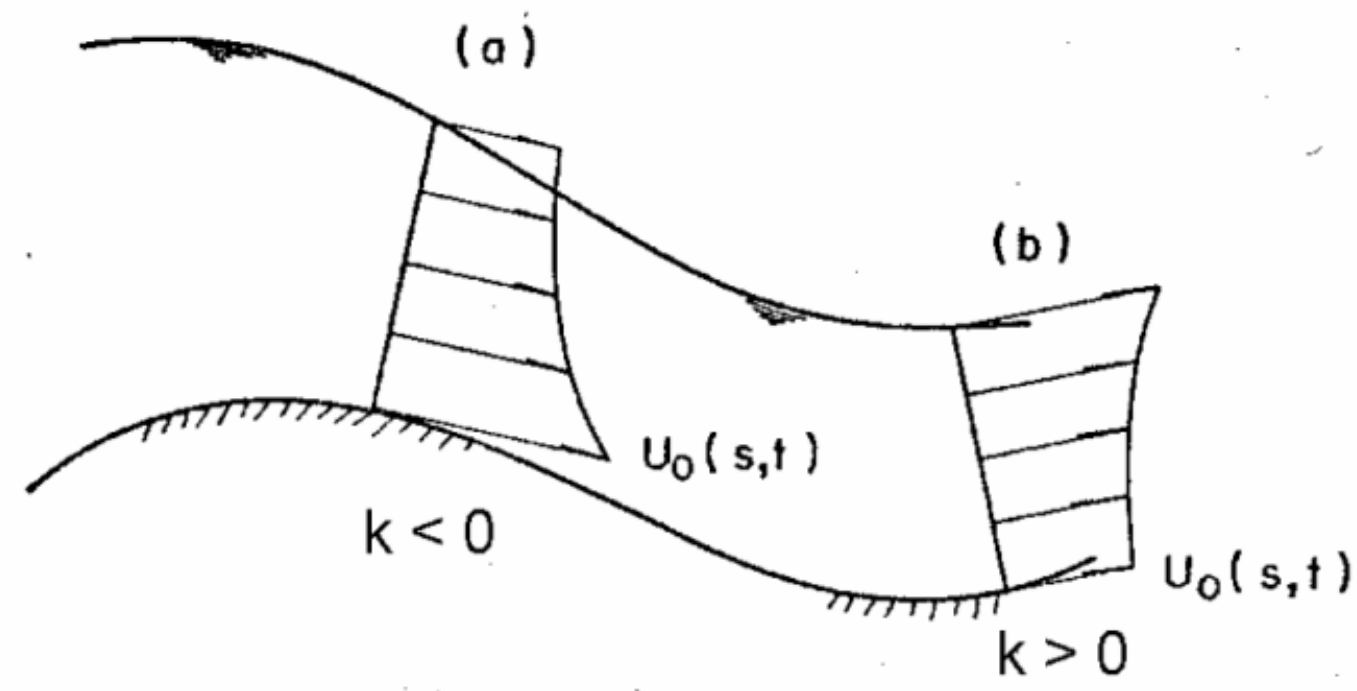

Figura 17 - Distribuição de Velocidades para Fundo convexo $(k<0)$ e fundo côncavo $(k>0)$. Fonte: SOUZA, 1985

\subsection{Lei de Vazão}

Adotando-se uma seção correspondente a um plano normal ao fundo do canal, a vazão por unidade de largura fica expressa por: 


$$
q=\int_{0}^{N} U(s, n, t) d n
$$

Adotando a distribuição de velocidade dada pela equação 64, a vazão pode ser determinada conforme equação 67:

$$
q=U(s, t) \int_{0}^{N(s, t)} \frac{d n}{1-k(s) n} \therefore q(s, t)=-\frac{U_{0}(s, t)}{k(s)} \ln [1-k(s) \cdot N(s, t)]
$$

\subsection{Distribuição de Pressão}

Para a obtenção da distribuição de pressão, duas hipóteses adicionais serão feitas:

1. W varia muito pouco em relação ao tempo, isto é, $\frac{\partial W}{\partial t} \equiv 0$.

2. O valor de $\mathrm{W}$ é muito pequeno quando comparado ao de $\mathrm{U}$, isto é $|W| \ll|U|$.

Pela hipótese (1) conclui-se, através da equação 56, que a carga "E” é constante e independente de " $n$ " para uma posição "s" e um instante " $t$ " fixados. Desde modo, e com o auxílio da equação 61, pode-se escrever:

$$
\eta+n \cos \theta+\frac{p}{\rho g}+\frac{U^{2}+W^{2}}{2 g}=C
$$

Pela hipótese (2) esta última expressão fica reduzida a:

$$
\eta+n \cos \theta+\frac{p}{\rho g}+\frac{U^{2}}{2 g}=C
$$

Usando-se a distribuição de velocidade definida na equação 64 , modifica-se a equação 69 para:

$$
\eta+n \cos \theta+\frac{p}{\rho g}+\frac{U_{0}^{2}}{2 g(1-k n)^{2}}=C
$$

Para $\mathrm{n}=\mathrm{N}$ (superfície livre), $\mathrm{p}=\mathrm{p}_{\mathrm{atm}}=0$, que na equação anterior evidencia que:

$$
C=\eta+N \cos \theta+\frac{U_{0}{ }^{2}}{2 g(1-k N)^{2}}
$$

A substituição deste resultado na equação 70 fornece a distribuição de pressão:

$$
\frac{p(s, n, t)}{\rho g}=(N-\eta) \cos \theta+\left[\frac{1}{(1-k N)^{2}}-\frac{1}{(1-k n)^{2}}\right] \frac{U_{0}{ }^{2}}{2 g}
$$


Pela equação 72 percebe-se que a distribuição de pressão é composta de uma contribuição do tipo hidrostática, $(\mathrm{N}-\mathrm{n}) \cos \theta$, e uma outra tipo centrífuga, que completa o segundo membro da equação 72. Pode-se notar que esta contribuição do tipo centrífuga anula-se para $\mathrm{k}=0$.

Para k<0 a distribuição de pressão apresenta, para um "n” arbitrário, valores de pressão menores que os fornecidos pela distribuição hidrostática. Para k>0, ao contrário, os valores são maiores. A Figura 18 apresenta a distribuição de pressões, conforme o equacionamento 72 .

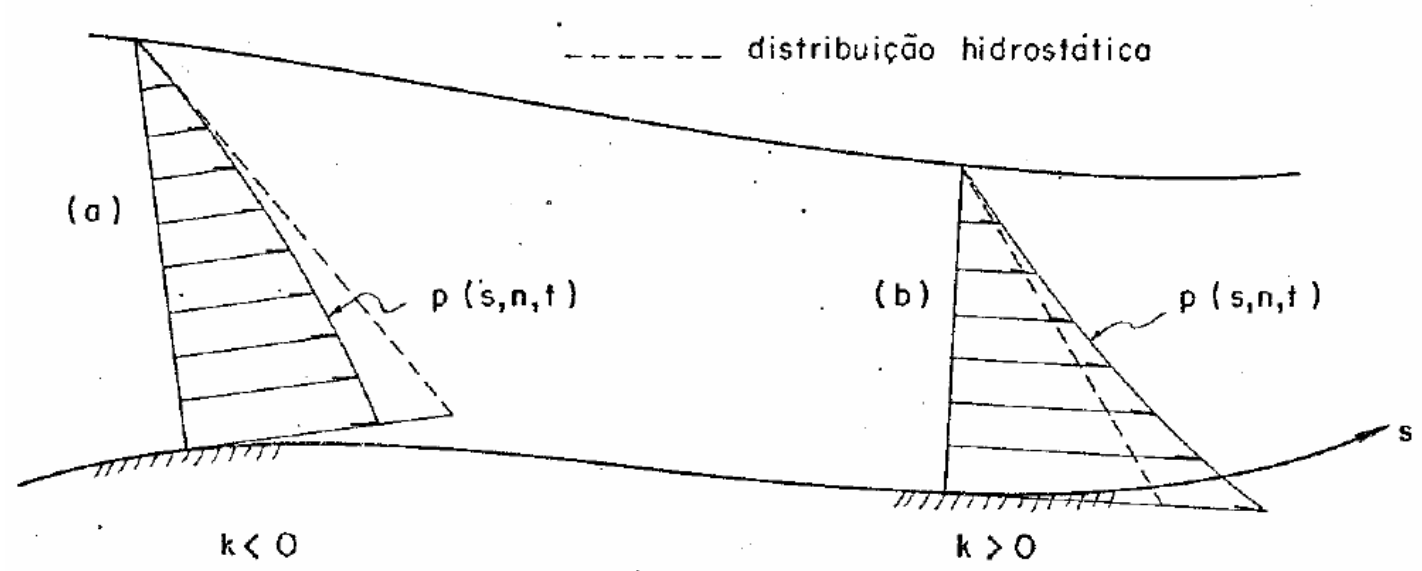

Figura 18 - Distribuição de Pressão p(s,n,t) para fundo convexo $(k<0)$ e fundo côncavo $(k>0)$. Fonte: SOUZA, 1985

\subsection{Efeito do Atrito (Perda de Carga)}

A equação do movimento projetada na direção $\hat{e}_{s}$; , apresentado pela equação 55 , pode ser escrita como:

$$
\frac{\partial U}{\partial t}+\frac{g}{J} \frac{\partial E}{\partial s}=0
$$

Nesta forma a dimensão de cada parcela é de aceleração[ $\left[L T^{-2}\right]$.

Para se introduzir o efeito da tensão de cisalhamento na equação de 73 é necessário que se tome a força resultante deste tipo de tensão, que se divida tal força ela massa de fluido no volume de controle considerado, e que se obtenha assim a parcela “ $\mathrm{a}_{\mathrm{m}}$ ” com a dimensão de aceleração. A equação 73 fica então transformada em: 


$$
\frac{\partial U}{\partial t}+\frac{g}{J} \frac{\partial E}{\partial s}+a_{m}=0
$$

Para o trecho de canal de comprimento elementar de comprimento $\Delta \mathrm{s}$, de largura "b", de curvatura média "k" e com um escoamento com profundidade médio "N", a massa de fluído no trecho pode ser calculada por:

$$
\begin{gathered}
M=\int_{0}^{N} \rho b \Delta l d n=\int_{0}^{N} \rho b(1-k n) \Delta s d n \\
M=\rho\left(1-\frac{k N}{2}\right) N b \Delta s
\end{gathered}
$$

A hipótese de que a tensão de cisalhamento $\tau_{0}$, na interface água parede, é proporcional ao quadrado da velocidade junto a parede, $\mathrm{U}_{\mathrm{p}}^{2}$, será fundamental para a determinação de “ $\mathrm{a}_{\mathrm{m}}$ ”. Por razões de ordem dimensional e por coerência com o tratamento universal de perda distribuída, esta hipótese deve ser colocada sob a forma.

$$
\tau_{p}=\rho \frac{f}{8} U_{p}^{2}
$$

Com base na equação 64, a velocidade junto ao fundo do canal vale $\mathrm{U}_{0}$ e a correspondente tensão de cisalhamento.

$$
\tau_{0}=\rho \frac{f}{8} U_{o}^{2}
$$

A resultante da força de cisalhamento no fundo do canal fica então:

$$
F_{f}=\frac{\rho f U_{o}^{2} b \Delta s}{8}
$$

Já a resultante da força de cisalhamento na parede do canal fica:

$$
F_{p}=-\frac{2}{8} \rho f U_{o}^{2} \frac{\ln (1-k N)}{k} \Delta s
$$

Desta maneira temos que o termo " $\mathrm{a}_{\mathrm{m}}$ " que representa a aceleração devido a resistência ao escoamento, é a soma da força de cisalhamento do fundo com a força de 
cisalhamento das paredes e tudo divido pela massa de fluido, conforme apresentado na equação 81

$$
a_{m}=\frac{F_{f}+F_{p}}{M}
$$

Resumindo temos a equação 82 , que é usada para a determinação da perda de carga.

$$
a_{m}=\frac{f\left[b-\frac{2 \ln (1-k N)}{k}\right]}{4\left[1-\frac{k N}{2}\right] N b} \frac{U_{0}{ }^{2}}{2}
$$




\section{EQUACIONAMENTO PROPOSTO}

O equacionamento proposto do perfil cossenoidal deverá ser ajustado seus parâmetros de modo a conseguir se aproximar de um perfil do tipo Creager. Desta maneira os coeficientes "a" e "b" foram ajustados de modo que a crista e o trecho praticamente linear coincidissem, foi adotado uma relação de 1 na vertical para 0,6 na horizontal como inclinação do trecho retilíneo, valor este típico para barragens em concreto convencional. Fazendo a coincidência entre o Creager e Cossenoidal temos:

$$
\begin{gathered}
\frac{Y}{H_{d}}=\frac{1}{2}\left(\frac{X}{H_{d}}\right)^{1,85} \text { (Creager) } \\
y=\operatorname{a~} \cos \left(\frac{\pi}{2} \times \frac{x}{\mathrm{~b}}\right) \text { (Cossenoidal) } \\
\text { Creager } \equiv \text { Cossenoidal } \\
\text { Para tan }=\left(\frac{1}{0,6}\right) \therefore \frac{X}{\frac{Y}{H_{d}}}=2,0 \\
\text { Para }\left(\frac{b}{H_{d}}\right) \equiv\left(\frac{X}{H_{d}}\right)=2,0 \rightarrow y=a \cos \left(\frac{\pi}{2} \cdot \frac{x}{2 H_{d}}\right) \\
\text { Para }\left(\frac{a}{H_{d}}\right) \equiv\left(\frac{Y}{H_{d}}\right)=1,8 \rightarrow y=1,8 H_{d} \cos \left(\frac{\pi}{2} \cdot \frac{x}{2 H_{d}}\right)
\end{gathered}
$$

A Figura 19 apresenta a curva cossenoidal e os pontos utilizados para coincidência. 


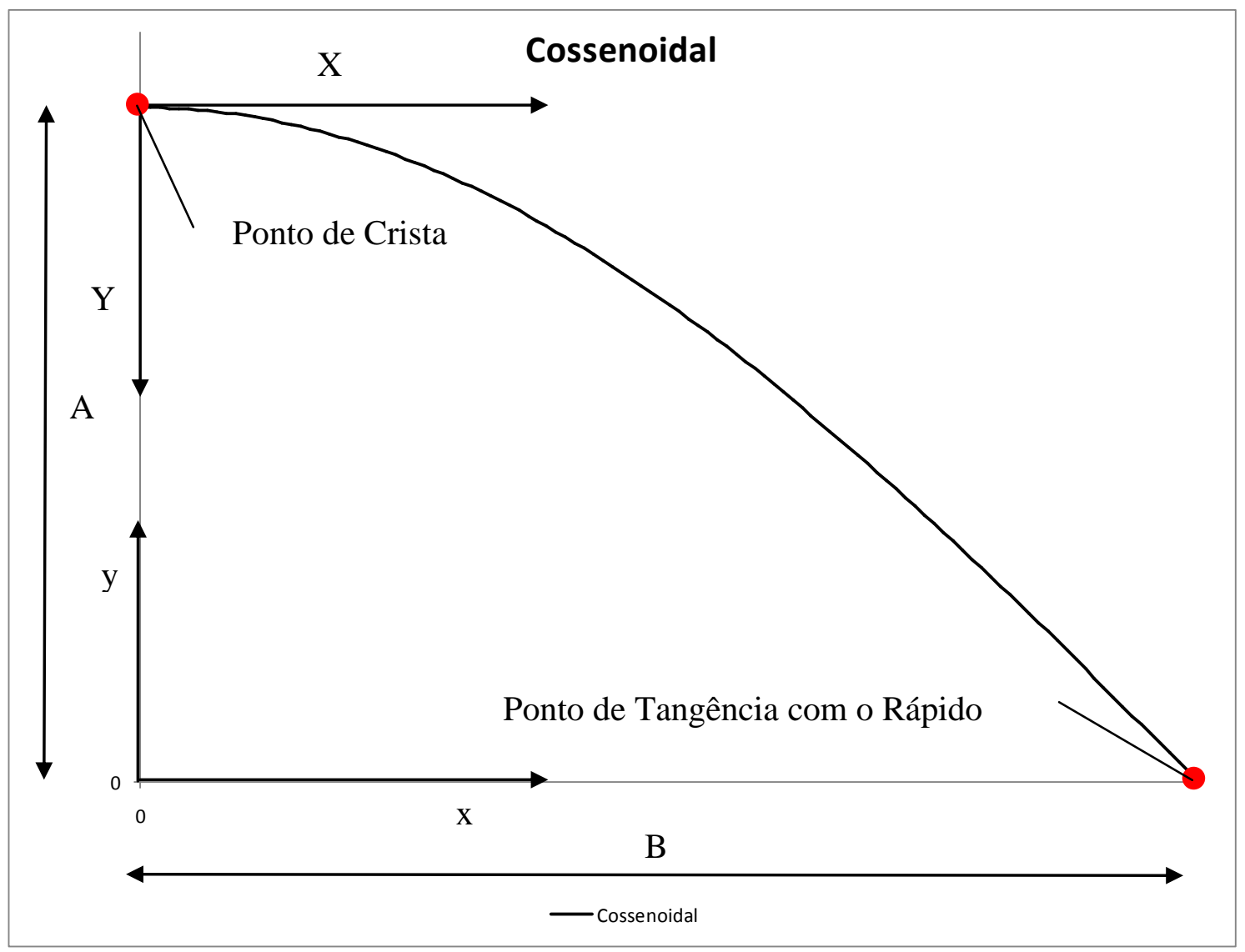

Figura 19 - Perfil cossenoidal com os pontos de coincidência

A formulação proposta ajustada para "coincidir" com o perfil Creager é a apresentada pela Equação 83:

$$
\frac{y}{H_{d}}=1,8 \cos \left(\frac{\pi}{2} \times \frac{x}{2 H_{d}}\right)
$$

Onde:

$y=$ Coordenada na direção $y$;

$x=$ Coordenada na direção $\mathrm{x}$;

$H_{d}=$ Carga de projeto

A Figura 20 apresenta os perfis Creager e Cossenoidal ajustados e adimensionalizados. 


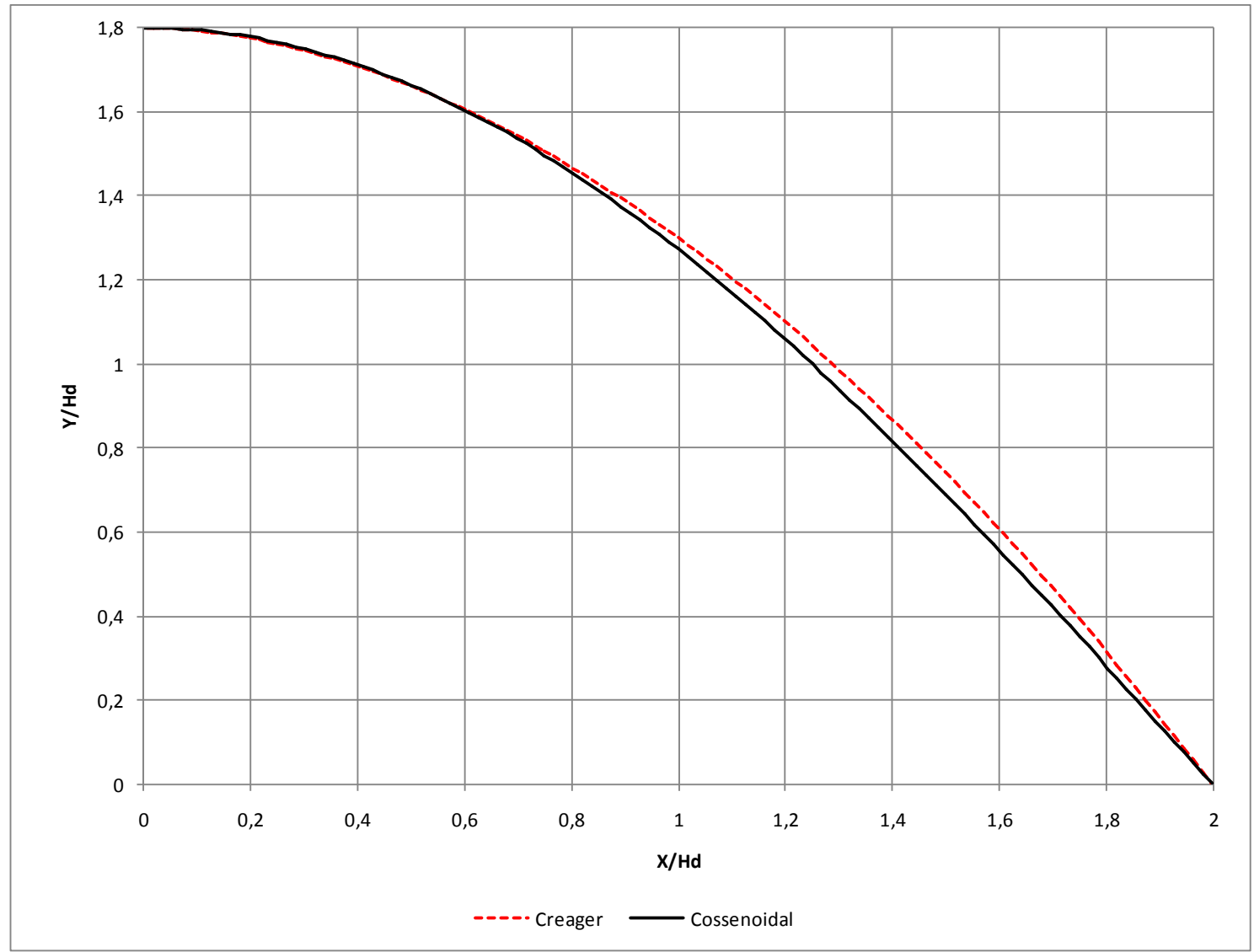

Figura 20 - Perfis Cossenoidal ajustado e Creager, adimensionalizados

O raio de curvatura da curva cossenoidal na crista é definido pela equação 84 .

$$
\begin{gathered}
r_{c}=\frac{4}{\pi^{2}} \frac{B^{2}}{A}(\text { Cossenoidal }) \\
A \equiv 1,8 H_{d} ; B \equiv 2,0 H_{d} \\
r_{c}=0,9006 H_{d}
\end{gathered}
$$

O Quadro 1 apresenta os valores adimensionalizados para o perfil Cossenoidal. 
Quadro 1 - Valores adimensionalizados para perfil geométrico da soleira Cossenoidal

\begin{tabular}{|c|c|}
\hline $\mathbf{X} / \mathbf{H d}$ & $\mathbf{Y} / \mathbf{H d}$ \\
\hline 0,000 & 1,800 \\
\hline 0,125 & 1,791 \\
\hline 0,250 & 1,765 \\
\hline 0,375 & 1,722 \\
\hline 0,500 & 1,663 \\
\hline 0,625 & 1,587 \\
\hline 0,750 & 1,497 \\
\hline 0,875 & 1,391 \\
\hline 1,000 & 1,273 \\
\hline 1,125 & 1,142 \\
\hline 1,250 & 1,000 \\
\hline 1,375 & 0,849 \\
\hline 1,500 & 0,689 \\
\hline 1,625 & 0,523 \\
\hline 1,750 & 0,351 \\
\hline 1,875 & 0,176 \\
\hline 2,000 & 0,000 \\
\hline
\end{tabular}

De maneira semelhante foi desenvolvido um ajuste à elipse proposta por Maynord de modo que a nova curva denominada de "Maynord Modificada" apresentasse o mesmo raio de curvatura obtida na curva cossenoidal. A elipse proposta por Maynord é apresentada na equação 85.

$$
\left(\frac{x}{a}\right)^{2}+\left(\frac{y}{b}\right)^{2}=\left(\frac{x}{0,280}\right)^{2}+\left(\frac{y}{0,167}\right)^{2}=1 \text { (Elipse Maynord) }
$$

O raio de curvatura de uma elipse na crista é definido conforme apresentado na equação 86.

$$
r_{c}=\frac{a^{2}}{b}
$$

Considerando que o comprimento da soleira mantém a mesma relação para a carga hidráulica proposta por Maynord, ajustou-se a altura na nova curva para a coincidência de raio de curvatura. Assim têm-se:

$$
\begin{gathered}
r_{c(\text { cossenoidal })} \equiv r_{c(\text { elipse })} \\
\frac{4}{\pi^{2}} \frac{B^{2}}{A} \equiv \frac{a^{2}}{b} \\
A \equiv 1,8 H_{d} ; B \equiv 2,0 H_{d} \\
\frac{4}{\pi^{2}} \frac{\left(2,0 H_{d}\right)^{2}}{\left(1,8 H_{d}\right)} \equiv \frac{a^{2}}{b}
\end{gathered}
$$




$$
\begin{aligned}
0,90 H_{d} & =\frac{a^{2}}{b}=\frac{\left(0,28 H_{d}\right)^{2}}{b} \\
b & =0,0871 H_{d}
\end{aligned}
$$

Desta maneira têm-se o perfil "Maynord Modificado" e está apresentada na equação 87.

$$
\left(\frac{x}{0,280 H_{d}}\right)^{2}+\left(\frac{y}{0,087 H_{d}}\right)^{2}=1
$$

A Figura 21 apresenta os perfis de Maynord e "Maynord Modificado" resultantes do ajuste para o raio de curvatura coincidente ao do perfil cossenoidal.

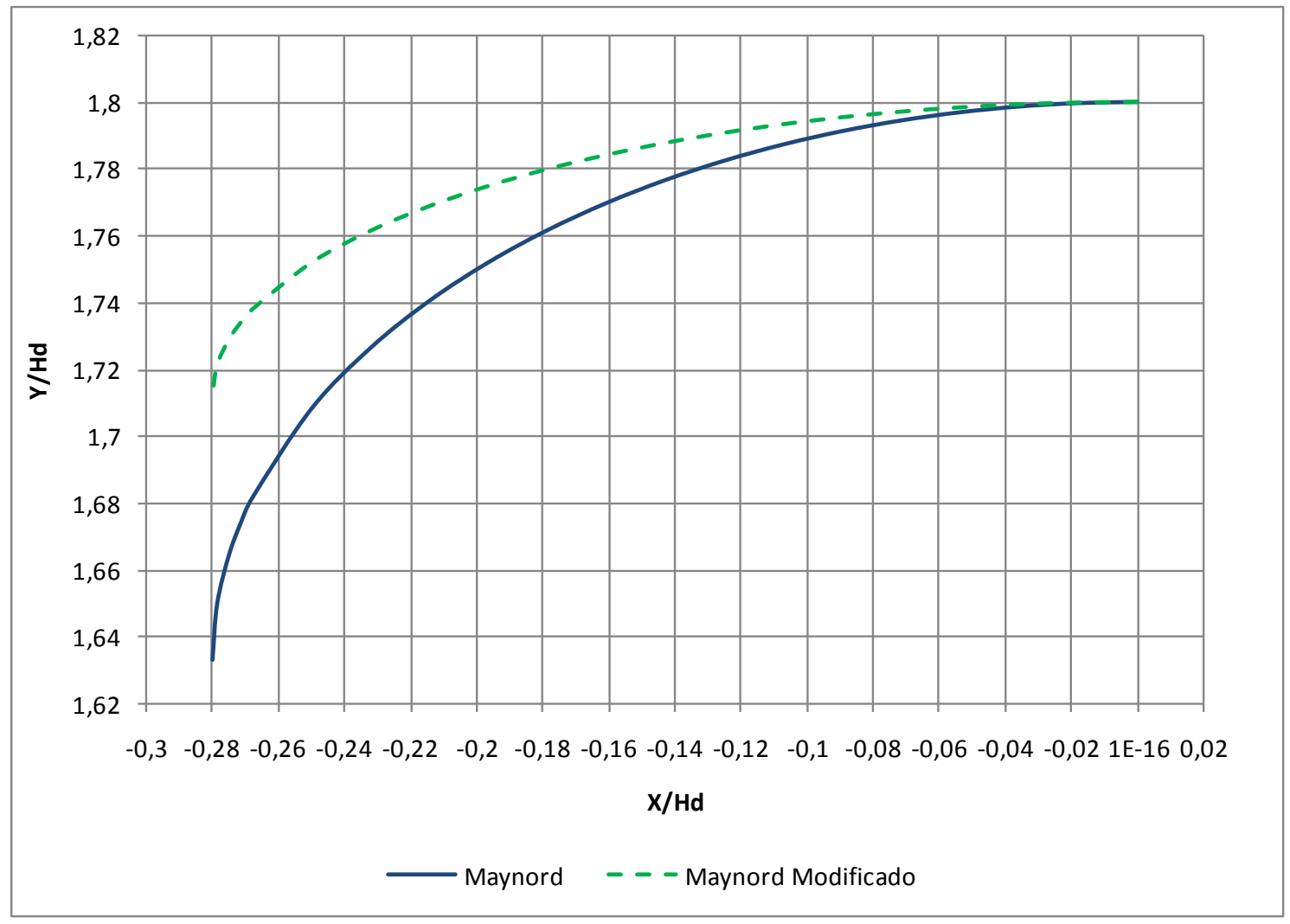

Figura 21 - Perfis Maynord e "Maynord Modificado", adimensionalizados

Verifica-se através da Figura 21 que o perfil "Maynord Modificado" apresenta uma ligeira elevação em relação ao perfil originalmente apresentado por Maynord. Esta elevação é responsável por dar continuidade entre raios de curvatura e tangência na crista da soleira vertente. A Figura 22 apresenta todos os perfis adimensionalizados combinados. 


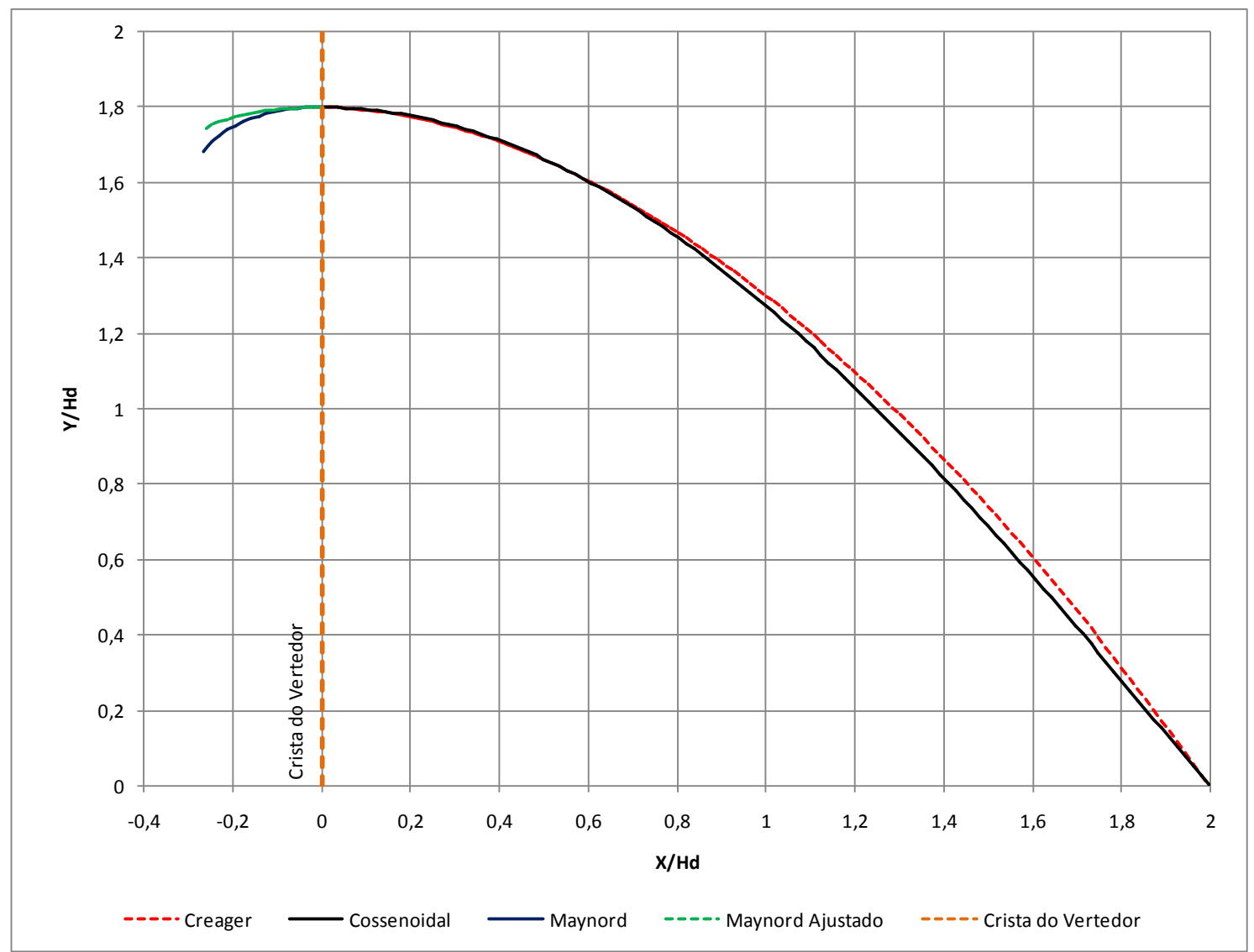

Figura 22 - Perfis agrupados (Maynord, Maynord Modificado, Creager e Cossenoidal)

Verifica-se no perfis que o perfil cossenoidal é levemente inferior ao perfil do Creager, enquanto que o perfil do "Maynord Modificado" é superior ao do perfil do Maynord.

O perfil cossenoidal combinado com o perfil de "Maynord Modificado" de modo que ocorra a concordância de raio de curvatura na crista apresentou um volume por metro linear de seção ligeiramente inferior à utilização dos perfis tradicionais de Creager e Maynord. As (Eq.88 e89) apresentam o valor do volume por metro linear de seção.

Perfil Tradicional (Creager + Maynord)

$$
\text { Volume }=2,7959 \mathrm{H}_{d}^{2}\left[\mathrm{~m}^{3} / \mathrm{m}\right]
$$

Perfil Cossenoidal + Perfil "Maynord Modificado"

$$
\text { Volume }=2,7695{H_{d}}^{2}\left[\mathrm{~m}^{3} / \mathrm{m}\right]
$$


Deste modo verifica-se que a nova proposição de perfil cossenoidal associado a um perfil de "Maynord Modificado" apresenta economia em volume de concreto para sua execução.

A modelagem matemática desenvolvida no Capítulo 7 utilizou-se das equações dos perfis apresentadas neste item para a determinação das linhas d'água e pressão. 


\section{MODELAGEM MATEMÁTICA}

Para a modelagem matemática foi utilizado como vertedor de referência as características do vertedor da Usina Hidrelétrica de Água Vermelha conforme apresentado na dissertação de Kanashiro, 1989 e que possui as características apresentadas abaixo:

- Carga de projeto: $\mathrm{H}_{\mathrm{d}}=14 \mathrm{~m}$;

- Vazão máxima prevista: $\mathrm{Q}_{\text {máx }}=20.000 \mathrm{~m}^{3} / \mathrm{s}$;

- Vazão para carga de projeto: $\mathrm{Q}=14.000 \mathrm{~m}^{3} / \mathrm{s}$;

- Largura do vão do vertedor: $\mathrm{L}_{\mathrm{vert}}=15,0 \mathrm{~m}$;

- Número de vãos = 8 vãos;

- Número de pilares $=7$ pilares;

- Espessura do pilar: e $=3 \mathrm{~m}$;

- Vazão específica: q=141,85 m³/(s.m.)

\subsection{Determinação da Linha d'água}

Através do apoio de planilha eletrônica foram realizados todos os cálculos necessários para a obtenção da linha d'água e de pressão para a nova geometria (perfil Cossenoidal) e realizar a comparação com o os valores obtidos para uma soleira do tipo Creager com arco elíptico de montante proposto por Maynord.

A Figura 23 apresenta uma visão geral resumida da planilha eletrônica utilizada para os cálculos matemáticos, uma vez que ela apresenta um total de 130 linhas. A planilha total está apresentada no Anexo I. 


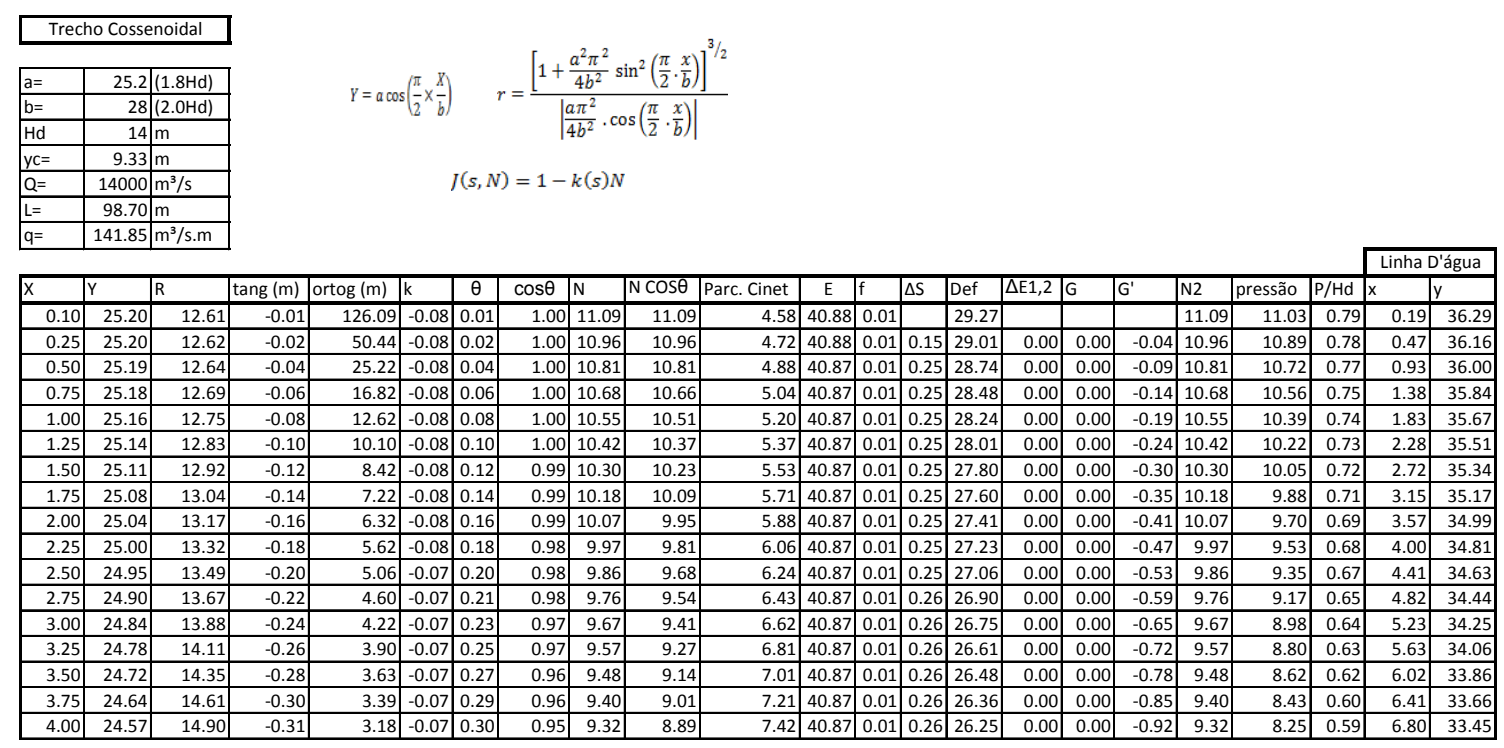

Figura 23 - Vista geral da planilha eletrônica de cálculo

Onde:

$\mathrm{X}, \mathrm{Y}$ - coordenadas nas direções $\mathrm{x}$ e $\mathrm{y}$;

$\mathrm{R}$ - raio de curvatura no ponto de coordenada $\left(\mathrm{X}_{\mathrm{i}}, \mathrm{Y}_{\mathrm{i}}\right)$;

tang $(\mathrm{m})$ - valor da tangente do ponto de coordenada $\left(\mathrm{X}_{\mathrm{i}}, \mathrm{Y}_{\mathrm{i}}\right)$;

ortog $(\mathrm{m})$ - valor da ortogonal no ponto de coordenada $\left(\mathrm{X}_{\mathrm{i}}, \mathrm{Y}_{\mathrm{i}}\right)$;

$\mathrm{k}$ - inverso do raio de curvatura local;

$\theta$ - ângulo da tangente local;

$\mathrm{N}$ - profundidade do escoamento normal ao ponto de coordenada $\left(\mathrm{X}_{\mathrm{i}}, \mathrm{Y}_{\mathrm{i}}\right)$;

Parc. Cinet - Parcela cinética do escoamento em superfícies curvas;

$\mathrm{E}$ - Carga total no ponto de coordenada $\left(\mathrm{X}_{\mathrm{i}}, \mathrm{Y}_{\mathrm{i}}\right)$;

$\mathrm{f}$ - fator de atrito;

$\Delta S-$ deslocamento na superfície curva entre dois pontos;

Def. - diâmetro hidráulico efetivo;

$\Delta \mathrm{E} 1,2$ - variação da carga entre pontos 1 e 2;

$\mathrm{G}$ - função resultante $\left(\mathrm{G}=\mathrm{E}_{2}+\Delta \mathrm{E}_{1,2}-\mathrm{E}_{1}=0\right) ;$

G' - derivada da função resultante;

N2 - altura do escoamento normal no ponto de coordenada subsequente $\left(\mathrm{X}_{\mathrm{i}+1}, \mathrm{Y}_{\mathrm{i}+1}\right)$ 
A partir dos resultados obtidos através da planilha eletrônica tem-se a Figura 24 que apresenta o perfil cossenoidal juntamente com a linha d'água para as características apresentadas no início deste capítulo.

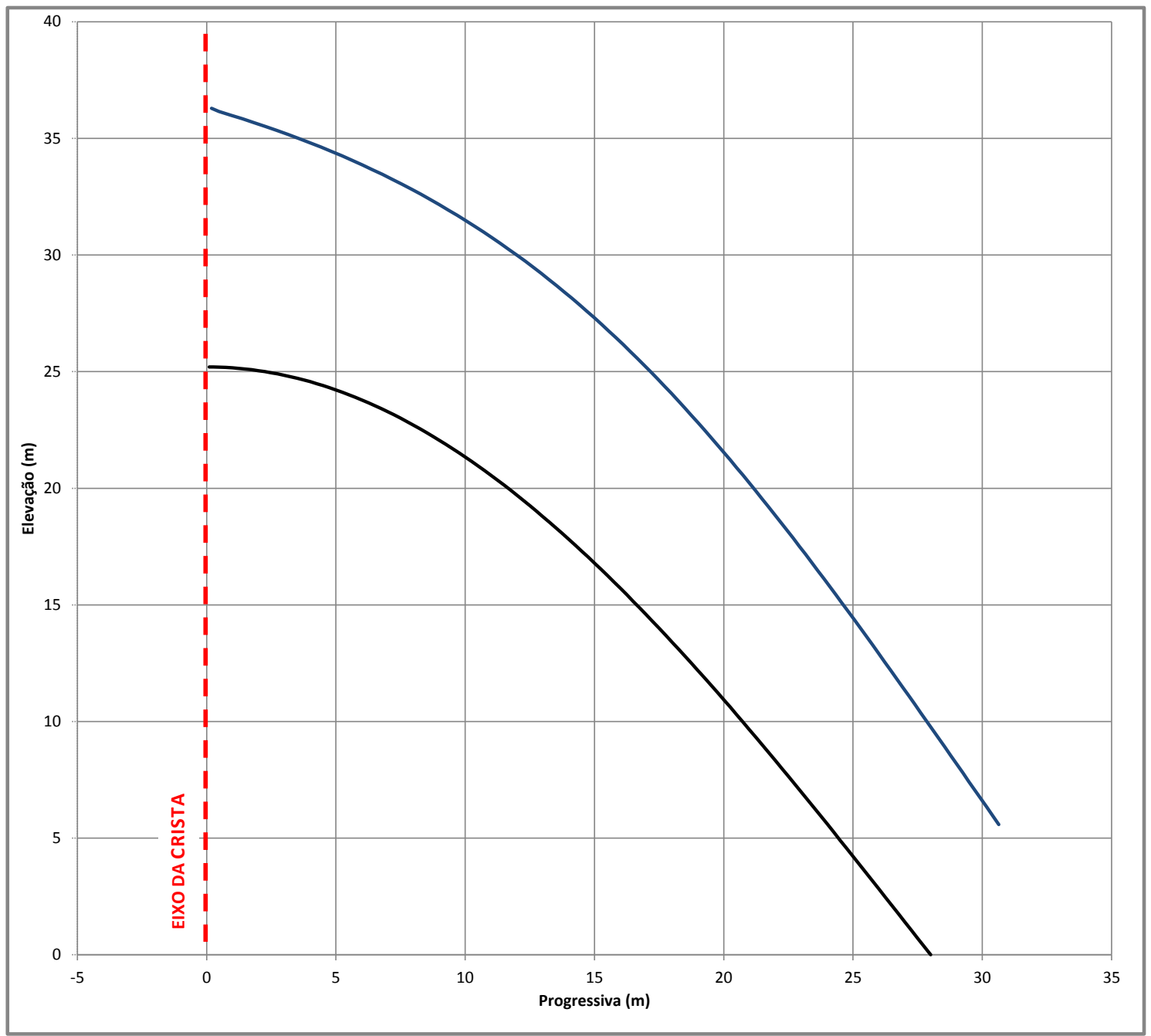

Figura 24 - Perfil cossenoidal e linha d’água

$\mathrm{Na}$ determinação da linha d'água para o perfil Creager foi adotada a curva plotada com os dados apresentados no Hydraulic Design Criteria, conforme apresentado na Figura 25. 


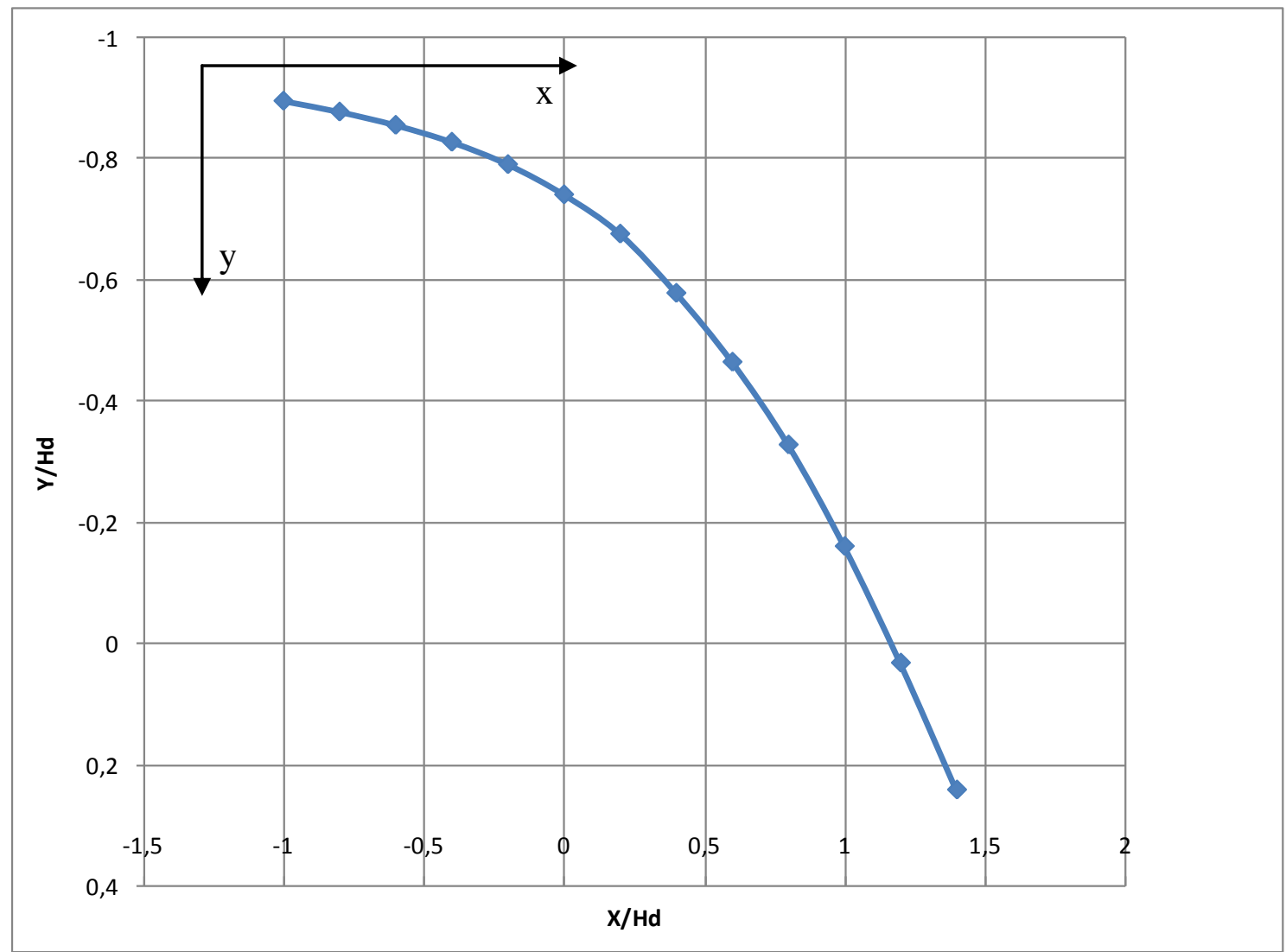

Figura 25 - Linha d'água para perfil Cregaer

Através da Figura 25 extraiu-se a relação apresentada no Quadro 2, que apresenta a linha d'água para um perfil Creager em relação a uma determinada carga hidráulica $\left(\mathrm{H}_{\mathrm{d}}\right)$.

Quadro 2 - Posições X,Y para linha d'água em perfil do tipo Creager

\begin{tabular}{|c|c|}
\hline $\mathbf{X} / \mathbf{H d}$ & Y/Hd \\
\hline$-1,000$ & $-0,897$ \\
\hline$-0,800$ & $-0,879$ \\
\hline$-0,600$ & $-0,857$ \\
\hline$-0,400$ & $-0,829$ \\
\hline$-0,200$ & $-0,792$ \\
\hline 0,000 & $-0,742$ \\
\hline 0,200 & $-0,677$ \\
\hline 0,400 & $-0,579$ \\
\hline 0,600 & $-0,465$ \\
\hline 0,800 & $-0,328$ \\
\hline 1,000 & $-0,160$ \\
\hline 1,200 & 0,033 \\
\hline 1,400 & 0,243 \\
\hline
\end{tabular}


De maneira semelhante realizou-se o cálculo para o trecho de montante considerando o perfil proposto por Maynord e o perfil de "Maynord Modificado". A Figura 26 apresenta as linhas d'água considerando os perfis citados.

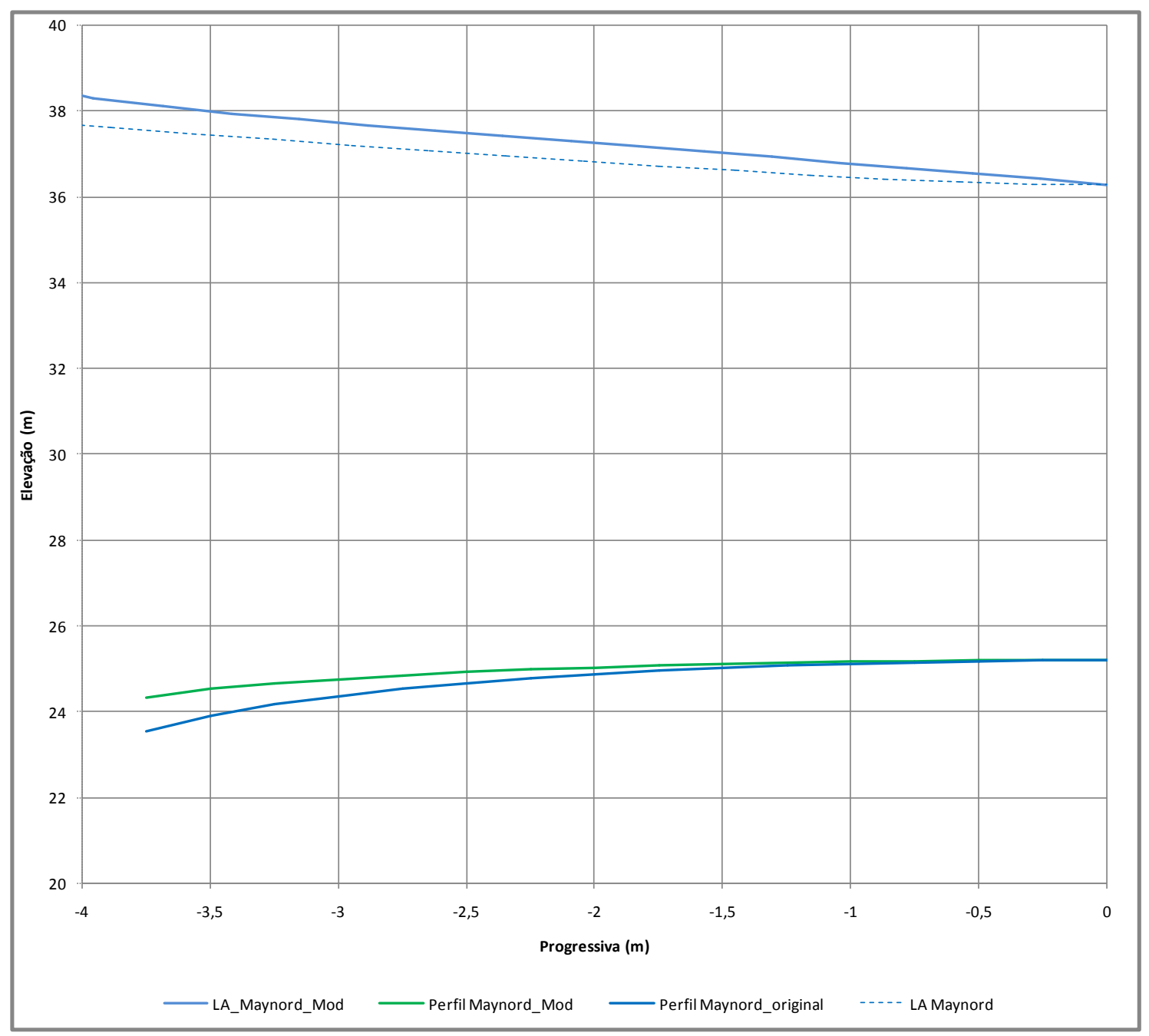

Figura 26 - Linhas d'água para perfil Maynord e "Maynord Modificado"

Com a utilização dos resultados obtidos pela modelagem matemática a Figura 27 apresenta as linhas d'água para a soleira com o perfil cossenoidal e para a soleira em perfil Creager, enquanto que o Quadro 3 apresenta os valores adimensionalizados para a determinação da linha d'água para o perfil de Maynord Modificado. 
Quadro 3 - Posições X,Y para linha d'água em perfil do tipo Maynord Modificado

\begin{tabular}{|c|c|}
\hline $\mathbf{X} / \mathbf{H d}$ & $\mathbf{Y} / \mathbf{H d}$ \\
\hline 0,000 & 2,592 \\
\hline$-0,017$ & 2,601 \\
\hline$-0,035$ & 2,609 \\
\hline$-0,052$ & 2,618 \\
\hline$-0,070$ & 2,627 \\
\hline$-0,087$ & 2,635 \\
\hline$-0,105$ & 2,643 \\
\hline$-0,122$ & 2,652 \\
\hline$-0,140$ & 2,660 \\
\hline$-0,157$ & 2,668 \\
\hline$-0,174$ & 2,676 \\
\hline$-0,192$ & 2,685 \\
\hline$-0,209$ & 2,693 \\
\hline$-0,227$ & 2,702 \\
\hline$-0,244$ & 2,711 \\
\hline$-0,262$ & 2,721 \\
\hline$-0,296$ & 2,755 \\
\hline
\end{tabular}

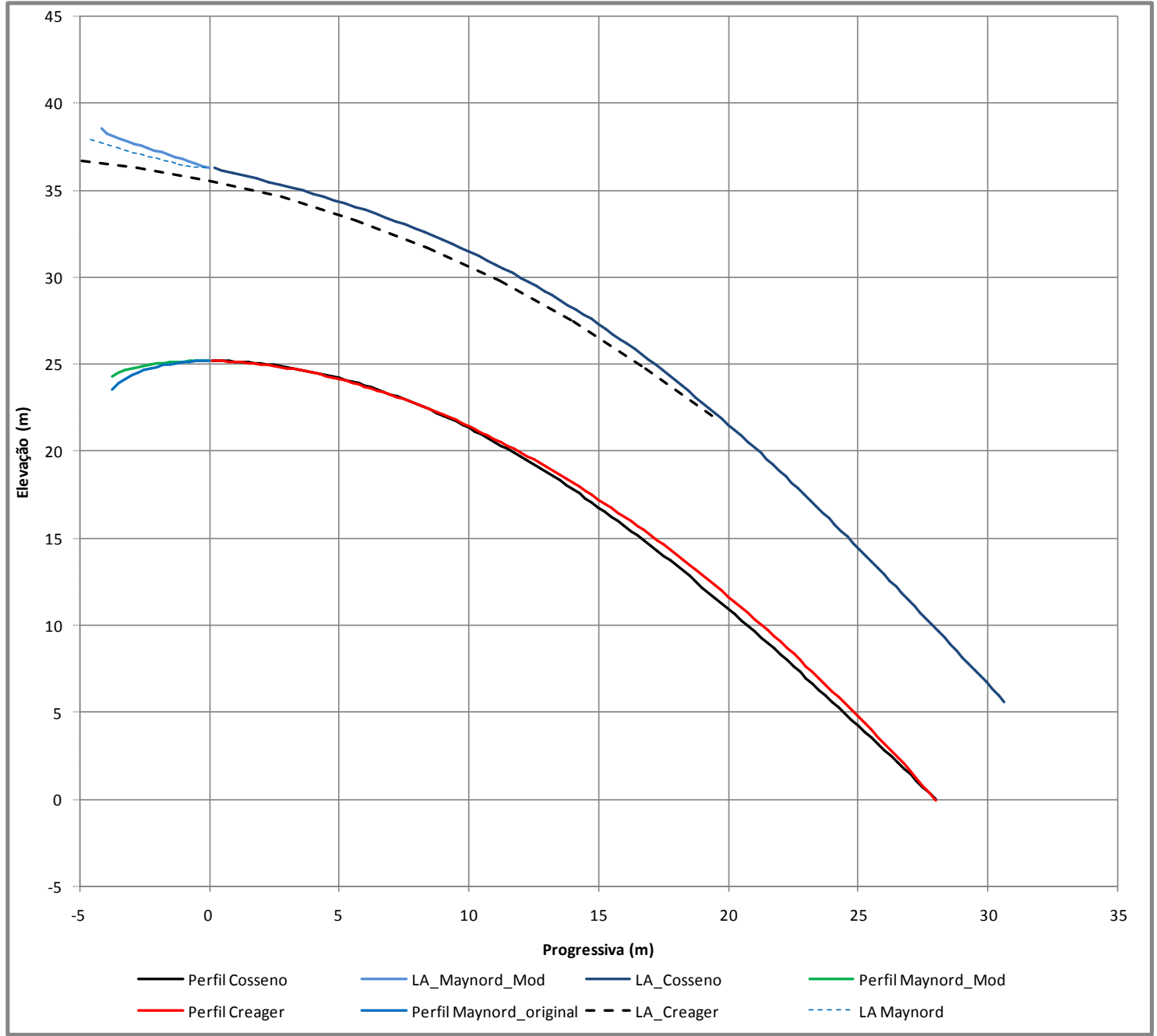

Figura 27 - Linhas d'água para perfil cossenoidal e perfil Creager 


\subsection{Cálculo do Coeficiente de Descarga}

O coeficiente de descarga pode ser descrito pela conforme apresentado pela equação 90.

$$
C=\frac{Q}{L H^{(3 / 2)}}
$$

Onde:

$Q=\operatorname{vazão}\left(\mathrm{m}^{3} / \mathrm{s}\right)$;

$L=$ comprimento da soleira vertente $(\mathrm{m})$;

$H=$ carga hidráulica $(\mathrm{m})$

Através da modelagem matemática é possível calcular o coeficiente de descarga para o conjunto de nova soleira vertente (Maynord Modificado + Cossenoidal), aplicando a Eq.(90) verifica-se que o coeficiente de descarga deste vertedor é de 2,28 $\left[m^{1 / 2} / s\right]$.

O coeficiente de descarga para os perfis Maynord + Creager apresentou o valor de $2,71\left[m^{1 / 2} / \mathrm{s}\right]$.

Isso demonstra que o a combinação do perfil Maynord Modificado + Cossenoidal apresenta uma capacidade de descarga 15,9\% inferior ao perfil Maynord + Creager, para as mesmas condições de cálculo.

\subsection{Determinação da Linha de Pressão}

A determinação da linha de pressão seguiu o mesmo procedimento utilizado para a determinação da linha d'água, utilizando-se de planilhas eletrônicas e dos equacionamentos apresentados nos itens antecedentes, realizou-se a determinação das linhas de pressões. 
A Figura 28 apresenta as linhas de pressão adimensionalizadas para a composição de perfil cossenoidal e "Maynord Modificado" comparadas ao perfil composto por um perfil Maynord e Creager.

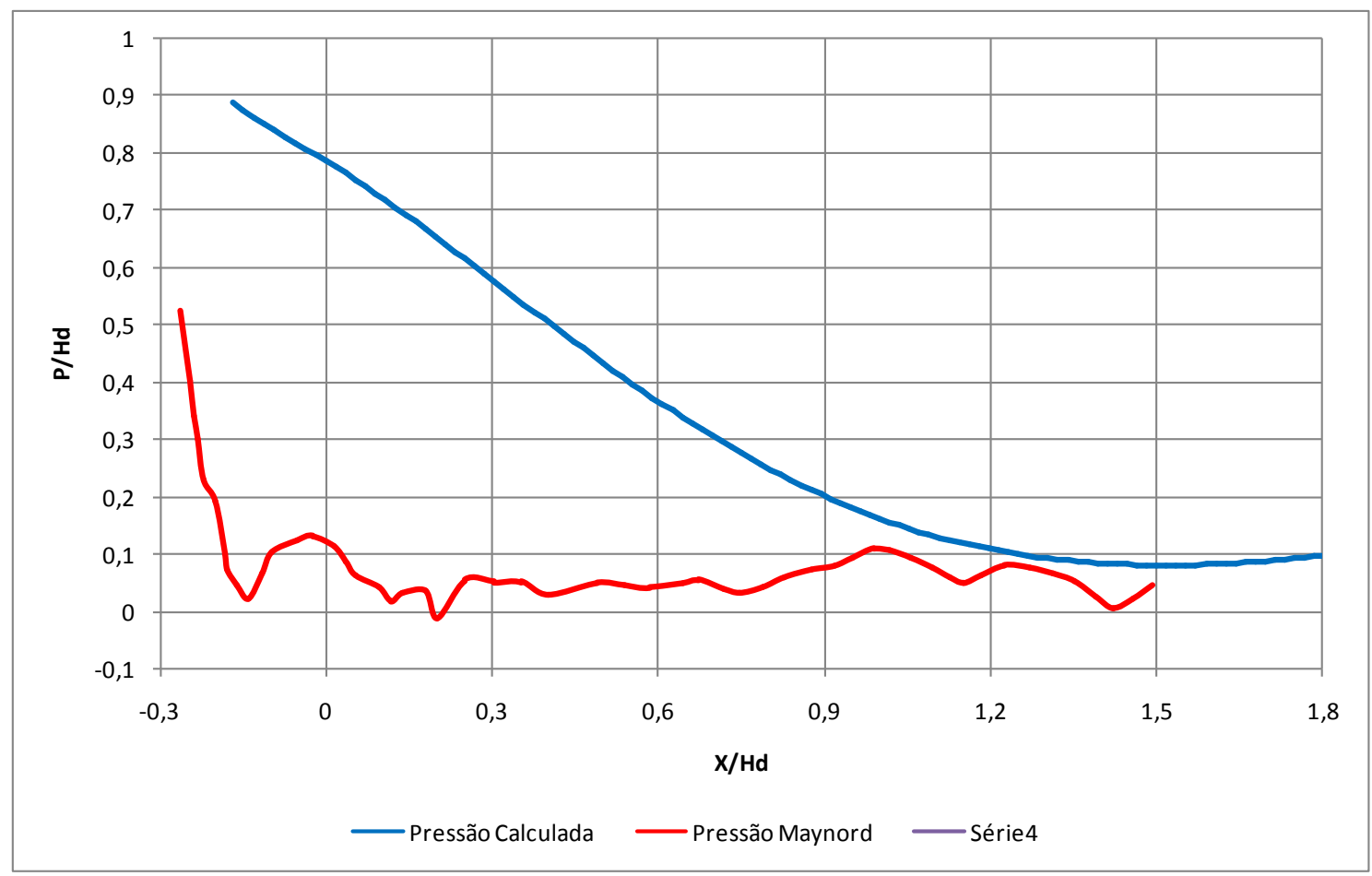

Figura 28 - Linhas de pressão para perfil cossenoidal e perfil Creager

O Quadro 4 apresenta os valores obtidos nos cálculos, juntamente com os valores obtidos pela publicação de MURPHY, 1973. 
Quadro 4 - Valores de pressão adimensionalizados para os perfis cossenoidal e Creager

\begin{tabular}{|c|c|}
\hline \multicolumn{2}{|c|}{ Cossenoidal +Maynord Modificado } \\
\hline $\mathbf{X} / \mathbf{H d}$ & $\mathbf{P} / \mathbf{H d}$ \\
\hline-0.25 & 0.796 \\
\hline-0.20 & 0.795 \\
\hline-0.10 & 0.791 \\
\hline 0.00 & 0.787 \\
\hline 0.10 & 0.722 \\
\hline 0.20 & 0.652 \\
\hline 0.30 & 0.578 \\
\hline 0.40 & 0.505 \\
\hline 0.50 & 0.433 \\
\hline 0.60 & 0.366 \\
\hline 0.70 & 0.304 \\
\hline 0.80 & 0.248 \\
\hline 0.90 & 0.201 \\
\hline 1.00 & 0.161 \\
\hline 1.10 & 0.130 \\
\hline 1.20 & 0.107 \\
\hline 1.30 & 0.092 \\
\hline 1.40 & 0.083 \\
\hline 1.50 & 0.080 \\
\hline & \\
\hline
\end{tabular}

\begin{tabular}{|c|c|}
\hline \multicolumn{2}{|c|}{ Creager + Maynord } \\
\hline $\mathbf{X} /$ Hd & P/Hd \\
\hline-0.25 & 0.417 \\
\hline-0.20 & 0.191 \\
\hline-0.10 & 0.100 \\
\hline 0.00 & 0.119 \\
\hline 0.10 & 0.036 \\
\hline 0.20 & -0.010 \\
\hline 0.30 & 0.051 \\
\hline 0.40 & 0.027 \\
\hline 0.50 & 0.048 \\
\hline 0.60 & 0.043 \\
\hline 0.70 & 0.046 \\
\hline 0.80 & 0.047 \\
\hline 0.90 & 0.075 \\
\hline 1.00 & 0.108 \\
\hline 1.10 & 0.073 \\
\hline 1.20 & 0.070 \\
\hline 1.30 & 0.068 \\
\hline 1.40 & 0.020 \\
\hline 1.50 & 0.046 \\
\hline
\end{tabular}

Verificou-se que as linhas de pressão apresentaram um comportamento bem suavizado em relação a curva de pressão apresentada nos estudos de MURPHY. Tal efeito é explicado pelo ajuste realizado na soleira vertente, onde se reduziu a curvatura que força o surgimento de pressões negativas. 


\section{CONCLUSÕES}

A equação cossenoidal proposta por este trabalho apresentou resultados satisfatórios quanto ao comportamento da linha d'água, bem como para a linha de pressão.

Através da curva cossenoidal foi possível ajustar o raio de curvatura no ponto da crista do vertedor realizando deste modo uma concordância perfeita entre a elipse de Maynord modificada proposta por este trabalho com a curva cossenoidal também apresentada neste trabalho.

A concordância realizada por raio de curvatura e tangência apresenta características contínuas, não ocorrendo perturbações que possam afetar o escoamento. O fenômeno chamado de "RollWave" são redemoinhos que originados em transições que no decorrer do escoamento são incrementados até encontrarem obstáculos, causando esforços excessivos podendo danificar a estrutura hidráulica.

O novo perfil de soleira vertente apresenta uma área de seção transversal inferior se comparando com o tradicional perfil Creager, resultando, desta maneira, em um volume menor necessário à sua execução, isso traz economia a sua execução uma vez que o trecho do vertedor costuma ser uma das partes que mais encarecem uma barragem devido aos grandes volumes de concreto convencional de categoria especial empregado.

A linha d'água calculada para a nova composição de soleira vertente (Cossenoidal + Maynord Modificado) comparada com a soleira composta por Creager e Maynord são muito semelhantes, não apresentando grandes diferenças entre elas.

A sobrelevação na linha d'água observada em relação ao perfil Creager + Maynord é em virtude da redução do coeficiente de descarga para o perfil proposto. de acordo com os cálculos o perfil Creager + Maynord apresentou um coeficiente de descarga de $2,71\left[\mathrm{~m}^{1 / 2} / \mathrm{s}\right]$, enquanto que a soleira composta pelos perfis Cossenoidal + Maynord Modificado apresentou como coeficiente de descarga 2,28 $\left[\mathrm{m}^{1 / 2} / \mathrm{s}\right]$.

De acordo com a análise de coeficientes de descarga, o novo perfil proposto demonstrou que é da ordem de 15,9\% menos eficiente em relação ao perfil Creager + Maynord.

Também verifica-se que as linha pressão para a nova soleira proposta não apresenta valores negativos. Esse fenômeno é suavizado pelo ajuste proposto na elipse de Maynord chamado neste trabalho de Maynord Modificado. O abatimento na curva 
resultante reduz o ataque que o perfil causa no escoamento reduzindo o efeito ascendente do fluxo na aproximação.

Neste trabalho o perfil foi estudado para uma situação de vertedor construído e concreto convencional, tendo como declividade do rápido de jusante a relação 1:0.6 (Vertical : Horizontal), recomenda-se estudos para paramentos de jusante com outras inclinações variando de 1:0,7 a 1:1 (V:H) para barragem em concreto compactado a rolo (CCR) ou até mesmo em relações maiores nos casos de implantações de rápidos em declividades naturais de ombreiras.

Neste trabalho fixou-se o comprimento do perfil de Maynord ajustando-se a altura de modo que se obtivesse a concordância de raio de curvatura na crista, com isso, recomenda-se para trabalhos futuros o estudo no perfil modificado de Maynord feito neste trabalho com a adoção de outras relações de ajuste de modo a conseguir aumentar o coeficiente de descarga do vertedor.

O trabalho demonstrou que o perfil estudado apresenta seção transversal menor em relação ao perfil de Creager com Maynord, com um coeficiente de descarga inferior para uma mesma carga hidráulica. Isso pode ser um indicativo da possibilidade de se criar um perfil com seção transversal menor criando um borde de ataque mais pronunciado, aumentando-se o coeficiente de descarga. Assim teríamos um perfil de menor seção transversal com capacidade de vazão semelhante ao de um perfil Creager e Maynord. e redução nos custos de construção.

Como sugestão para próximos estudos, o pesquisador poderá propor novas proporções a serem ajustadas nos eixos " $x$ " e " $y$ " no perfil de montante, buscando reduzir mais o perfil e aumentar o coeficiente de descarga, buscando uma maior eficiência no vertedor e economia para sua construção. 


\section{SÍNTESE BIBLIOGRÁFICA}

ACKERS, Peter, et al. Weirs and Flumes for Flow Measurement, Chicherster, 1989;

ARAUZ, Ivan Juncioni de. Vertedor de Superfície e Escoamento sob Comportas, 2005 ;

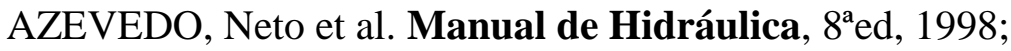

BUREAU OF RECLAMATION.Design of Small Dams, $3^{\mathrm{a} e d, ~ 1987 ; ~}$

CHANSON, Hubert. The Hydraulic of Open Channel Flow: An Introduction, $2^{\mathrm{a}} \mathrm{ed}$. 2004;

CHOW, V.T.; Open Channel Hydraulics,[S.I.]: McGraw Hill Book, 2009;

COSTAL \& HYDRAULICS LABORATORY.Hydraulic Design Criteria, 1987;

DANESHFARAZ, Rasul et al. Numerical Investigation of Upstream Face Slope and Curvature of Ogee Spillway on Flow Pattern.Journal of Environmental Science and Engineering, 2012;

DEPARTMENT OF THE ARMY, USACE.Hydraulic Design of Spillways, Washington, DC: [s.n]. 1992;

KANASHIRO, Winston Hisasi. Vertedor com Perfil tipo Lemniscata, Dissertação apresentada à escola Politécnica da Universidade de São Paulo, para a obtenção do título de Mestre em Engenharia, São Paulo 1989;

MURPHY, T. E.; Spillway Crest Design, Vicksburg, Mississippi, 1973;

NOVAK, P. etal.Hydraulic Structures, $4^{\mathrm{a} e d}$, 2007;

PORTO, Rodrigo de Melo. Hidráulica Básica, 2aed. 2003;

SAVAGE, B. M.; JOHNSON, M. C.; Flow Over Ogee Spillway: Physical and Numerical Model Case Study, Journal of Hydraulic Engineering, 2001;

SOUZA, P. A.; Histerese em Escoamento sobre Salto-de-Esqui, Tese apresentada à escola Politécnica da Universidade de São Paulo, para obtenção de título de Doutor em Engenharia, 1985. 
ANEXO I - PLANILHAS DE CÁlCULO 
Planilha de Cálculo Soleira Cossenoidal

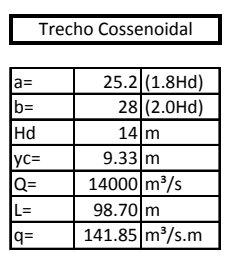

\begin{tabular}{|c|c|c|c|c|c|c|c|c|c|c|c|c|c|c|c|c|c|c|c|c|}
\hline & & & & & & & & & & & & & & & & & & & & \\
\hline & Y & $R$ & $\operatorname{tang}(\mathrm{m})$ & ortog $(\mathrm{m})$ & & $\theta$ & $\cos \theta$ & 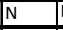 & \begin{tabular}{c|}
$\cos \theta$ \\
\end{tabular} & \begin{tabular}{|l|} 
Parc. Cinet \\
\end{tabular} & $E$ & $f$ & $\Delta S$ & Def & $\Delta E 1,2$ & G & $\mathrm{G}^{\prime}$ & N2 & pressão & $\mathrm{P} / \mathrm{Hd}$ \\
\hline 0.10 & 25.20 & 12.61 & -0.01 & 126.09 & \begin{tabular}{|l|}
-0.08 \\
\end{tabular} & 0.01 & 1.00 & \begin{tabular}{|l|}
11.09 \\
\end{tabular} & 11.09 & 4.58 & 40.88 & 0.01 & & \begin{tabular}{|l|}
29.27 \\
\end{tabular} & & & & \begin{tabular}{|l|}
11.09 \\
\end{tabular} & 11.03 & 0.79 \\
\hline 0.25 & 25.20 & 12.62 & -0.02 & 50.44 & -0.08 & 0.02 & 1.00 & 10.96 & 10.96 & 4.72 & \begin{tabular}{|l|}
40.88 \\
\end{tabular} & \begin{tabular}{ll|} 
& 0.01 \\
\end{tabular} & 0.15 & 29.01 & 0.00 & \begin{tabular}{l|l}
0.00 \\
\end{tabular} & -0.04 & 10.96 & 10.89 & 0.78 \\
\hline 0.50 & 25.19 & 12.64 & -0.04 & 25.22 & $\mid-0.08$ & 0.04 & 1.00 & 10.81 & 10.81 & 4.88 & 40.87 & 0.01 & 0.25 & \begin{tabular}{|l|}
28.74 \\
\end{tabular} & 0.00 & 0.00 & -0.09 & 10.81 & 10.72 & 0.77 \\
\hline 0.75 & 25.18 & 12.69 & -0.06 & 16.82 & -0.08 & 0.06 & 1.00 & 10.68 & 10.66 & 5.04 & 40.87 & 0.01 & 0.25 & 28.48 & 0.00 & 0.00 & -0.14 & 10.68 & 10.56 & 0.75 \\
\hline 1.00 & 25.16 & 12.75 & -0.08 & 2.62 & -0.08 & 0.08 & 1.00 & 10.55 & 10.51 & 5.20 & 40.87 & 0.01 & 0.25 & \begin{tabular}{|l|}
28.24 \\
\end{tabular} & 0.00 & 0.00 & -0.19 & 10.55 & 10.39 & 0.74 \\
\hline 1.25 & 25.14 & 12.83 & -0.10 & 10.10 & $\mid-0.08$ & 0.10 & 1.00 & 10.42 & 10.37 & 5.37 & \begin{tabular}{|l|l|}
40.87 \\
\end{tabular} & 0.01 & 0.25 & \begin{tabular}{|l|}
28.01 \\
\end{tabular} & 0.00 & 0.00 & -0.24 & 10.42 & 10.22 & 0.73 \\
\hline 1.50 & 25.11 & 12.92 & -0.12 & 8.42 & $\mid-0.08$ & 0.12 & 0.99 & 10.30 & 10.23 & 5.53 & \begin{tabular}{|l|l|}
40.87 \\
\end{tabular} & 0.01 & 0.25 & \begin{tabular}{|l|l|}
27.80 \\
\end{tabular} & 0.00 & 0.00 & -0.30 & 10.30 & 10.05 & 0.72 \\
\hline 1.75 & 25.08 & 13.04 & -0.14 & 7.22 & -0.08 & 0.14 & 0.99 & 10.18 & 10.09 & 5.71 & \begin{tabular}{|l|}
40.87 \\
\end{tabular} & 0.01 & 0.25 & 27.60 & 0.00 & $\begin{array}{ll}0.00 \\
\end{array}$ & -0.35 & 10.18 & 9.88 & 0.71 \\
\hline 2.00 & 25.04 & 13.17 & -0.16 & 6.32 & -0.08 & 0.16 & 0.99 & \begin{tabular}{|l|l|}
10.07 \\
\end{tabular} & 9.95 & 5.88 & 40.87 & 0.01 & 0.25 & 27.41 & 0.00 & 0.00 & -0.41 & 10.07 & 9.70 & 0.69 \\
\hline 2.25 & 25.00 & 13.32 & -0.18 & 5.62 & \begin{tabular}{|l|}
-0.08 \\
\end{tabular} & 0.18 & 0.98 & 9.97 & 9.81 & 6.06 & \begin{tabular}{|l|}
40.87 \\
\end{tabular} & 0.01 & 0.25 & 27.23 & $\begin{array}{l}0.00 \\
\end{array}$ & \begin{tabular}{l|l}
0.00 \\
\end{tabular} & \begin{tabular}{|c|}
-0.47 \\
\end{tabular} & \begin{tabular}{|l|}
9.97 \\
\end{tabular} & \begin{tabular}{|l|}
9.53 \\
\end{tabular} & \begin{tabular}{l|l|}
0.68 \\
\end{tabular} \\
\hline 2.50 & 24.95 & 13.49 & -0.20 & 5.06 & $\mid-0.07$ & \begin{tabular}{|l|l|}
0.20 \\
\end{tabular} & 0.98 & 9.86 & 9.68 & 6.24 & \begin{tabular}{|l|l|} 
\\
\end{tabular} & 0.01 & \begin{tabular}{|l|}
0.25 \\
\end{tabular} & 27.06 & 0.00 & 0.00 & \begin{tabular}{c|}
-0.53 \\
\end{tabular} & 9.86 & 9.35 & $\begin{array}{ll}0.67 \\
\end{array}$ \\
\hline 2.75 & 24.90 & 13.67 & \begin{tabular}{l|}
-0.22 \\
\end{tabular} & 4.60 & \begin{tabular}{|l|}
-0.07 \\
\end{tabular} & \begin{tabular}{|l|l|}
0.21 \\
\end{tabular} & 0.98 & 9.76 & 9.54 & 6.43 & \begin{tabular}{|l|l|}
40.87 \\
\end{tabular} & 0.01 & \begin{tabular}{|l|}
0.26 \\
\end{tabular} & 26.90 & $\begin{array}{ll}0.00 \\
\end{array}$ & \begin{tabular}{l|l}
0.00 \\
\end{tabular} & \begin{tabular}{l|l}
-0.59 \\
\end{tabular} & $\begin{array}{l}9.76 \\
\end{array}$ & \begin{tabular}{|l|}
9.17 \\
\end{tabular} & $\begin{array}{ll}0.65 \\
\end{array}$ \\
\hline 3.00 & 24.84 & 13.88 & -0.24 & 4.22 & $|-0.07|$ & 0.23 & 0.97 & 9.67 & 9.41 & 6.62 & \begin{tabular}{|l|l|}
40.87 \\
\end{tabular} & 0.01 & \begin{tabular}{|l|}
0.26 \\
\end{tabular} & \begin{tabular}{|l|}
26.75 \\
\end{tabular} & 0.00 & 0.00 & -0.65 & 9.67 & 8.98 & 0.64 \\
\hline 3.25 & 24.78 & 14.11 & -0.26 & 3.90 & -0.07 & 0.25 & 0.97 & \begin{tabular}{|l|l|}
9.57 \\
\end{tabular} & 9.27 & 6.81 & 40.87 & 0.01 & 0.26 & \begin{tabular}{|l|}
26.61 \\
\end{tabular} & 0.00 & \begin{tabular}{l|l}
0.00 \\
\end{tabular} & -0.72 & \begin{tabular}{|l|}
9.57 \\
\end{tabular} & 8.80 & \begin{tabular}{l|l}
0.63 \\
\end{tabular} \\
\hline 3.50 & 24.72 & 14.35 & \begin{tabular}{l|}
-0.28 \\
\end{tabular} & 3.63 & $\mid-0.07$ & \begin{tabular}{|l|}
0.27 \\
\end{tabular} & 0.96 & $\begin{array}{l}9.48 \\
\end{array}$ & 9.14 & 7.01 & \begin{tabular}{|l|l|} 
\\
\end{tabular} & 0.01 & \begin{tabular}{|c|}
0.26 \\
\end{tabular} & 26.48 & $\begin{array}{ll}0.00 \\
\end{array}$ & \begin{tabular}{l|l}
0.00 \\
\end{tabular} & \begin{tabular}{|c|}
-0.78 \\
\end{tabular} & \begin{tabular}{l|l}
9.48 \\
\end{tabular} & \begin{tabular}{l|l|}
8.62 \\
\end{tabular} & \begin{tabular}{l|l}
0.62 \\
\end{tabular} \\
\hline 3.75 & 24.64 & 4.61 & -0.30 & 3.39 & \begin{tabular}{|l|}
-0.07 \\
\end{tabular} & \begin{tabular}{|l|}
0.29 \\
\end{tabular} & 0.96 & 9.40 & 9.01 & 7.21 & 40.87 & 0.01 & \begin{tabular}{|l|}
0.26 \\
\end{tabular} & 26.36 & $\begin{array}{ll}0.00 \\
\end{array}$ & \begin{tabular}{l|l}
0.00 \\
\end{tabular} & \begin{tabular}{c|}
-0.85 \\
\end{tabular} & \begin{tabular}{l|l}
9.40 \\
\end{tabular} & \begin{tabular}{|l|}
8.43 \\
\end{tabular} & 0.60 \\
\hline 4.00 & 24.57 & 14.90 & -0.31 & 3.18 & -0.07 & \begin{tabular}{|l|}
0.30 \\
\end{tabular} & 0.95 & $\begin{array}{l}9.32 \\
\end{array}$ & 8.89 & 7.42 & 40.87 & 0.01 & \begin{tabular}{|l|}
0.26 \\
\end{tabular} & \begin{tabular}{|l|}
26.25 \\
\end{tabular} & $\begin{array}{ll}0.00 \\
\end{array}$ & \begin{tabular}{l|l}
0.00 \\
\end{tabular} & \begin{tabular}{l|}
-0.92 \\
\end{tabular} & \begin{tabular}{l|l}
9.32 \\
\end{tabular} & 8.25 & 0.59 \\
\hline $\begin{array}{ll}4.25 \\
\end{array}$ & 24.49 & 15.21 & \begin{tabular}{|c|c|}
-0.33 \\
\end{tabular} & 3.00 & \begin{tabular}{|l|}
-0.07 \\
\end{tabular} & $\begin{array}{ll}0.32 \\
\end{array}$ & 0.95 & $\begin{array}{l}9.23 \\
\end{array}$ & 8.76 & $\begin{array}{l}7.62 \\
\end{array}$ & 40.87 & 0.01 & 0.26 & 26.14 & $\begin{array}{l}0.00 \\
\end{array}$ & \begin{tabular}{l|l|l}
0.00 \\
\end{tabular} & \begin{tabular}{|c|}
-0.99 \\
\end{tabular} & \begin{tabular}{|l|}
9.23 \\
\end{tabular} & 8.06 & \begin{tabular}{ll|}
0.58 \\
\end{tabular} \\
\hline $\begin{array}{l}4.50 \\
\end{array}$ & 24.40 & 15.53 & -0.35 & 2.83 & -0.06 & 0.34 & 0.94 & 9.16 & 8.63 & 7.83 & \begin{tabular}{|l|l|} 
\\
\end{tabular} & 0.01 & 0.26 & 26.04 & 0.00 & 0.00 & -1.06 & $\begin{array}{l}9.16 \\
\end{array}$ & 7.88 & 0.56 \\
\hline 4.75 & 24.31 & 15.88 & -0.37 & 2.69 & \begin{tabular}{|l|}
-0.06 \\
\end{tabular} & 0.36 & 0.94 & 9.08 & 8.51 & 8.05 & \begin{tabular}{|l|l|} 
\\
\end{tabular} & 0.01 & 0.27 & \begin{tabular}{|l|}
25.94 \\
\end{tabular} & 0.00 & 0.00 & \begin{tabular}{|c|}
-1.13 \\
\end{tabular} & 9.08 & 7.69 & 0.55 \\
\hline 5.00 & 24.22 & 16.25 & \begin{tabular}{|c|}
-0.39 \\
\end{tabular} & 2.56 & \begin{tabular}{|l|}
-0.06 \\
\end{tabular} & \begin{tabular}{|l|}
0.37 \\
\end{tabular} & $\begin{array}{l}0.93 \\
\end{array}$ & \begin{tabular}{|c|}
9.01 \\
\end{tabular} & 8.39 & 8.27 & \begin{tabular}{|l|l|}
407 \\
\end{tabular} & 0.01 & \begin{tabular}{|l|}
0.27 \\
\end{tabular} & 25.85 & $\begin{array}{l}0.00 \\
\end{array}$ & \begin{tabular}{l|l}
0.00 \\
\end{tabular} & -1.21 & \begin{tabular}{|l|}
9.01 \\
\end{tabular} & $\begin{array}{l}7.51 \\
\end{array}$ & \begin{tabular}{|l|l|}
0.54 \\
\end{tabular} \\
\hline \begin{tabular}{|l|}
5.25 \\
\end{tabular} & 24.11 & $\begin{array}{l}16.64 \\
\end{array}$ & -0.41 & 2.44 & \begin{tabular}{|l|}
-0.06 \\
\end{tabular} & \begin{tabular}{|l|}
0.39 \\
\end{tabular} & $\begin{array}{l}0.93 \\
\end{array}$ & 8.94 & 8.27 & 8.49 & \begin{tabular}{|l|l|} 
\\
\end{tabular} & 0.01 & \begin{tabular}{|l|}
0.27 \\
\end{tabular} & 25.76 & $\begin{array}{l}0.00 \\
\end{array}$ & \begin{tabular}{l|l|l}
0.00 \\
\end{tabular} & \begin{tabular}{|c|}
-1.28 \\
\end{tabular} & \begin{tabular}{|l|}
8.94 \\
\end{tabular} & 7.33 & \begin{tabular}{l|l|}
0.52 \\
\end{tabular} \\
\hline 5.50 & 24.01 & 17.06 & -0.43 & 2.33 & -0.06 & \begin{tabular}{|l|l|}
0.41 \\
\end{tabular} & 0.92 & 8.87 & 8.15 & 8.71 & 40.87 & 0.01 & \begin{tabular}{|c|}
0.27 \\
\end{tabular} & \begin{tabular}{|l|}
25.68 \\
\end{tabular} & $\begin{array}{ll}0.00 \\
\end{array}$ & \begin{tabular}{l|l}
0.00 \\
\end{tabular} & \begin{tabular}{|c|}
-1.36 \\
\end{tabular} & 8.87 & 7.14 & 0.51 \\
\hline 5.75 & 23.90 & 17.49 & -0.45 & 2.23 & $\mid-0.06$ & \begin{tabular}{|l|l|}
0.42 \\
\end{tabular} & 0.91 & 8.80 & 8.03 & 8.94 & \begin{tabular}{|l|l|} 
\\
\end{tabular} & 0.01 & \begin{tabular}{|c|}
0.27 \\
\end{tabular} & 25.61 & 0.00 & 0.00 & \begin{tabular}{|c|}
-1.44 \\
\end{tabular} & 8.80 & 6.96 & 0.50 \\
\hline 6.00 & 23.79 & 7.96 & -0.47 & 14 & \begin{tabular}{|l|} 
\\
\end{tabular} & \begin{tabular}{|l|l|}
0.44 \\
\end{tabular} & 0.91 & \begin{tabular}{|l|}
8.73 \\
\end{tabular} & 7.91 & 9.17 & 40.87 & 0.01 & \begin{tabular}{|l|}
0.27 \\
\end{tabular} & 25.53 & $\begin{array}{ll}0.00 \\
\end{array}$ & \begin{tabular}{l|l}
0.00 \\
\end{tabular} & \begin{tabular}{|c|}
-1.51 \\
\end{tabular} & \begin{tabular}{|l|l|}
8.73 \\
\end{tabular} & $\begin{array}{ll}6.78 \\
\end{array}$ & $\begin{array}{ll}0.48 \\
\end{array}$ \\
\hline $\begin{array}{ll}6.25 \\
\end{array}$ & 23.67 & 18.44 & $\begin{array}{l}-0.49 \\
\end{array}$ & 06 & -0.05 & \begin{tabular}{|l|l|}
0.45 \\
\end{tabular} & 0.90 & \begin{tabular}{|l|}
8.67 \\
\end{tabular} & 7.80 & 9.40 & \begin{tabular}{|l|l|}
40.87 \\
\end{tabular} & 0.01 & \begin{tabular}{|l|}
0.28 \\
\end{tabular} & 25.46 & $\begin{array}{ll}0.00 \\
\end{array}$ & \begin{tabular}{l|l}
0.00 \\
\end{tabular} & \begin{tabular}{|c|}
-1.59 \\
\end{tabular} & 8.67 & 6.60 & $\begin{array}{l}.47 \\
\end{array}$ \\
\hline \begin{tabular}{ll|}
6.50 \\
\end{tabular} & 23.54 & 18.96 & -0.50 & 1.98 & -0.05 & 0.47 & 0.89 & 8.60 & 7.68 & 9.64 & \begin{tabular}{|l|l|}
40.87 \\
\end{tabular} & 0.01 & \begin{tabular}{|l|}
0.28 \\
\end{tabular} & \begin{tabular}{|l|}
25.39 \\
\end{tabular} & 0.00 & 0.00 & -1.68 & 8.60 & 6.42 & 0.46 \\
\hline $\begin{array}{ll}6.75 \\
\end{array}$ & 23.41 & 19.49 & -0.52 & 1.91 & \begin{tabular}{|l|} 
\\
\end{tabular} & \begin{tabular}{|l|l|}
0.48 \\
\end{tabular} & 0.89 & 8.54 & \begin{tabular}{|c|}
7.57 \\
\end{tabular} & 9.88 & 40.86 & \begin{tabular}{|l|l|}
5.01 \\
\end{tabular} & \begin{tabular}{|l|}
0.28 \\
\end{tabular} & 25.33 & $\begin{array}{ll}0.00 \\
\end{array}$ & \begin{tabular}{l|l}
0.00 \\
\end{tabular} & \begin{tabular}{|c|}
-1.76 \\
\end{tabular} & \begin{tabular}{|l|l}
8.54 \\
\end{tabular} & $\begin{array}{ll}6.25 \\
\end{array}$ & \begin{tabular}{l|l}
0.45 \\
\end{tabular} \\
\hline 7.00 & 23.28 & .06 & -0.54 & 85 & -0.05 & 0.50 & 0.88 & 8.48 & 7.46 & 10.12 & 40.86 & \begin{tabular}{|l|l|}
5 \\
\end{tabular} & \begin{tabular}{|l|}
0.28 \\
\end{tabular} & \begin{tabular}{|l|}
25.27 \\
\end{tabular} & 0.00 & 0.00 & \begin{tabular}{|c|}
-1.84 \\
\end{tabular} & 8.48 & 6.07 & $\begin{array}{l}.43 \\
\end{array}$ \\
\hline $\begin{array}{l}7.25 \\
\end{array}$ & 23.14 & .65 & -0.56 & 1.79 & \begin{tabular}{|l|}
-0.05 \\
\end{tabular} & \begin{tabular}{|l|}
0.51 \\
\end{tabular} & 0.87 & 8.42 & 7.35 & 10.37 & 40.86 & \begin{tabular}{|l|l|} 
& 0.01 \\
\end{tabular} & \begin{tabular}{|l|}
0.29 \\
\end{tabular} & \begin{tabular}{|l|}
25.20 \\
\end{tabular} & $\begin{array}{l}0.00 \\
\end{array}$ & \begin{tabular}{ll|l}
0.00 \\
\end{tabular} & \begin{tabular}{|c|}
-1.93 \\
\end{tabular} & \begin{tabular}{ll|}
8.42 \\
\end{tabular} & $\begin{array}{l}5.90 \\
\end{array}$ & $\begin{array}{ll}0.42 \\
\end{array}$ \\
\hline $\begin{array}{l}7.50 \\
\end{array}$ & 23.00 & 21.27 & \begin{tabular}{|c|c|}
-0.58 \\
\end{tabular} & 1.73 & -0.05 & \begin{tabular}{|l|}
0.52 \\
\end{tabular} & 0.87 & 8.36 & 7.24 & 10.62 & 40.86 & \begin{tabular}{|l|l|}
5 & 0.01 \\
\end{tabular} & \begin{tabular}{|c|}
0.29 \\
\end{tabular} & 25.14 & $\begin{array}{ll}0.00 \\
\end{array}$ & \begin{tabular}{l|l|l}
0.00 \\
\end{tabular} & \begin{tabular}{|c|}
-2.01 \\
\end{tabular} & $\begin{array}{l}8.36 \\
\end{array}$ & $\begin{array}{l}5.73 \\
\end{array}$ & $\begin{array}{l}0.41 \\
\end{array}$ \\
\hline 7.75 & 22.86 & 92 & \begin{tabular}{|c|}
-0.60 \\
\end{tabular} & 68 & -0.05 & \begin{tabular}{|l|l|}
0.54 \\
\end{tabular} & 0.86 & 8.31 & 7.14 & 10.87 & 40.86 & \begin{tabular}{|l|l|} 
& 0.01 \\
\end{tabular} & 0.29 & \begin{tabular}{|l|l|}
25.08 \\
\end{tabular} & 0.00 & 0.00 & \begin{tabular}{|c|}
-2.10 \\
\end{tabular} & 8.31 & 5.56 & 0.40 \\
\hline 8.00 & 22.7 & $\mid 59$ & -0.61 & 63 & -0.04 & 0.55 & 0.85 & 8.25 & 7.03 & 11.12 & \begin{tabular}{|l|l|}
40.86 \\
\end{tabular} & 0.01 & \begin{tabular}{|l|}
0.29 \\
\end{tabular} & \begin{tabular}{|l|}
25.02 \\
\end{tabular} & 0.00 & 0.00 & -2.19 & 8.25 & 5.39 & 0.38 \\
\hline 8.25 & 22.55 & 23.30 & \begin{tabular}{|c|}
-0.63 \\
\end{tabular} & 1.58 & \begin{tabular}{|l|} 
\\
\end{tabular} & \begin{tabular}{|l|}
0.56 \\
\end{tabular} & $\begin{array}{ll}0.85 \\
\end{array}$ & 8.20 & 6.93 & 11.38 & 40.86 & \begin{tabular}{|l|l|}
5 \\
\end{tabular} & \begin{tabular}{|l|}
0.29 \\
\end{tabular} & \begin{tabular}{|l|}
24.97 \\
\end{tabular} & 0.00 & \begin{tabular}{l|l}
0.00 \\
\end{tabular} & -2.27 & \begin{tabular}{l|l}
8.20 \\
\end{tabular} & $\begin{array}{l}5.22 \\
\end{array}$ & $\begin{array}{l}0.37 \\
\end{array}$ \\
\hline 8.50 & 22.39 & 24.04 & -0.65 & 1.54 & \begin{tabular}{|l|}
-0.04 \\
\end{tabular} & \begin{tabular}{|l|}
0.58 \\
\end{tabular} & 0.84 & 8.14 & \begin{tabular}{ll|}
6.83 \\
\end{tabular} & 11.64 & 40.86 & \begin{tabular}{|l|l|} 
\\
\end{tabular} & \begin{tabular}{|l|}
0.30 \\
\end{tabular} & \begin{tabular}{|l|}
24.91 \\
\end{tabular} & $\begin{array}{ll}0.00 \\
\end{array}$ & \begin{tabular}{l|l}
0.00 \\
\end{tabular} & -2.37 & 8.14 & 5.06 & 0.36 \\
\hline 8.75 & 22.2 & .81 & -0.67 & 50 & \begin{tabular}{|l|}
-0.04 \\
\end{tabular} & \begin{tabular}{|l|}
0.59 \\
\end{tabular} & 0.83 & $8 .($ & 73 & 11.91 & 40.86 & \begin{tabular}{|l|l|} 
\\
\end{tabular} & \begin{tabular}{|l|}
0.30 \\
\end{tabular} & 24.85 & $\begin{array}{ll}0.00 \\
\end{array}$ & \begin{tabular}{l|l}
0.00 \\
\end{tabular} & \begin{tabular}{|c|}
-2.46 \\
\end{tabular} & 8.09 & 4.90 & 0.35 \\
\hline 9.00 & 22.06 & 25.61 & -0.68 & 1.46 & $\mid-0.04$ & 0.60 & 0.83 & 8.0 & 6.63 & .17 & 40.86 & \begin{tabular}{|l|l|} 
& 0.01 \\
\end{tabular} & 0.30 & 24.79 & 0.00 & 0.00 & \begin{tabular}{l|}
-2.55 \\
\end{tabular} & 8.03 & 4.74 & 0.34 \\
\hline \begin{tabular}{|c|}
9.25 \\
\end{tabular} & 21.88 & 5.45 & \begin{tabular}{|c|}
-0.70 \\
\end{tabular} & 43 & -0.04 & \begin{tabular}{|l|l|}
0.61 \\
\end{tabular} & 0.82 & 7.98 & T & 2.44 & 40.86 & 0.01 & \begin{tabular}{|l|}
0.30 \\
\end{tabular} & \begin{tabular}{|l|l|}
24.73 \\
\end{tabular} & $\begin{array}{ll}0.00 \\
\end{array}$ & \begin{tabular}{l|l}
0.00 \\
\end{tabular} & -2.64 & $\begin{array}{ll}7.98 \\
\end{array}$ & $\begin{array}{ll}4.59 \\
\end{array}$ & \begin{tabular}{l|l}
0.33 \\
\end{tabular} \\
\hline \begin{tabular}{l|l}
9.50 \\
\end{tabular} & 21.71 & 32 & $\begin{array}{l}-0.72 \\
\end{array}$ & 9 & \begin{tabular}{|l|}
-0.04 \\
\end{tabular} & \begin{tabular}{|l|}
0.62 \\
\end{tabular} & 0.81 & $\begin{array}{l}7.93 \\
\end{array}$ & 4 & 71 & 40.86 & \begin{tabular}{|l|l|} 
\\
\end{tabular} & \begin{tabular}{|l|}
0.31 \\
\end{tabular} & \begin{tabular}{|l|}
24.67 \\
\end{tabular} & $\begin{array}{ll}0.00 \\
\end{array}$ & \begin{tabular}{l|l}
0.00 \\
\end{tabular} & \begin{tabular}{|c|}
-2.74 \\
\end{tabular} & $\begin{array}{ll}7.93 \\
\end{array}$ & \begin{tabular}{|l|}
4.44 \\
\end{tabular} & $\begin{array}{ll}0.32 \\
\end{array}$ \\
\hline 9.75 & 21.52 & 3.23 & -0.74 & 36 & \begin{tabular}{|l|} 
\\
\end{tabular} & \begin{tabular}{|l|}
0.63 \\
\end{tabular} & 0.81 & 7.88 & 6.35 & 12.99 & 40.86 & \begin{tabular}{|l|l|} 
\\
\end{tabular} & \begin{tabular}{|c|}
0.31 \\
\end{tabular} & \begin{tabular}{|l|}
24.61 \\
\end{tabular} & 0.00 & 0.00 & -2.84 & $\begin{array}{l}7.88 \\
\end{array}$ & 4.29 & 0.31 \\
\hline \begin{tabular}{|c|}
10.00 \\
\end{tabular} & 21.34 & 9.17 & -0.75 & 33 & $\mid-0.03$ & \begin{tabular}{|l|}
0.64 \\
\end{tabular} & 0.80 & \begin{tabular}{|l|l}
7.83 \\
\end{tabular} & 6.26 & 13.26 & 40.85 & \begin{tabular}{|l|l|} 
\\
\end{tabular} & \begin{tabular}{|c|}
0.31 \\
\end{tabular} & 24.55 & $\begin{array}{ll}0.00 \\
\end{array}$ & \begin{tabular}{l|l}
0.00 \\
\end{tabular} & \begin{tabular}{|c|}
-2.93 \\
\end{tabular} & $\begin{array}{l}7.83 \\
\end{array}$ & \begin{tabular}{|l|}
4.14 \\
\end{tabular} & 0.30 \\
\hline 10.25 & 21.15 & 1.16 & \begin{tabular}{|c|c|} 
\\
\end{tabular} & 30 & \begin{tabular}{|l|}
-0.03 \\
\end{tabular} & 0.66 & 0.79 & 7.78 & 6.16 & 13.54 & 40.85 & \begin{tabular}{|l|l|} 
\\
\end{tabular} & \begin{tabular}{|l|}
0.31 \\
\end{tabular} & \begin{tabular}{|l|l|}
248 \\
\end{tabular} & 0.00 & $\begin{array}{ll}0.00 \\
\end{array}$ & \begin{tabular}{|c|}
-3.03 \\
\end{tabular} & 7.78 & 4.00 & 0.29 \\
\hline \begin{tabular}{l|l}
10.50 \\
\end{tabular} & 20.9 & 3 & \begin{tabular}{|c|}
-0.79 \\
\end{tabular} & 27 & \begin{tabular}{|l|}
-0.03 \\
\end{tabular} & \begin{tabular}{|l|}
0.67 \\
\end{tabular} & 0.79 & $\begin{array}{l}7.73 \\
\end{array}$ & 38 & 82 & 40.85 & \begin{tabular}{ll|} 
& 0.01 \\
\end{tabular} & $\begin{array}{ll}0.32 \\
\end{array}$ & \begin{tabular}{|l|}
24.42 \\
\end{tabular} & $\begin{array}{l}0.00 \\
\end{array}$ & \begin{tabular}{ll|l}
0.00 \\
\end{tabular} & \begin{tabular}{|l|}
-3.13 \\
\end{tabular} & 7.73 & 3.86 & $\begin{array}{ll}0.28 \\
\end{array}$ \\
\hline 10.75 & 20.75 & .24 & \begin{tabular}{|c|}
-0.80 \\
\end{tabular} & 25 & \begin{tabular}{|l|}
-0.03 \\
\end{tabular} & \begin{tabular}{|l|}
0.68 \\
\end{tabular} & 0.78 & $\begin{array}{l}7.68 \\
\end{array}$ & 5.99 & 4.11 & 40.85 & \begin{tabular}{|l|l|} 
\\
\end{tabular} & 0.32 & 24.36 & $\begin{array}{l}0.00 \\
\end{array}$ & \begin{tabular}{l|l}
0.00 \\
\end{tabular} & \begin{tabular}{|c|}
-3.24 \\
\end{tabular} & $\begin{array}{l}7.68 \\
\end{array}$ & 3.72 & \begin{tabular}{l|l}
0.27 \\
\end{tabular} \\
\hline 11.00 & 20.55 & 33.34 & -0.82 & 1.22 & \begin{tabular}{|l|} 
\\
\end{tabular} & \begin{tabular}{|l|l|}
0.69 \\
\end{tabular} & 0.77 & 7.63 & 5.90 & 14.39 & 40.85 & 0.01 & \begin{tabular}{|l|}
0.32 \\
\end{tabular} & \begin{tabular}{|l|}
24.29 \\
\end{tabular} & 0.00 & 0.00 & -3.34 & 7.63 & 3.59 & 0.26 \\
\hline \begin{tabular}{|c|}
11.25 \\
\end{tabular} & 20.35 & 4.49 & \begin{tabular}{|c|c|}
-0.83 \\
\end{tabular} & 20 & \begin{tabular}{|l|}
-0.03 \\
\end{tabular} & \begin{tabular}{|l|}
0.70 \\
\end{tabular} & \begin{tabular}{|c|}
0.77 \\
\end{tabular} & $\begin{array}{ll}7.58 \\
\end{array}$ & 5.82 & 14.68 & 40.85 & \begin{tabular}{|l|l|} 
& 0.01 \\
\end{tabular} & 0.32 & 24.22 & $\begin{array}{ll}0.00 \\
\end{array}$ & \begin{tabular}{l|l|}
0.00 \\
\end{tabular} & \begin{tabular}{|c|}
-3.44 \\
\end{tabular} & 7.58 & 3.46 & $\begin{array}{ll}0.25 \\
\end{array}$ \\
\hline \begin{tabular}{|c|}
11.50 \\
\end{tabular} & 20.14 & 5.68 & \begin{tabular}{|c|c|} 
\\
\end{tabular} & 8 & -0.03 & 0.70 & 0.76 & 7.53 & 5.74 & 14.98 & 40.85 & \begin{tabular}{|l|l|} 
\\
\end{tabular} & 0.33 & 24.16 & 0.00 & $\begin{array}{ll}0.00 \\
\end{array}$ & \begin{tabular}{|c|} 
\\
\end{tabular} & \begin{tabular}{|l|l|}
7.53 \\
\end{tabular} & 3.33 & 0.24 \\
\hline 11.75 & 19.92 & 36.92 & -0.87 & 1.15 & -0.03 & \begin{tabular}{|l|l|}
0.71 \\
\end{tabular} & 0.76 & 7.48 & 5.66 & 15.27 & 40.85 & 0.01 & \begin{tabular}{|l|}
0.33 \\
\end{tabular} & \begin{tabular}{|l|}
24.09 \\
\end{tabular} & 0.00 & \begin{tabular}{l|l}
0.00 \\
\end{tabular} & \begin{tabular}{|c|}
-3.66 \\
\end{tabular} & 7.48 & 3.21 & 0.23 \\
\hline \begin{tabular}{|l|l|}
12.00 \\
\end{tabular} & 19.7 & 3.20 & -0.88 & 13 & -0.03 & \begin{tabular}{|l|}
0.72 \\
\end{tabular} & 0.75 & 7.44 & 5.58 & 15.57 & 40.85 & \begin{tabular}{|l|l|} 
\\
\end{tabular} & 0.33 & \begin{tabular}{|l|}
24.01 \\
\end{tabular} & $\begin{array}{ll}0.00 \\
\end{array}$ & \begin{tabular}{l|l}
0.00 \\
\end{tabular} & \begin{tabular}{|c|} 
\\
\end{tabular} & 7.44 & 3.09 & $\begin{array}{ll}0.22 \\
\end{array}$ \\
\hline 12.25 & 19.48 & 9.53 & -0.9 & & -0.03 & \begin{tabular}{|l|}
0.73 \\
\end{tabular} & 74 & 7.39 & in & 36 & 40.85 & 0.01 & 0.33 & 23.94 & 0.00 & 0.00 & \begin{tabular}{|c|}
-3.88 \\
\end{tabular} & 7.39 & 2.97 & 0.21 \\
\hline \begin{tabular}{l|l}
12.50 \\
\end{tabular} & 19.25 & .92 & -0.9 & 0 & \begin{tabular}{|l|}
-0.02 \\
\end{tabular} & \begin{tabular}{|l|l|}
0.74 \\
\end{tabular} & 74 & 7.34 & 5.42 & 5.17 & 40.84 & 0.01 & \begin{tabular}{|l|}
0.34 \\
\end{tabular} & \begin{tabular}{|l|}
23.87 \\
\end{tabular} & $\begin{array}{ll}0.00 \\
\end{array}$ & \begin{tabular}{l|l}
0.00 \\
\end{tabular} & \begin{tabular}{|c|}
-3.99 \\
\end{tabular} & \begin{tabular}{ll|}
7.34 \\
\end{tabular} & 2.86 & 0.20 \\
\hline 12.75 & 19.02 & 42.36 & \begin{tabular}{|c|}
-0.93 \\
\end{tabular} & 1.08 & -0.02 & \begin{tabular}{|l|}
0.75 \\
\end{tabular} & 0.73 & $\begin{array}{l}7.30 \\
\end{array}$ & 5.35 & $\begin{array}{ll}16.47 \\
\end{array}$ & 40.84 & 0.01 & \begin{tabular}{|l|}
0.34 \\
\end{tabular} & \begin{tabular}{|l|}
23.79 \\
\end{tabular} & $\begin{array}{l}0.00 \\
\end{array}$ & $\begin{array}{ll}0.00 \\
\end{array}$ & -4.10 & \begin{tabular}{|l|}
7.30 \\
\end{tabular} & 2.75 & 0.20 \\
\hline \begin{tabular}{l|l}
13.00 \\
\end{tabular} & 18.79 & 4385 & \begin{tabular}{l|}
-0.94 \\
\end{tabular} & 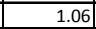 & \begin{tabular}{|l|} 
\\
\end{tabular} & \begin{tabular}{|l|}
0.76 \\
\end{tabular} & $\begin{array}{l}0.73 \\
\end{array}$ & 7.25 & 5.28 & 6.77 & 40.84 & 0.01 & \begin{tabular}{|l|}
0.34 \\
\end{tabular} & 23.72 & $\begin{array}{ll}0.00 \\
\end{array}$ & \begin{tabular}{l|l}
0.00 \\
\end{tabular} & -4.22 & $\begin{array}{ll}7.25 \\
\end{array}$ & 2.65 & $\begin{array}{ll}0.19 \\
\end{array}$ \\
\hline \begin{tabular}{|c|}
13.25 \\
\end{tabular} & 18.5 & 45.40 & -0.9 & 5 & \begin{tabular}{|c|} 
\\
\end{tabular} & \begin{tabular}{|l|}
0.76 \\
\end{tabular} & 72 & 7.20 & 21 & 88 & 40.84 & 0.01 & \begin{tabular}{|l|}
0.34 \\
\end{tabular} & 23.64 & $\begin{array}{ll}0.00 \\
\end{array}$ & \begin{tabular}{l|l}
0.00 \\
\end{tabular} & -4.34 & 7.20 & 2.55 & 0.18 \\
\hline \begin{tabular}{|l|l|}
13.50 \\
\end{tabular} & 18.31 & 7.00 & -0.97 & 1.03 & -0.02 & 0.77 & 0.72 & 7.16 & 5.14 & 17.39 & 40.84 & 0.01 & 0.35 & 23.56 & 0.00 & 0.00 & \begin{tabular}{l|}
-4.45 \\
\end{tabular} & 7.16 & 2.45 & 0.17 \\
\hline \begin{tabular}{|c|}
13.75 \\
\end{tabular} & 18. & & \begin{tabular}{|c|}
-0.99 \\
\end{tabular} & & \begin{tabular}{|l|}
-0.02 \\
\end{tabular} & \begin{tabular}{|l|}
0.78 \\
\end{tabular} & 71 & $\begin{array}{l}7.12 \\
\end{array}$ & 5.07 & U & 40.84 & 0.01 & $\begin{array}{ll}0.35 \\
\end{array}$ & \begin{tabular}{|l|}
23.48 \\
\end{tabular} & $\begin{array}{l}0.00 \\
\end{array}$ & \begin{tabular}{l|l|l}
0.00 \\
\end{tabular} & -4.57 & $\begin{array}{l}7.12 \\
\end{array}$ & 35 & \begin{tabular}{l|l|}
0.17 \\
\end{tabular} \\
\hline 14.00 & 17.8 & \pm & 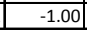 & & \begin{tabular}{|l|}
-0.02 \\
\end{tabular} & 0. & t & 7.07 & f & 02 & \begin{tabular}{|l|l|} 
\\
\end{tabular} & 0.01 & \begin{tabular}{|l|}
0.35 \\
\end{tabular} & 23.40 & 0.00 & \begin{tabular}{l|l}
0.00 \\
\end{tabular} & -4.70 & $\begin{array}{l}7.07 \\
\end{array}$ & 2.26 & 0.16 \\
\hline 14.25 & 17.57 & 52.21 & -1.01 & 0.99 & \begin{tabular}{|l|}
-0.02 \\
\end{tabular} & \begin{tabular}{|l|}
0.79 \\
\end{tabular} & 0.70 & 7.03 & 4.93 & 18.33 & \begin{tabular}{|l|l|}
40.83 \\
\end{tabular} & 0.01 & \begin{tabular}{|l|l|} 
\\
\end{tabular} & \begin{tabular}{|l|}
23.32 \\
\end{tabular} & 0.00 & 0.00 & -4.82 & 7.03 & 2.18 & 0.16 \\
\hline \begin{tabular}{l|l}
14.50 \\
\end{tabular} & 17.3 & 1.08 & \begin{tabular}{|c|}
-1.03 \\
\end{tabular} & 97 & \begin{tabular}{|l|}
-0.02 \\
\end{tabular} & \begin{tabular}{|l|}
0.80 \\
\end{tabular} & 0.70 & $\begin{array}{ll}6.98 \\
\end{array}$ & 4.87 & 18.65 & 40.83 & \begin{tabular}{|c|c|} 
& 0.01 \\
\end{tabular} & \begin{tabular}{|l|}
0.36 \\
\end{tabular} & 23.24 & $\begin{array}{ll}0.00 \\
\end{array}$ & \begin{tabular}{l|l|}
0.00 \\
\end{tabular} & -4.94 & \begin{tabular}{|l|}
6.98 \\
\end{tabular} & $\begin{array}{l}.10 \\
\end{array}$ & \begin{tabular}{l|l}
0.15 \\
\end{tabular} \\
\hline 14.75 & 17.0 & 00 & -104 & 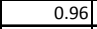 & -0.02 & \begin{tabular}{|l|l|}
0.81 \\
\end{tabular} & 691 & 6.94 & 81 & 97 & 40.83 & \begin{tabular}{|l|l|} 
& 0.01 \\
\end{tabular} & 0.36 & 23.16 & 0.00 & \begin{tabular}{l|l}
0.00 \\
\end{tabular} & -5.07 & 6.94 & 02 & 0.14 \\
\hline 15.00 & 16.79 & 3.04 & -1.05 & 95 & -0.02 & \begin{tabular}{|l|l|}
0.81 \\
\end{tabular} & 0.69 & 6.90 & 4.75 & .29 & \begin{tabular}{|l|l|}
40.83 \\
\end{tabular} & 0.01 & \begin{tabular}{|l|}
0.36 \\
\end{tabular} & \begin{tabular}{|l|l|}
23.08 \\
\end{tabular} & $\begin{array}{ll}0.00 \\
\end{array}$ & \begin{tabular}{l|l}
0.00 \\
\end{tabular} & -5.20 & 6.90 & 1.94 & 0.14 \\
\hline 15.25 & 16.53 & 60.15 & \begin{tabular}{|c|}
-1.07 \\
\end{tabular} & 0.94 & -0.02 & 0.82 & 0.68 & 6.85 & 4.69 & 19.61 & 40.83 & \begin{tabular}{ll|}
3 & 0.01 \\
\end{tabular} & \begin{tabular}{|l|}
0.36 \\
\end{tabular} & 22.99 & $\begin{array}{ll}0.00 \\
\end{array}$ & 0.00 & -5.33 & 6.85 & 1.87 & \begin{tabular}{l|l}
0.13 \\
\end{tabular} \\
\hline 15.50 & 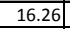 & & -1.0 & 93 & -0.02 & 0.82 & 0.68 & 6.8 & & & 40.83 & 0.01 & \begin{tabular}{|l|}
0.37 \\
\end{tabular} & 22.91 & 0.00 & 0.00 & \begin{tabular}{|c|}
-5.46 \\
\end{tabular} & 6.81 & 80 & 0.13 \\
\hline \begin{tabular}{|l|}
15.75 \\
\end{tabular} & 15.9 & 6 & -1.0 & t & -0.02 & 0.8 & $\begin{array}{ll}0.68 \\
\end{array}$ & s & 7 & 27 & 40.82 & 0.01 & \begin{tabular}{|l|}
0.37 \\
\end{tabular} & \begin{tabular}{|l|}
22.82 \\
\end{tabular} & $\begin{array}{ll}0.00 \\
\end{array}$ & \begin{tabular}{l|l|}
0.00 \\
\end{tabular} & \begin{tabular}{|c|}
-5.59 \\
\end{tabular} & \begin{tabular}{|l|l|}
6.77 \\
\end{tabular} & \begin{tabular}{l|l|}
1.74 \\
\end{tabular} & 0.12 \\
\hline 16.00 & 15.71 & 66.97 & \begin{tabular}{|c|}
-1.11 \\
\end{tabular} & 0.90 & \begin{tabular}{|l|} 
\\
\end{tabular} & \begin{tabular}{|l|l|}
0.84 \\
\end{tabular} & 0.67 & 6.73 & 4.51 & 20.60 & 40.82 & 0.01 & 0.37 & \begin{tabular}{|l|l|}
22.73 \\
\end{tabular} & 0.00 & 0.00 & -5.73 & $\begin{array}{l}6.73 \\
\end{array}$ & 1.68 & 0.12 \\
\hline 16.25 & 15.4 & 69.43 & -1.1 & , & -0.01 & 0.84 & 0.67 & 6.69 & 4.46 & 20.93 & 40.82 & 0.01 & \begin{tabular}{|c|}
0.37 \\
\end{tabular} & 22.65 & $\begin{array}{ll}0.00 \\
\end{array}$ & \begin{tabular}{l|l}
0.00 \\
\end{tabular} & \begin{tabular}{|c|}
-5.86 \\
\end{tabular} & $\begin{array}{l}6.69 \\
\end{array}$ & 1.62 & $\begin{array}{ll}0.12 \\
\end{array}$ \\
\hline \begin{tabular}{l|l}
16.50 \\
\end{tabular} & 15.1 & & $-1,1$ & & \begin{tabular}{|l|}
-0.01 \\
\end{tabular} & \begin{tabular}{|l|}
0.85 \\
\end{tabular} & & 6.65 & & & \begin{tabular}{|l|}
40.82 \\
\end{tabular} & 0.01 & \begin{tabular}{|l|}
0.38 \\
\end{tabular} & 222.56 & $\begin{array}{ll}0.00 \\
\end{array}$ & \begin{tabular}{l|l|}
0.00 \\
\end{tabular} & \begin{tabular}{|c|}
-6.00 \\
\end{tabular} & \begin{tabular}{l|l}
6.65 \\
\end{tabular} & \begin{tabular}{|l|}
1.57 \\
\end{tabular} & $\begin{array}{ll}0.11 \\
\end{array}$ \\
\hline 16.75 & 14.87 & 74.67 & \begin{tabular}{|l|}
-1.14 \\
\end{tabular} & 0.88 & -0.01 & 0.85 & 0.66 & 6.61 & 4.35 & 21.59 & 40.82 & 0.01 & \begin{tabular}{|l|}
0.38 \\
\end{tabular} & \begin{tabular}{|l|l|}
22.47 \\
\end{tabular} & 0.00 & $\begin{array}{ll}0.00 \\
\end{array}$ & -6.14 & 6.61 & 1.52 & $\begin{array}{ll} \\
\end{array}$ \\
\hline \begin{tabular}{ll|}
17.00 \\
\end{tabular} & \begin{tabular}{l|l|}
14.58 \\
\end{tabular} & 77.46 & -1.15 & 374 & $\begin{array}{ll}-0.01 \\
\end{array}$ & \begin{tabular}{|l|}
0.86 \\
\end{tabular} & 0.66 & $\begin{array}{l}6.57 \\
\end{array}$ & 4.30 & 21.93 & 40.81 & 0.01 & \begin{tabular}{|l|l|}
0.38 \\
\end{tabular} & \begin{tabular}{|l|}
22.38 \\
\end{tabular} & $\begin{array}{l}0.00 \\
\end{array}$ & \begin{tabular}{ll|l}
0.00 \\
\end{tabular} & -6.28 & $\begin{array}{l}6.57 \\
\end{array}$ & 1.47 & $\begin{array}{l}0.11 \\
\end{array}$ \\
\hline \begin{tabular}{ll|}
17.25 \\
\end{tabular} & 2 & & & & \begin{tabular}{|l|l|} 
\\
\end{tabular} & & & & & & & & \begin{tabular}{|l|}
0.38 \\
\end{tabular} & 222.30 & 0.00 & \begin{tabular}{l|l}
0.00 \\
\end{tabular} & $\begin{array}{l}-6.42 \\
\end{array}$ & $\begin{array}{l}6.53 \\
\end{array}$ & 43 & 0.10 \\
\hline 17.50 & 14.00 & 83.42 & \begin{tabular}{|l|l|}
-1.18 \\
\end{tabular} & 85 & \begin{tabular}{|l|}
-0.01 \\
\end{tabular} & \begin{tabular}{|l|}
0.87 \\
\end{tabular} & 0.65 & 6.49 & 4.21 & 22.60 & \begin{tabular}{|l|l|} 
\\
\end{tabular} & 0.01 & \begin{tabular}{|l|}
0.38 \\
\end{tabular} & 22.21 & $\begin{array}{ll}0.00 \\
\end{array}$ & \begin{tabular}{l|l}
0.00 \\
\end{tabular} & -6.57 & $\begin{array}{ll}6.49 \\
\end{array}$ & $\begin{array}{ll}1.39 \\
\end{array}$ & $\begin{array}{l}0.10 \\
\end{array}$ \\
\hline \begin{tabular}{|c|}
17.75 \\
\end{tabular} & 13.71 & 86.60 & \begin{tabular}{|c|}
-1.19 \\
\end{tabular} & 84 & $\mid-0.01$ & \begin{tabular}{|l|}
0.87 \\
\end{tabular} & 0.64 & $\begin{array}{ll}6.45 \\
\end{array}$ & 4.16 & 22.95 & 40.81 & 0.01 & \begin{tabular}{|l|}
0.39 \\
\end{tabular} & \begin{tabular}{|l|}
22.12 \\
\end{tabular} & $\begin{array}{ll}0.00 \\
\end{array}$ & \begin{tabular}{l|l}
0.00 \\
\end{tabular} & \begin{tabular}{|c|}
-6.71 \\
\end{tabular} & $\begin{array}{ll}6.45 \\
\end{array}$ & 1.35 & $\begin{array}{l}0.10 \\
\end{array}$ \\
\hline 18.00 & 13.41 & .93 & \begin{tabular}{|c|}
-1.20 \\
\end{tabular} & 84 & -0.01 & \begin{tabular}{|l|l|}
0.87 \\
\end{tabular} & 0.64 & 6.41 & 4.11 & 29 & 40.81 & 0.01 & \begin{tabular}{|l|l|}
0.39 \\
\end{tabular} & \begin{tabular}{|l|l|}
22.03 \\
\end{tabular} & 0.00 & \begin{tabular}{l|l}
0.00 \\
\end{tabular} & -6.86 & 6.41 & 1.32 & 0.09 \\
\hline 18.25 & 13.1 & & -1.2 & & -0.01 & 0.8 & & & & & 40.80 & 0.01 & \begin{tabular}{|l|}
0.39 \\
\end{tabular} & \begin{tabular}{|l|}
21.94 \\
\end{tabular} & 0.00 & \begin{tabular}{l|l}
0.00 \\
\end{tabular} & \begin{tabular}{|c|} 
\\
\end{tabular} & $\begin{array}{ll}6.38 \\
\end{array}$ & 29 & 0.09 \\
\hline \begin{tabular}{l|l}
18.50 \\
\end{tabular} & 12.80 & 97.08 & -1.22 & 0.82 & $\begin{array}{ll}-0.01 \\
\end{array}$ & \begin{tabular}{|l|}
0.88 \\
\end{tabular} & $\begin{array}{l}0.63 \\
\end{array}$ & 6.34 & 4.02 & 23.98 & 40.80 & 0.01 & \begin{tabular}{|l|}
0.39 \\
\end{tabular} & 21.86 & $\begin{array}{ll}0.00 \\
\end{array}$ & \begin{tabular}{l|l}
0.00 \\
\end{tabular} & \begin{tabular}{|c|}
-7.16 \\
\end{tabular} & \begin{tabular}{|l|l|}
6.34 \\
\end{tabular} & 1.26 & 0.09 \\
\hline 18.75 & 12.50 & 100.92 & -1.23 & 0.81 & $\mid-0.01$ & \begin{tabular}{|c|}
0.89 \\
\end{tabular} & 0.63 & \begin{tabular}{ll|}
6.30 \\
\end{tabular} & 3.98 & 24.32 & 40.80 & 0.01 & \begin{tabular}{|l|}
0.39 \\
\end{tabular} & \begin{tabular}{|l|l|}
21.77 \\
\end{tabular} & \begin{tabular}{l|l|}
0.00 \\
\end{tabular} & \begin{tabular}{l|l}
0.00 \\
\end{tabular} & \begin{tabular}{|c|} 
\\
\end{tabular} & \begin{tabular}{l|l}
6.30 \\
\end{tabular} & $\begin{array}{l}1.23 \\
\end{array}$ & \begin{tabular}{l|l|}
0.09 \\
\end{tabular} \\
\hline
\end{tabular}

Continua 
Continuação

Trecho Cossenoidal

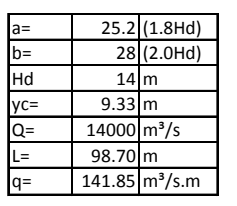

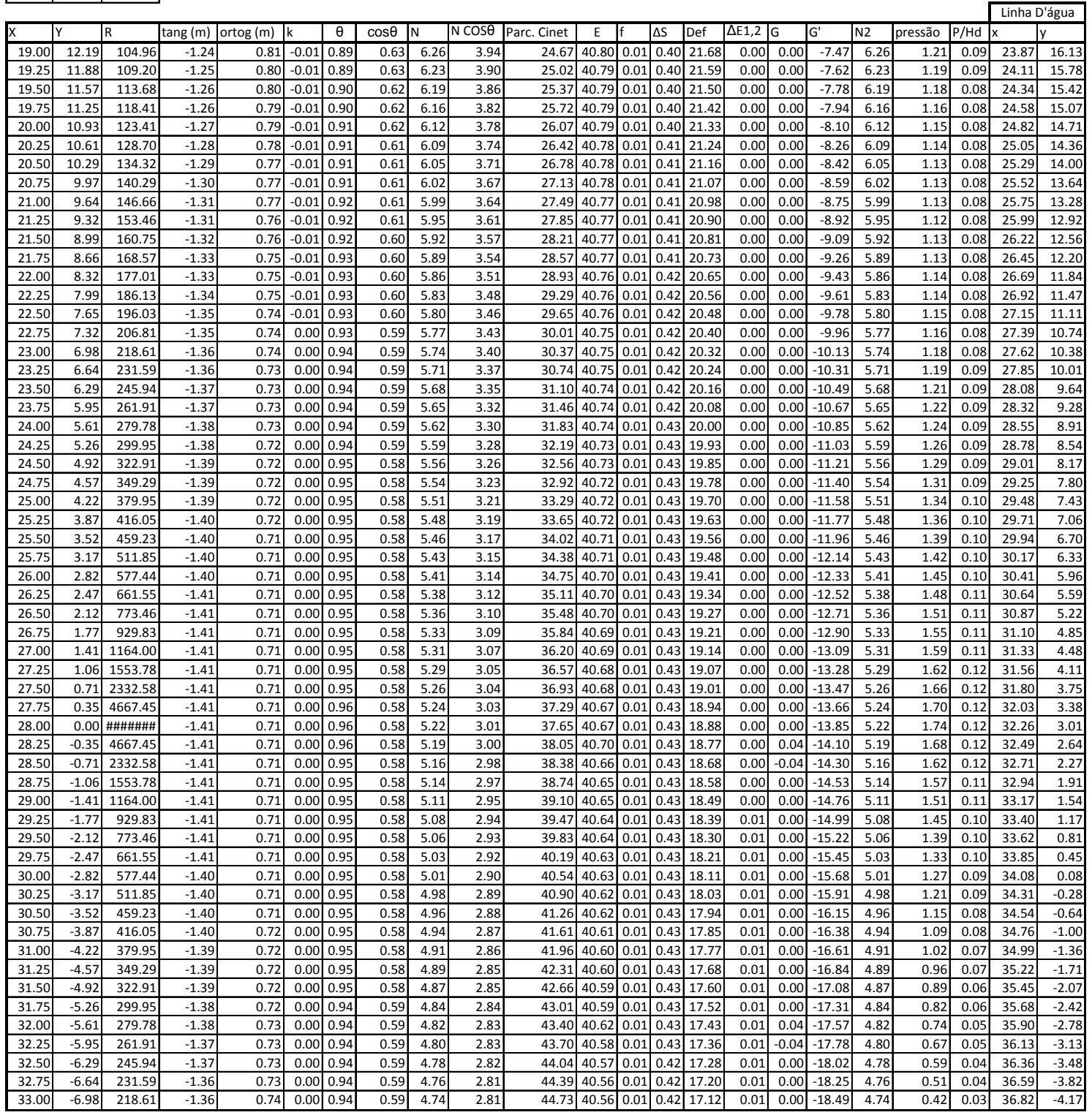


Planilha de Cálculo Soleira Maynord Modificado

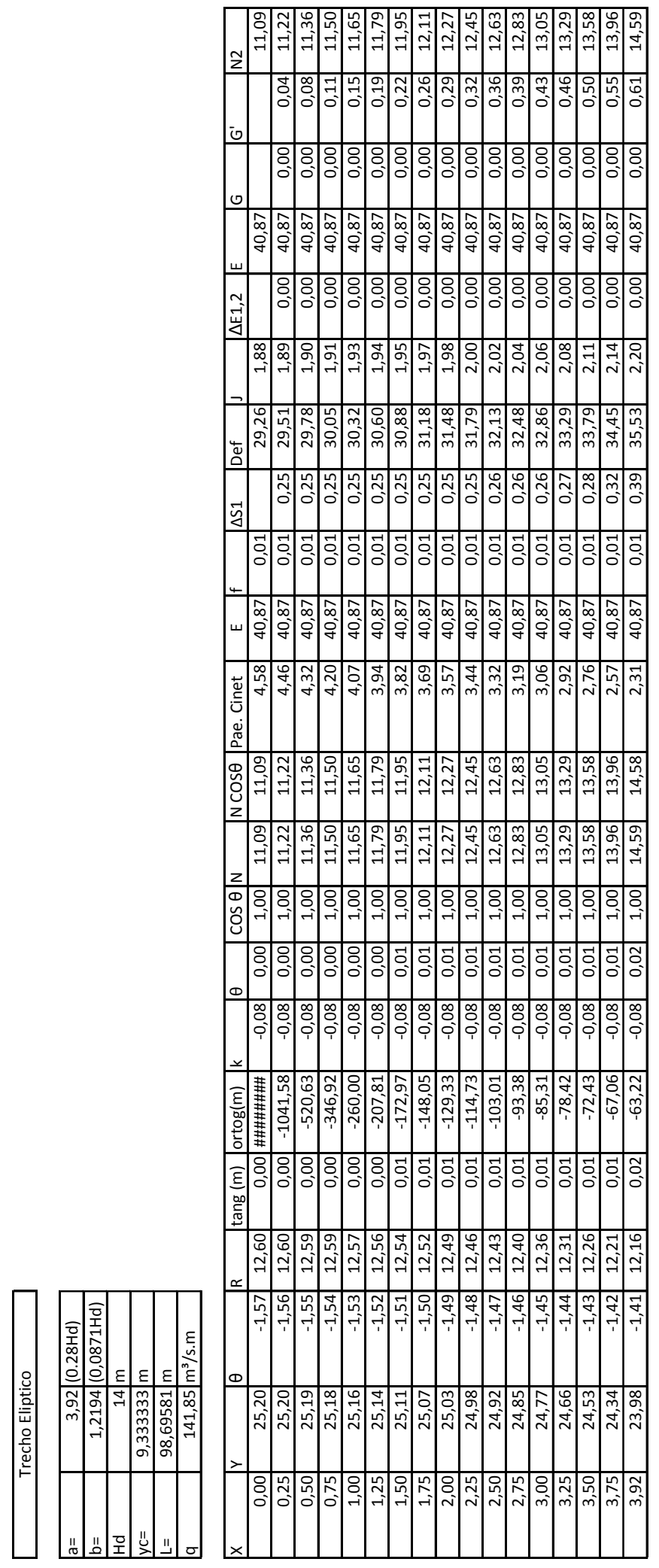

